Rodolpho Freire

\title{
Uma abordagem matemática para auxiliar o diagnóstico de demências: tratando incertezas e quantificando processos
}

\author{
Tese apresentada à Faculdade de Medicina da \\ Universidade de São Paulo como parte dos requisitos \\ para obtenção do título de Doutor em Ciências \\ Programa de Patologia \\ Orientadora: Profa ${ }^{\mathrm{a}}$ Dra ${ }^{\mathrm{a}}$ Neli Regina Siqueira Ortega
}

São Paulo

2014 
Rodolpho Freire

\title{
Uma abordagem matemática para auxiliar o diagnóstico de demências: tratando incertezas e quantificando processos
}

\author{
Tese apresentada à Faculdade de Medicina da \\ Universidade de São Paulo como parte dos requisitos \\ para obtenção do título de Doutor em Ciências \\ Programa de Patologia \\ Orientadora: Profa ${ }^{\mathrm{a}}$ Dra ${ }^{\mathrm{a}}$ Neli Regina Siqueira Ortega
}

São Paulo

2014 


\section{Resumo}

Freire,Rodolpho. Uma abordagem matemática para auxiliar o diagnóstico de demências:tratando incertezas e quantificando processos.[Tese].São Paulo. Faculdade de Medicina. Universidade de São Paulo;2014

Este trabalho apresenta o desenvolvimento de um modelo para quantificar e apoiar o processo diagnóstico de demências (Demência de Alzheimer, Demência Vascular, Demência Frontotemporal e Demência de Corpos de Lewy), composto por três sub modelos. O primeiro modelo matemático proposto é baseado na teoria dos conjuntos fuzzy e tem como objetivo fornecer um escore de comprometimento cognitivo. Como resultado de sua aplicação em uma base com dados reais com 60 casos, obtivemos 52 acertos e 8 erros (13,33\%), um Índice de Concordância Kappa de 0,67 e uma área sob a curva ROC de 0,80. O segundo modelo permite identificat o tipo de demência, e optou-se por utilizar um diagrama de decisão para representar o conhecimento do especialista. O diagrama foi modelado com base nas características de cada patologia e quando submetido aos testes dos especialistas obtivemos índices de erro que variam de $2,0 \%$ a $18,33 \%$. Sendo a demência de Alzheimer a mais prevalente entre as demências e considerando a importância das neuroimagens para o diagnóstico diferencial, realizamos a avaliação de três técnica de análise de neuroimagem, sendo duas multivariadas e uma univariada. Como resultado obtivemos que os modelos multivariados se mostram mais eficientes para avaliação de alterações morfológicas no cerébro em relação aos modelos univariados. Porém a complexidade de realização das análises não permite nesse momento a integração de técnicas de avaliação de neuroimagens com modelos diagnósticos a serem usados em ambulatório. Durante a anamnese, o médico avalia, além do comprometimento cognitivo, sinais e sintomas que permitam identificar o tipo de demência um conjunto de fatores de risco 
e de proteção que permite mensurar o risco do indivíduo desenvolver algum tipo de demência. Para avaliar esses fatores foi criado um modelo de risco de demência com base nos fatores de risco e proteção que comumente são analisados pelos médicos. Esse modelo foi avaliado por três especialistas e obtivemos indíces de erro que variaram entre $13,33 \%$ e $20 \%$ e um índice de correlação de Spearman que variou de 0,63 a 0,69.

Palavras-chave: Lógica Fuzzy, Demência, Tomada de decisões assistida por computador, Modelos matemáticos, Processamento de imagens assistida por Computador, Sistemas especialistas 


\section{Summary}

Freire,Rodolpho. A mathematical approach to assist the diagnosis of dementia: treating uncertainties and quantifying processes.[Thesys]. São Paulo. School of Medicine. University of São Paulo, 2014

This study proposes the development of a model to quantify and support the process of diagnose of dementia (Alzheimer's Dementia, Vascular Dementia, Frontotemporal Dementia and Dementia with Lewy Bodies) composed by three sub-models. The first mathematical model is based in the theory of fuzzy sets, and provides a score for cognitive impairment. As a result we obtained 52 correct classifications and eight errors $(13.33 \%)$, the index of Kappa was 0.67 and the area under the ROC curve was 0.80 . In the second model a decision tree was elaborated to represent the expert's knowledge of the type of dementia. The decision diagram was modeled based on the characteristics of each pathology and the decision paths was tested by experts, resulting in erros varing between 2.0 to $18,3 \%$. Since the Alzheimer's Disease is the most prevalent dementia and considering the importance of neuroimage exams to the differential diagnosis, we perform a evaluation of three techniques focused on neuroimage analisys, two multivariate techniques and one univariate technique. As a result it was verified that multivariate models are more efective to evaluate the morphological changes in the brain, compared to univariate models. However, the complexity to perform a analysis does not allows, at this moment, to integrate the neuroimage evaluation techniques whith diagnostic models designed to support the clinician in the ambulatory rotine. During the anamnesis the doctor evaluates (in addition to cognitive impairment and symptoms focused on identify the type of dementia), a number of risk and protection factors that allows measure the risk of the individual developing dementia. To perform the evaluation of these factors, a model of dementia risk 
was created based on the risk and protective factors that are commonly evaluated during the anmnese process.

This model was evaluated by three experts and we achieve erros varing between $13.33 \%$ and $20 \%$ and Spearman's correlation value between the scores of 0.63 to 0.69 .

Keywords: Fuzzy Logic, Dementia, Decision Making, Computer-Assisted, Mathematical Models, Image Processing, Computer-Assisted, Expert systems 


\section{Agradecimentos}

Primeiramente à Deus, sem o qual não haveriam motivos para agradecer.

Nada na vida se realiza sozinho, devo muito deste trabalho a ajuda de recebi da família, amigos e profissionais que são referências em sua área de atuação em sua ética e em sua visão de futuro.

Agradeço ao Prof. Dr. Cássio Bottino do PROTER - IPq USP pelo apoio no desenvolvimento deste trabalho e das valiosas contribuições. Extendo essa gratidão a todo o grupo de especialistas do grupo do PROTER que participaram deste trabalho, em especial a Dra. Barbara Correia que esteve mais próxima durante o período da modelagem e contou com tanta paciência e interesse em cooperar com o trabalho.

Ao Dr. Marcos Machado Domingos que me indicou o caminho do IPq para desenvolvimento das pesquisas e me colocou em contato com pessoas que sempre se dispuseram em me ajudar.

Agradeço ao meu orientador de mestrado Prof. Dr. Paulo E. Santos, ao Prof. Dr. Carlos Eduardo Thomaz e ao Prof. Dr. Jair Minoro Abe por suas considerações na banca de qualificação, ajudando no direcionamento da pesquisa.

Agradeço por algumas pessoas que passaram por minha vida, mesmo que brevemente dentro do meio corporativo e que apoiaram a minha decisão, sonho e obstinação em continuar minha formação scrictu sensu, em especial ao meu amigo Fábio Arca que sempre deixou claro seu apoio até onde lhe foi permitido e além.

Agradeço à minha Mãe Fátima Aparecida, meu amigo e pai a mais de 20 anos Marcos Antônio Furlan, meu já nao presente Pai Cesário Freire, mas eternamente parte de mim, e aos meus avós Aparecida Manara e Benjamim José. A minha família pela educação, apoio e 
criação que me deram, por uma base sólida que me fez colocar a moral, ética e o amor acima de valores materiais e mundanos.

Agradeço em especial à Prof. Dra. Neli Regina Siqueira Ortega que é uma pessoa e profissional "fora da curva", pelo trabalho de orientação, paciência, pelas conversas e apoio nessa caminhada.

Agradeço a minha esposa Dra. Renata Maria que me apoia nas minhas incursões acadêmicas e tolera minhas ausências pontuais ou prolongadas.

À todos um abraço fraterno de agradecimento. 
O conhecimento do justo implica o ser-se justo

Platão 


\section{Sumário}

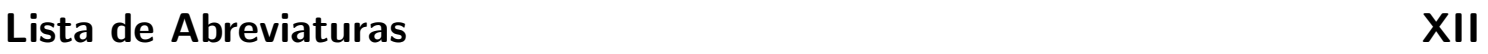

$\begin{array}{ll}\text { Lista de Figuras } & \text { XIV }\end{array}$

$\begin{array}{ll}\text { Lista de Tabelas } & \text { XVII }\end{array}$

1 Introdução 1

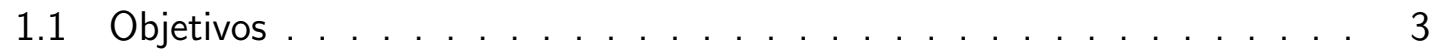

1.1 .1 Objetivo geral ..................... 3

1.1 .2 Objetivos específicos . . . . . . . . . . . . 3

2 Revisão da Literatura 5

2.1 Demência . . . . . . . . . . . . . . . . . . 5

2.1.1 Demência de Alzheimer . . . . . . . . . . . . . . . . 6

2.1.2 A demência vascular . . . . . . . . . . . . . . . . . . . 9

2.1.3 Demência Frontotemporal . . . . . . . . . . . . . . . . . 10

2.1.4 Demência de Corpos de Lewy . . . . . . . . . . . . . . . . . . . 11

2.2 Técnicas de modelagem para apoio ao diagnóstico . . . . . . . . . . . 13

2.2.1 Teoria dos Conjuntos fuzzy . . . . . . . . . . . . . . . . . . 14

2.2.2 Diagrama de Decisão Tipo Árvore . . . . . . . . . . . . . . . 20 
2.3 Análise de Neuroimagens . . . . . . . . . . . . . . . . . . . . . 22

2.3.1 Pré processamento de Neuroimagens . . . . . . . . . . . . 23

2.3.2 Análises Massivamente Univariadas voxel a voxel . . . . . . . . . 25

2.3.3 Análises Multivariadas . . . . . . . . . . . . . . . . . . 25

2.3.4 Modelo Discriminante Estatístico - SDM . . . . . . . . . . . 26

2.3.5 Máquinas de Suporte Vetorial - SVM . . . . . . . . . . . . . . 28

3 Metodologia $\quad 30$

3.1 Modelo Computacional de apoio ao diagnóstico de demências . . . . . . 30

3.1.1 Modelo fuzzy de comprometimento cognitivo . . . . . . . . . . . 33

3.1.2 Modelo de decisão para o tipo de demência . . . . . . . . . . . . 39

3.1.3 Análise de Neuroimagens . . . . . . . . . . . . . . . . . . . . . 44

3.1.4 Modelo fuzzy de risco de demência . . . . . . . . . . . . . . . . . 45

3.2 Bancos de dados para testes e análise dos modelos . . . . . . . . . . . . 54

3.2.1 Banco de dados hipotético para avaliação do modelo de Comprometimento Cognitivo . . . . . . . . . . . . . . . . 54

3.2.2 Banco de dados real para análise de performance do modelo de Comprometimento Cognitivo . . . . . . . . . . . . . 55

3.2.3 Análise do modelo de Tipo de Demência . . . . . . . . . . . . 55

3.2.4 Banco de dados hipotético para avaliação do modelo de Risco de Demência . . . . . . . . . . . . . . . 56

3.2.5 Banco de dados real para análises de neuroimagem . . . . . . . . 57

4.1 Resultados do modelo de Comprometimento Cognitivo . . . . . . . . . . 61 
4.1 .1 Índice de Concordância Kappa . . . . . . . . . . . . . . . . . . 61

4.1.2 Correlação das notas do modelo versus notas dos especialistas . . 64

4.1.3 Resultados do modelo com a Base de Dados do PROTER/IPq-USP 65

4.1.4 Curva ROC do modelo de Comprometimento Cognitivo . . . . . 67

4.2 Resultados do modelo de tipo de demência . . . . . . . . . . . . . . . 67

4.3 Resultados das Análises Estatísticas de Neuroimagens . . . . . . . . . . 69

4.3.1 Resultados dos Classificadores Estatísticos . . . . . . . . . . . 69

4.3.2 Identificação de regiões discriminantes . . . . . . . . . . . . 72

4.4 Resultados para o Modelo de Risco de Demência . . . . . . . . . . . . 73

4.4.1 Correlação das notas do modelo de risco de demência com as notas dos especialistas . . . . . . . . . . . . . . . . . . . 77

$\begin{array}{lll}5 & \text { Discussão } & 78\end{array}$

6 Conclusão $\quad 86$

$\begin{array}{lr}\text { Referências Bibliográficas } & 90\end{array}$

Apêndice 


\section{Lista de Siglas}

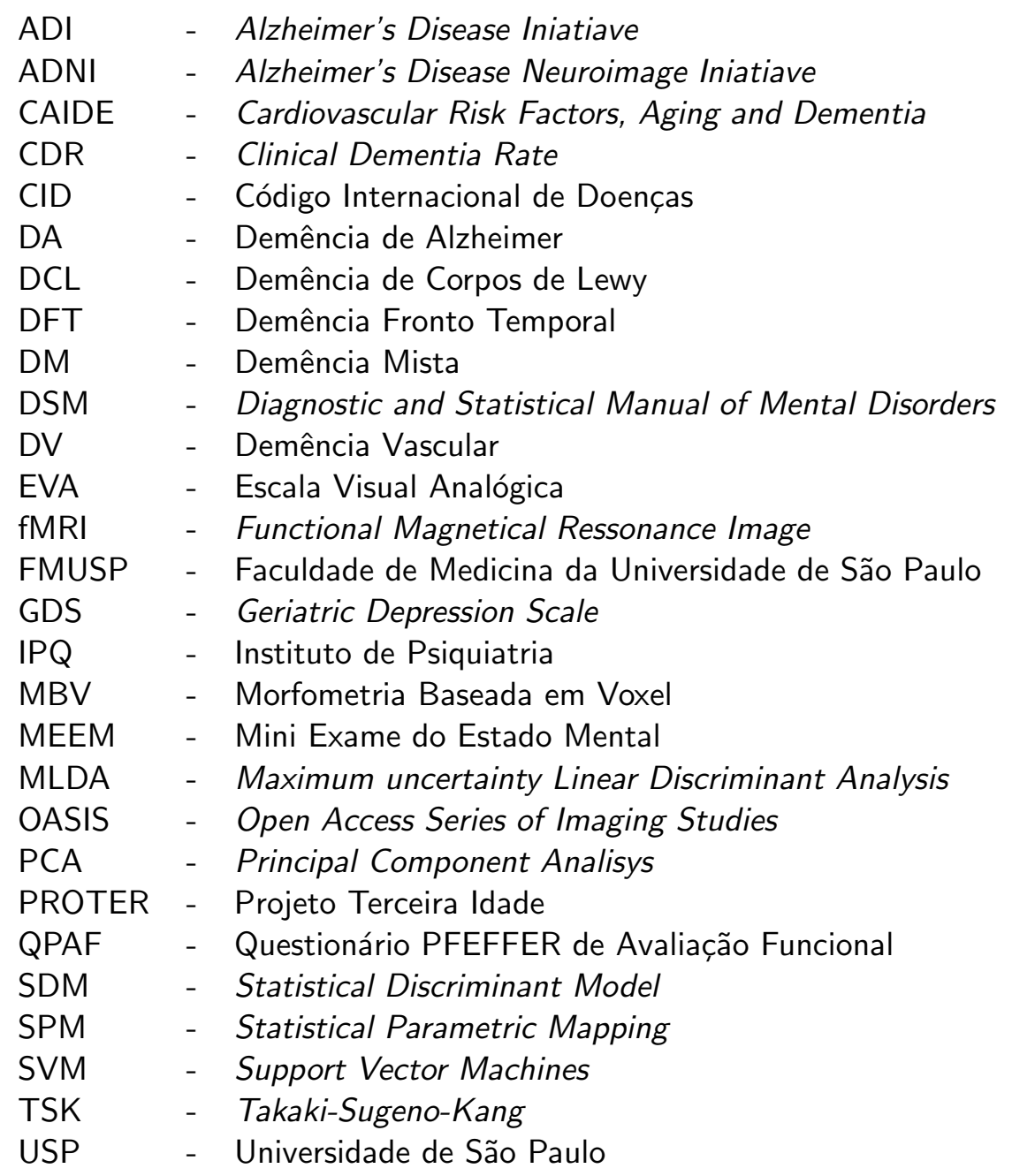




\section{Lista de Figuras}

2.1 Exame de neuroimagem caracteristico de DV . . . . . . . . . . . . 10

2.2 Estrutura geral de um modelo linguístico fuzzy tipo Mamdani . . . . . . 15

2.3 Exemplo de ativação e agregação do conjunto fuzzy . . . . . . . . . . . . 20

2.4 Exemplo de diagrama de decisão tipo ávore. . . . . . . . . . . . . . . . 21

2.5 Etapas de pré-processamento para realização da análise estatistica . . . . 24

2.6 Hiperplano de separação do MLDA . . . . . . . . . . . . . . . . . 27

2.7 Hiperplano do classificador SVM . . . . . . . . . . . . . . . . . . . . 29

3.1 Diagrama do sistema de apoio a decisão para diagnóstico de demência. . 31

3.2 Diagrama do modelo fuzzy de comprometimento cognitivo. . . . . . . 33

3.3 Funções de pertinência da variável linguística que representam os conjuntos fuzzy para o MEEM. . . . . . . . . . . . . . . . . . . . 35

3.4 Funções de pertinência da variável linguistica fuzzy para o teste do relógio. 36

3.5 Funções de pertinência da variável linguistica fuzzy para o teste de fluência verbal. . . . . . . . . . . . . . . . . . . . 37

3.6 Funções de pertinência da variável de saida do modelo de comprometimento cognitivo. . . . . . . . . . . . . . . . . . . . . 37

3.7 Diagrama de Decisão para o tipo de demência - parte 1 . . . . . . . . . 41 
3.8 Diagrama de Decisão para o tipo de demência - parte 2 . . . . . . . . 42

3.9 Diagrama de Decisão para o tipo de demência - parte 3 . . . . . . . . 43

3.10 Diagrama do modelo fuzzy de risco de desenvolvimento de demência. . . 46

3.11 Funções de pertinência da variável linguística que representa o questionário de fatores de risco para demência.

3.12 Funções de pertinência da variável linguística que representa o questionário de fatores de proteção para demência.

3.13 Funções de pertinência da variável que representa a variável de comprometimento cognitivo.

3.14 Funções de pertinência da variável de saida do modelo de risco de demência 50

3.15 Escala visual analógica contínua para aferição da nota para os casos da base de dados hipotética .

3.16 Exemplo do Formulário utilizado para teste dos caminhos de decisão do Modelo de Tipo de Demência

4.1 Espalhamento das notas de comprometimento cognitivo da base hipotética para os casos discordantes com o modelo

4.2 Espalhamento das notas do modelo de comprometimento cognitivo versus escolaridade.

4.3 Curva ROC do modelo de comprometimento cognitivo pelo padrão do CDR.

4.4 Hiperplano de separação resultante da classificação do MLDA. . . . . . . 70

4.5 Hiperplano de separação resultante da classificação do SVM . . . . . . . 70 
4.6 Hiperplanos dos classificadores do MLDA e SVM agrupados por variáveis

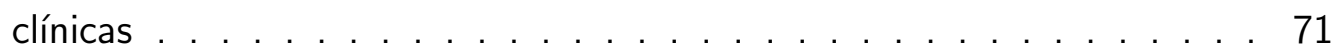

4.7 Diferença entre as alterações estatisticamente relevantes entre as técnicas de análise de neuroimagem $\ldots \ldots \ldots 72$

4.8 Exemplo da segmentação por fatias da imagem das regiões ativadas utilizando modelos deformavéis . . . . . . . . . . . . . . . . . . 73

4.9 Quantidade total de voxels ativados nas técnicas do SDM, SVM e SPM . 75

4.10 Espalhamento das notas do modelo de risco de demência . . . . . . . . . 76

1 Espalhamento dos valores do teste de MEEM da base hipotética . . . . 107

2 Espalhamento dos valores do teste do Teste do Relógio da base hipotética 108

3 Espalhamento dos valores do teste de Fluência Verbal da base hipotética 108

4 Espalhamento dos valores de compromentimento cognitivo da base hipotética para o modelo de Risco de Demência . . . . . . . . . . . . . . . 109

5 Espalhamento dos valores do questionário de fatores de risco para o Modelo de Risco de Demência . . . . . . . . . . . . . . . . . . . . . 110

6 Espalhamento dos valores do questionário de fatores de proteção para o Modelo de Risco de Demência . . . . . . . . . . . . . . . . . . . . . . 110 


\section{Lista de Tabelas}

2.1 Comparação entre os protocolos de diagnóstico CID-10, DSM-IV e NINCDS-

ADRA. Os sinais de + indicam se o item é coberto pelo critério. . . . . . 8

3.1 Base de regras para o modelo de compromentimento cognitivo. . . . . . 38

3.2 Perguntas do questionário de fatores de risco com peso atribuído a cada questão.

3.3 Perguntas do questionário de Fatores de Proteção com peso atribuído a cada questão. . . . . . . . . . . . . . . . . . . . . . . . . . 48

3.4 Regras para o modelo de Risco de Demência . . . . . . . . . . . . . . 50

3.5 Resumo dos casos gerados para base hipotética com base nos questionários de Risco e Proteção. . . . . . . . . . . . . . . . . . . . . . 57

3.6 Distribuição demográfica da base de dados de neuroimagens . . . . . . . 58

3.7 Interpretação dos escores do CDR . . . . . . . . . . . . . . . . . . 58

4.1 Quantidade total de erros, acertos e percentual de erro do modelo de comprometimento cognitivo

4.2 Índice de concordância Kappa entre os especialistas e o modelo e entre os especialistas.

4.3 Casos da base hipotética com com discordância entre especialistas e modelo 62 
4.4 Casos discordantes em relação a média dos especialistas e o modelo . . . 64

4.5 Correlação de Spearman entre as notas atribuídas pelos especialistas e pelo modelo. . . . . . . . . . . . . . . . . . . . . . . . . . . 64

4.6 Casos classificados incorretamente pelo modelo em relação ao CDR. . . . 65

4.7 Índice de erros, acertos e percentual de erros do diagrama de decisão de tipo de demência. . . . . . . . . . . . . . . . . . . . . . . . 68

4.8 Casos classificados incorretamente pelos especialistas . . . . . . . . . . 68

4.9 Sensibilidade, especificidade e acurácia dos classificadores multivariados do SDM e SVM. . . . . . . . . . . . . . . . . . . . . . . . . . . 69

4.10 Regiões estatisticamente relevantes identificadas pelas análises estatitiscas 74

4.11 Definição dos intervalos dos grupos para o modelo de Risco de Demência. 75

4.12 Quantidade total de erros, acertos e percentual de erro do modelo de Risco de Demência em relação aos especialistas . . . . . . . . . . . . . . 75

4.13 Casos discordantes entre especialistas e o modelo de Risco de Demência . 76

4.14 Correlação de Spearman entre o modelo e os especialistas. . . . . . . . . 77

4.15 Casos discordantes entre a média dos especialistas e o modelo . . . . . . 77

5.1 Fatores de Risco e proteção do CAID . . . . . . . . . . . . . . . . . . 83 


\section{Capítulo 1}

\section{Introdução}

As síndromes demênciais tem sido consideradas um problema de saúde pública em nível mundial. De acordo com o relatório publicado em 2009 pela Alzheimer's Disease Initiative (ADI) [1], estima-se que 115,4 milhões de pessoas venham a desenvolver algum tipo de demência até 2050. A ADI sugere que a questão da demência deva ser considerada como um prioridade para a saúde pública mundial.

O diagnóstico de demência é um processo naturalmente complexo. Além da percepção da demência como condição natural do envelhecimento pela população, existem diversas variáveis envolvidas na avaliação diagnóstica. Desta forma, sistemas de apoio a decisão podem tornar o diagnóstico de síndromes demenciais mais assertivos.

A utilização de técnicas de computação artificial que permitem capturar e formalizar o conhecimento do especialista ou auxilia-lo durante o processo de diagnóstico tem sido amplamente utilizadas na construção de modelos de apoio a decisão. Podemos citar trabalhos baseados na teoria dos conjuntos fuzzy [2-5], análises estatísticas aplicadas em exames de neuroimagens [6-8], lógica paraconsistente [9-11], ontologias para formalização de conhecimento [12], entre outros. 
Alguns modelos e sistemas tem sido propostos para apoiar o diagnóstico de demências. Podemos citar sistemas baseados em técnicas de aprendizado de máquina e análise multimodal utilizando neuroimagens [13]; sistemas de suporte a decisão clínica como o Dementia Management and Support System [14]; Modelos baseados na teoria dos conjuntos fuzzy, como: redes neurais fuzzy para diagnóstico de Alzheimer baseado em análise de eletroencefalograma [15]; mapa cognitivo fuzzy para avaliação de neuroimagens [16]; redes neurais fuzzy para diagnóstico de Alzheimer baseados nos sintomas da doença como perda de memória, problemas de linguagem esquecimento, mudança de personalidade [17], entre outros.

Neste trabalho propomos a criação de um modelo de apoio ao diagnóstico composto por três sub modelos de apoio ao diagnóstico para demências: 1) um Modelo de Compromentimento Cognitivo; 2) Um Modelo de Decisão para o Tipo de Demência; e 3) um Modelo fuzzy para avaliação do Risco de Desenvolvimento de Demência. Cada modelo pode ser utilizado em uma etapa do processo de diagnóstico de demências com objetivo de quantificar e apoiar a decisão do especialista.

A principal vantagem dos modelos apresentados neste trabalho é a formalização do conhecimento especialista acerca dos exames e fatores comumente avaliados durante o processo diagnóstico da demência, realizados nas consultas ambulatoriais. O modelo de decisão de demência aqui proposto requer um exame de neuroimagem, solicitação que faz parte da rotina de atendimentos dos pacientes no PROTER/IPq-USP. Apesar de diagramas de decisão serem comumente empregados com a finalidade de formalizar protocolos e rotinas de diagnóstico, não encontramos na literatura aplicações nesse sentido que utilizem modelos linguísticos fuzzy para avaliar as dimensões do diagnóstico como comprometimento cognitivo e risco de desenvolvimento de demência. 
Estes modelos foram construídos a partir de entrevistas com o grupo de médicos do PROTER/IPq-USP e baseados na experiência clínica do especialista. Também avaliamos técnicas de análise estatistica de neuroimagens como parte do processo de diagnóstico ambulatorial.

\subsection{Objetivos}

\subsubsection{Objetivo geral}

O principal objetivo desta tese é propor modelos matemáticos que possam auxiliar e quantificar o processo de diagnóstico das demências consideradas mais comuns, segundo os especialistas do PROTER/IPq-USP quais sejam: Doença de Alzheimer, Demência Frontotemporal, Demência Vascular e Demência de Corpos de Lewy.

\subsubsection{Objetivos específicos}

Podemos listar como objetivos específicos deste trabalho:

- Criar um modelo para apoio ao diagnóstico de comprometimento cognitivo, tratando as incertezas inerentes a esse diagnóstico através da teoria dos conjuntos fuzzy, baseado no conhecimento especialista;

- Criar um modelo tipo diagrama de decisão em árvore que apoie o diagnóstico dos tipos de demência comumente atendidos pelos especialistas do PROTER/IPqUSP;

- Avaliar a utilização de técnicas de análise de neuroimagem como parte do modelo de decisão; e 
- Criar um modelo com objetivo de mensurar o risco de um indivíduo desenvolver algum tipo de demência, utilizando um sistema de regras fuzzy baseado no conhecimento especialista. 


\section{Capítulo 2}

\section{Revisão da Literatura}

\subsection{Demência}

Demência é um termo geral utilizado para definir um grupo de patologias neurodegenerativas que comprometem as capacidades cognitivas, sociais e funcionais dos indivíduos acometidos. Entre as mais frequentes quais podemos citar a demência de Alzheimer (DA), demência vascular (DV), demência frontotemporal (DF), demência com corpos de Lewy (DCL), demência de Parkinson, demência de Huntington entre outras [18].

Entre os sintomas característicos de síndromes demênciais podemos destacar a perda das habilidades motoras, como movimentos e gestos precisos (apraxia), perda de memória, perda de compreensão da linguagem falada e escrita (afasia), perda da percepção (agnosia) e possíveis mudanças de personalidade e comportamento [19].

O diagnóstico das demências é um processo complexo, pois é comum assumir que idosos são suscetíveis a problemas cognitivos. Entretanto, as causas do esquecimento considerado natural podem ser incorrentes de um quadro de demência. De fato, é aceito de maneira geral que o indivíduo idoso apresentará algum comprometimento cognitivo, 
porém essa crença não é verdadeira [18]. Estudos conduzidos por Bottino et al. [20] afirmam que os idosos preservam o conhecimento adquirido, mas tem uma redução em algumas habilidades práxicas e executivas.

Apesar de não ser comprovada a perda de capacidade cognitiva em idosos, 50\% dos clínicos não diagnosticam demência em estágio inicial[21]. Segundo a Alzheimers Disease International [22], a percepção de que esquecer faz parte do processo natural de envelhecimento é mais comum (mas não exclusivo) em países com baixa ou média renda per capita. Essa percepção aliada a fatores como a progressão lenta de algumas demências, e ao fato dos indivíduos não procurarem cuidados médicos rapidamente faz das demências em geral um problema prioritário para a saúde no mundo.

Se ponderarmos a dificuldade do diagnóstico assertivo de demências e o envelhecimento natural da população devido ao aumento da expectativa de vida, temos um cenário onde a realização de um diagnóstico mais precoce dará a possibilidade de um tratamento adequado e menos angustiante ao paciente e ao cuidador [21].

\subsubsection{Demência de Alzheimer}

Em 1901 Aloysius Alzheimer (1864 - 1915), neurologista alemão, teve sob seus cuidados a paciente August D. admitida no Hospital de Frankfurt - Alemanha. Após examinála Alzheimer relatou que ela apresentava sintomas como redução da compreensão e memória, afasia, desorientação, comportamento imprevisível e alucinações auditivas [23]. O caso chamou a atenção de Alzheimer que mesmo deixando o hospital de Frankfurt acompanhou o caso de August D. até seu óbito em 8 de abril de 1906 e, em 4 de novembro deste mesmo ano Alzheimer publicou o caso e suas observações [23]. 
Entre as demências, a doença de Alzheimer (DA) é tida como mais comum. Petersen [24] em seu estudo preconiza que a DA é responsável por aproximadamente $56 \%$ de todas as ocorrências de demências no mundo. Este percetual de ocorrência de DA é corroborado por Herrera [25] em estudo realizado no Brasil com 1.656 indivíduos com 65 anos ou mais. Em 118 indivíduos diagnosticados com demência,o Alzheimer foi a causa de aproximadamente $55,1 \%$ das demências.

As causas da DA são de origem idiopáticas. Estudos genéticos sugerem que a presença do alelo $\epsilon 4$ da APOE aumenta significantemente o risco de desenvolver a patologia, sendo este o fator de risco genético mais comumente identificado em DA de início tardio (após 65 anos)

Segundo o Código Internacional de Doenças (CID) [26] e do National Institute of Neurological and Communicative Disorders and Stroke and the Alzheimer's Disease and Related Disorders Association (NINCDS-ADRDA) [27], o diagnóstico da DA é diferencial, realizado a partir de um conjunto de testes e exames afim de excluir outras demências ou patologias.

O critério mais utilizado nos estudos no Brasil é o do NINCDS-ADRDA, presente em $71 \%$ dos estudos, seguido pelos critérios da Associação de Psiquiatria Americana, o DSM-III-R e DSM-IV em 21\% e 29\%, respectivamente. Já os critérios estabelecidos no CID-10 aparecem em $17 \%$ dos estudos [28, 29].

Apesar dos critérios diagnósticos para DA compartilharem pontos em comum como declínio de memória, declínio de função intelectual, alteração em relação ao padrão basal, inicio insidioso e deterioração lenta, existem algumas diferenças entre as avaliações realizadas. A tabela 2.1 apresenta uma comparação entre os critérios do CID-10, DSMIV e NINCDS-ADRDA. 
Tabela 2.1: Comparação entre os protocolos de diagnóstico CID-10, DSM-IV e NINCDSADRA. Os sinais de + indicam se o item é coberto pelo critério.

\begin{tabular}{lccc} 
& CID-10 & DSM IV & NINCDS-ADRDA \\
\cline { 2 - 3 } Declínio de Memória & + & + & + \\
\hline Declínio em relação ao nível prévio & + & + & + \\
\hline $\begin{array}{l}\text { Prejuízo de pelo menos uma função intelectual } \\
\text { além da memória }\end{array}$ & + & + & \\
\hline Ausência de evidência clínica ou ambulatorial & & & + \\
para outras demências & + & + & - \\
\hline Início insidioso & + & + & + \\
\hline Deterioração lenta & + & - & + \\
\hline Deterioração contínua & - & + & + \\
\hline Sem início subíto & + & - & - \\
\hline Sem sinais neurológicos focais & + & - & - \\
\hline Declínio da capacidade de raciocinar & + & - & + \\
\hline Afasia, apaxia,agnosia ou disturbio de & & & + \\
função executiva & - & + & - \\
\hline Demência estabelecida por questionário & - & - & - \\
\hline Demência confirmada por testagem neuropsicológica & - & - & + \\
\hline Declínio das atividades da vida diaria & + & - & - \\
\hline Declínio social ou ocupacional & - & + & - \\
\hline Idade de início entre 40 e 90 anos & - & - & \\
\hline Sem abuso de substâncias & - & + & + \\
\hline Ausência de outro disturbio mental & - & + & \\
\hline
\end{tabular}

De forma geral, os testes e exames que podem ser solicitados ou realizados são preditivos, como exames de testagem genética, análise do líquido cefalorraquidiano para $\beta$-amilóide e tau (estudos que indicam uma correlação entre a diminuição da proteína $\beta$-amilóide e aumento tau e tau-fosforilada $[28,30])$ ou exames de neuroimagem e uma bateria de testes cognitivos e neuropsicológicos, onde podemos destacar o Mini Exame do Estado Mental (MEEM), teste do relógio e o teste de fluência verbal.

Entretanto, alguns exames como testagem genética, exame do líquido cefalorraquidiano para $\beta$-amilóide e tau e até mesmo os exames de neuroimagens não são acessíveis para a população em geral fora dos grandes centros, ou mesmos nestes, por encarecer o processo de diagnóstico $[18,21]$. 
O critério de diagnóstico para DA definitivo é dado com evidências histopatológicas difíceis de se confirmar em um primeiro atendimento. Porém é factível traçarmos uma possibilidade de diagnóstico com base em testes e avaliações do histórico do paciente.

\subsubsection{A demência vascular}

O termo demência vascular (DV) é utilizado para caracterizar demências causadas por uma doença vascular encefálica. A DV é tida como a segunda causa de demência mais comum com prevalência de 10 a 23\%, principalmente devido aos altos índices de doenças vasculares na população [18].

A DV se caracteriza pela existência de uma ou mais lesões cerebrais, o que implica em um início súbito e uma evolução percebida em degraus advindas da ocorrência de eventos vasculares. O diagnóstico de DV é realizado avaliando-se o declínio cognitivo e das funções executivas, bem como a execução de um exame de neuroimagem e a forma como a doença se manifestou [18]. Também é possível se utilizar do escore de Hashinsck para mensuração do risco isquêmico do paciente [31].

O quadro clínico causador de DV é diversificado. Os fatores de risco da demência são associados aos riscos para doenças vasculares como tabagismo, hipertensão, diabetes e hipercolestorelemia, e as causas podem estar associadas a lesões subcorticais (nos pequenos vasos), corticais, demência hemorrágica, entre outras [18].

As alterações no quadro clínico também podem ser distintas. Por exemplo, o déficit cognitivo na DV pode ser mais facilmente percebido quando ocorrem lesões em áreas estratégicas, como estruturas do sistema límbico. Nos casos onde a ocorrência de lesões vasculares é nos pequenos vasos, por exemplo, o grau de cognição pode parecer adequado ou levemente alterado [18]. 
Nesse cenário os exames de neuroimagem tem grande importância no diagnóstico da DV. É esperado encontrar em exames de neuroimagem de pacientes com DV lesões na substância branca, bem como aumento ventricular [18, 32]. A imagem 2.1 apresenta uma imagem característica de DV, onde se pode observar uma lesão extensa da substância branca, consistente com um quadro de demência vascular subcortical.

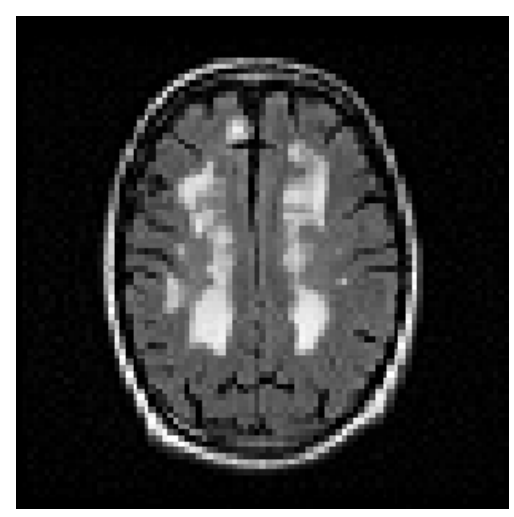

Figura 2.1: Exame de neuroimagem característico de DV, as lesões são perceptíveis nas manchas brancas. Fonte:[32].

\subsubsection{Demência Frontotemporal}

A Demência Frontotemporal (DFT) é caracterizada pela atrofia dos lobos temporais e/ou frontais. A doença tem um início insidioso e uma progressão lenta e afeta pessoas na faixa de idade de 45 a 70 anos [18]. A prevalência da DFT é desconhecida, e varia de acordo com o critério utilizado. Estudos apontam para uma prevalência que varia de 12 a $20 \%$ entre as demências [33].

A variação de diferentes critérios sejam clínicos, histológicos ou anatomopatológicos causaram problemas na classificação da doença [18]. Os principais sintomas critérios associados a DFT foram publicados a partir da conferência de consenso de Lund e Manchester [18, 34], sendo:

- Início incidioso e progressão lenta dos sintomas; 
- Alterações comportamentais como: mudanças na conduta pessoal, desinibição, hiperoralidade, entre outros;

- Sintomas afetivos, como depressão, indiferença e perda de empatia;

- Alterações na linguagem;

- Preservação da orientação espacial e praxia;

- Incontinência e reflexos primitivos; e

- Início pré senil e histórico familiar de primeiro grau.

Devido a falta de biomarcadores e sinais esperados, os critérios clínicos são de extrema importância para um diagnóstico mais efetivo da DFT. Por exemplo, alterações frontais e temporais associadas a patologia não aparecem nos estágios iniciais em exames de neuroimagem e, apesar de alguns casos da doença terem associadas mutações na proteína tau, essa mutação não é responsável por todas as formas de DFT, tendo sido mapeados outros cromossomos que podem estar relacionados a ocorrência da doença [18].

\subsubsection{Demência de Corpos de Lewy}

A Demência de Corpos de Lewy $(D C L)$ foi descrita à aproximadamente 30 anos atrás [18]. A DCL se caracteriza pela presença de corpos de Lewy no tecido cerebral, sendo que na DCL a ocorrência de corpos de Lewy ocorrem principalmente no córtex cerebral, núcleos subcorticais e tronco.

Apesar de não estar decrita nos critérios do DSM e CID-10 como uma doença que causa demência [18],os critérios de DCL foram publicados em um consenso para 
estabelecer seu diagnóstico clínico, sendo duas caracteristicas fundamentais para um diagnóstico provável ou uma para diagnóstico possível. São características fundamentais para o diagnóstico de DCL:

- Flutuação de cognição;

- Alucinações visuais recorrentes; e

- Características extrapiramidais espontâneas.

São características que dão suporte ao diagnóstico de DCL:

- Quedas repetidas;

- Síncope;

- Perda transitória de consciência;

- Sensibilidade a Neurolépticos;

- Delírios sistematizados;

- Alucinações de outras modalidades;

- Transtorno de comportamento do sono REM; e

- Depressão.

O reconhecimento da DCL tem aumentado e a patologia tem sido incluída como uma das causas mais frequentes de demência, podendo estar em segundo lugar das causas mais comuns, junto com a demência vascular. 


\subsection{Técnicas de modelagem para apoio ao diagnóstico}

Com os avanços tecnológicos das últimas décadas foram desenvolvidos sistemas computacionais para apoiar o processo de diagnóstico de diversas patologias. A partir de pesquisas e do desenvolvimento de novas teorias em inteligência artificial, foram criados sistemas inteligentes com base em técnicas como aprendizado de máquina, probabilidades bayesianas, redes neurais, árvores de decisão e lógica fuzzy [35].

Os sistemas de apoio a decisão clínica podem trazer maior qualidade no atendimento primário, agregando o conhecimento da literatura e pesquisas com evidências clínicas e a experiência do médico [36].

Para idealizar uma hipótese diagnóstica, o médico avalia um grande número de variáveis, que muitas vezes não são precisamente mensuráveis. Essa incerteza é natural ao processo de diagnóstico e se tornou uma área de pesquisa fértil para criação de modelos baseados na teoria dos conjuntos fuzzy focados no apoio a decisão [37]. Podemos citar trabalhos em epidemiologia [2, 38], modelagem de diagnóstico [4] e apoio a decisão em exames complementares [5, 39].

Outra técnica utilizada em modelos diagnósticos são diagramas de decisão. Os diagramas de decisão são utilizados para representar um conjunto de condições para execução de uma ação, organização e divisão do conjunto de dados. Em nosso caso, o conjunto de decisões necessárias para caracterização do tipo de demência pode ser formalizada em um diagrama de decisão clínica. 


\subsubsection{Teoria dos Conjuntos fuzzy}

A teoria de conjuntos difusos ou teoria de conjuntos fuzzy, ${ }^{1}$ foi elaborada em 1965 por Lofti Askar Zadeh [40] de forma a representar conjuntos que não possuem fronteiras bem definidas. Zadeh cita em sua pesquisa a necessidade de representar conceitos abstratos que apesar de não serem usualmente representados na matemática fazem todo sentido nos processos de reconhecimento de padrões, abstração e comunicação.

$\mathrm{Na}$ lógica clássica utiliza-se dois estados (verdadeiro e falso) para classificar se o elemento pertence ou não a um determinado conjunto. Entretanto essa condição nem sempre é aplicável na tomada de decisões em domínios onde existe algum grau de incerteza, ou onde estados intermediários podem levar a formação de outros conjuntos [41].

Através da teoria dos conjuntos fuzzy podemos lidar com as incertezas de identificação. Essa característica da modelagem dos conjuntos fuzzy é possível pela sua multivaloração que permite realizar uma transição gradual entre os conjuntos. Os graus de pertinência dados através da função de pertinência definem quanto um indivíduo pertence a um conjunto fuzzy através de um valor-verdade fuzzy [41, 42]

Dentre as diversas estruturas matemáticas nas quais se baseiam os sistemas fuzzy a mais utilizada em saúde são os modelos baseados em regras condicionais, particularmente os modelos linguísticos tipo Mamdani. A estrutura básica de um modelo linguístico do tipo Mamdani é composta por um módulo de fuzificação, que recebe uma variável de entrada (que pode ser uma medida ou uma variável linguística); uma base de regras do tipo Se-Então; um processo de inferência que produz uma saída do modelo; e, quando

\footnotetext{
${ }^{1}$ Optou-se por não usar a tradução do termo fuzzy no decorrer do trabalho devido a ampla aceitação e conhecimento da palavra em inglês.
} 
a saída é um conjunto fuzzy (como é o caso de modelos tipo Mamdani), um método de defuzificação que converte a saída fuzzy em uma saída clássica que melhor represente o conjunto linguístico da saída fuzzy. A imagem 2.2 apresenta um esquema da estrutura de um modelo linguístico fuzzy.

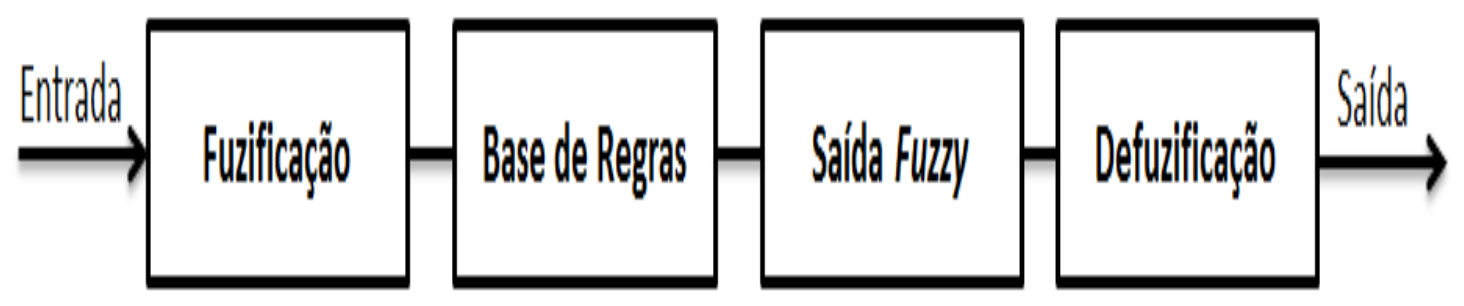

Figura 2.2: Estrutura geral de um modelo linguístico fuzzy tipo Mamdani

A lógica fuzzy é uma técnica da computação artificial que visa imitar a forma de raciocínio humano sobre conceitos imprecisos ou vagos [41, 42]. Para essa finalidade, as variáveis linguísticas fuzzy são amplamente utilizadas devido a possibilidade de expressar variáveis qualitativas de forma quantitativa, através de uma função de pertinência.

\section{Variáveis Linguísticas fuzzy}

A variável linguística fuzzy é uma variavel qualitativa adjetivada por termos linguísticos que tem seu valor quantitativo expresso através de uma função de pertinência fuzzy $[41,42]$.

Para exemplificar tomaremos como exemplo a variável linguística Altura, e que a altura de um indivíduo pode ser quantificada como Alto a partir de 1,80 metros, Médio a partir de 1,65 metros ou Baixo abaixo de 1,65 metros. Dado um indivíduo com 1,64 metros de altura, ele seria, pela formulação clássica, considerado como Baixo. Quando trabalhamos com variavéis linguísticas fuzzy, podemos associar os termos linguísticos que compõe uma variável liguística fuzzy a um universo de medidas que permite uma 
transição gradual entre os conjuntos. Sendo assim, o indivíduo de nosso exemplo, com 1,64 metros de altura, poderia ser considerado Médio com algum grau de pertinência e Baixo com algum outro grau de pertinência.

A estrutura de uma variável linguística deve conter o nome da variável, os termos linguísticos que caracterizam a variável, o universo de valores aos quais os termos linguísticos pertencem e um intervalo de medidas no qual cada conjunto fuzzy é representado [41, 42]. A variável Altura, por exemplo, será definida em um universo de medidas e os subconjuntos de medidas devem estar associados a cada termo linguístico (no caso Alto, Médio e Baixo).

Apesar de termos linguísticos facilitarem a modelagem e a formalização do conhecimento, a participação do especialista é geralmente uma condição fundamental para a correta definição do domínio de valores de uma variável linguística fuzzy, bem como, da partição de seus domínios e elaboração das regras. Essa participação é ainda mais relevante quando pensamos em modelos fuzzy como sistema de apoio ao diagnóstico.

\section{Regras Condicionais fuzzy}

Regras condicionais são amplamente utilizadas em modelos fuzzy, pois são instrumentos poderosos para formalização de conhecimento. Uma base de regra representa formalmente o conhecimento do domínio incluindo suas incertezas e imprecisões [38, 41].

As regras condicionais fuzzy são geralmente proposições condicionais que podem facilmente ser concebidas e avaliadas pelos especialistas e tem por objetivo formalizar o conhecimento sobre a relação entre as variáveis fuzzy que fazem parte do modelo.

As regras basicamente relacionam um conjunto de variáveis de entrada para uma ou mais variáveis de saída. A estrutura básica de uma regra condicional fuzzy é [41, 42]: 


\section{SE antecedentes ENTÃO consequentes}

Os antecedentes de uma regra fuzzy definem uma área no espaço fuzzy das varáveis de entrada, a partir de seus termos linguísticos, e o consequente é um espaço fuzzy de saída que representa a ação ou conclusão resultante da inferência [41]. Assim a saída de uma regra fuzzy demanda a existência de um conhecimento prévio (mesmo que empírico) do domínio, o que reforça a importância do especialista na construção dos modelos $[38,41]$.

\section{Modelos Baseados em Regras}

Os modelos baseados em regras permitem que o conhecimento específico do profissional e sua vivência possam ser traduzidos computacionalmente de forma simples, o que possibilita que estes modelos sejam amplamente aplicados na modelagem de sistemas em saúde. Podemos destacar dois modelos baseados em regras amplamente utilizados: os modelos linguísticos do tipo Mamdani e do tipo Takaki-Sugeno-Kang (TSK)[41].

Os Modelos linguísticos tipo Mamdani se caracterizam pela estrutura das variáveis de saída serem conjuntos fuzzy, o que facilita a compreensão do modelo pelo profissional especialista. Modelos como o Takaki-Sugeno-Kang (TSK) também se valem de uma estrutura de regras SE-ENTÃO e variáveis linguísticas de entrada, porém, o consequente de um modelo TSK prevê a saída com base em uma função matemática, portanto sua saída é clássica. Essa estrutura de modelagem é geralmente utilizada em modelos cujo conhecimento sobre o sistema é explicito [41, 42].

Devido aos modelos Mamdani terem a característica de representar todo o sistema de forma qualitativa com base em linguagem natural, esses modelos vem sendo amplamente utilizados em biomedicina e sistemas de apoio a diagnóstico médico [38, 41, 42]. 
Basicamente no modelo linguístico tipo Mamdani, as inferências do conjunto de regras são realizadas através dos operadores Mínimo e Máximo, que substituem operações clássicas como intersecção e união entre conjuntos. O algoritmo de inferência de um modelo do tipo Mamdani realiza os seguintes passos:

- Para cada regra: calcular o grau de ativação da regra (o quanto a regra esta sendo ativada) a depender da ativação das variáveis antecedentes;

- Associar através do operador mínimo a ativação de saída para cada regra ativada; e

- Agregar, através do operador Máximo os conjuntos fuzzy de saída.

A inferência é dada, portanto, pelo método min-max. São inicialmente calculados os graus de pertinência para todas as regras que satisfazem os antecendentes e realizada a intersecção dos conjuntos ativados (dado pelo operador min). Após obter os conjuntos de saída das regras ativadas é realizada a união desses conjuntos pelo operador max. Para exemplificar o processo de ativação do conjunto de saída, vamos considerar duas regras hipotéticas:

$$
\begin{aligned}
& \text { R1: Se x é } A_{1} \text { então y é } B_{1} \text {. } \\
& \text { R2: Se x é } A_{2} \text { então y é } B_{2} \text {. }
\end{aligned}
$$

Os valores de entrada são dados pelos valores de $x$, com algum grau de pertinência nos subconjuntos fuzzy $A_{1}$ e $A_{2}$. O conjunto de saída fuzzy da inferência do modelo tipo Mamdani é a agregação dos conjuntos ativados pelas regras $R_{1}$ e $R_{2}$. A imagem 2.3 apresenta de forma gráfica o processo de inferência dado por uma variável de entrada 
e uma variável de saída fuzzy através do operador de agregação (max), tipo união dos conjuntos.

Nesse caso, a saída desse modelo é um conjunto fuzzy. Porém as vezes é nescessário obter uma saída numérica clássica. Para tal utilizamos métodos de defuzificação.

\section{Defuzificação}

A defuzificação é um processo pelo qual as saídas agregadas das regras fuzzy ativadas são convertidas em uma saída quantitativa (um número apenas). Esse processo fornece um valor numérico que representa a distribuição de possibilidades dos conjuntos ativados. Os principais métodos utilizados são: média dos máximos, centro dos máximos e centro de área. Nesta sessão apresentaremos o método do centro de área por ser o mais comumente empregado e que será utilizado neste trabalho $[3,41]$.

O método do centro de área é também conhecido como método do centróide ou centro de gravidade. Este consiste em calcular o centróide da área ativada pelos conjuntos de saída fuzzy, ou seja, ele considera toda a distribuição de possibilidades ativadas pelas regras do modelo.

Basicamente o método do centro de área calcula inicialmente o centro de gravidade (centróide) da área composta por todas as saídas do sistema. O ponto no domínio escolhido como representante dessa saída fuzzy do sistema, é obtido com a projeção desse centróide no eixo das abscissas [41]. Este ponto é calculado pela fórmula 2.1, em espaço contínuo:

$$
\frac{\int_{x_{a}}^{x_{b}} x \mu_{s}(X) d x}{\int_{x_{a}}^{x_{b}} \mu_{s}(X) d x}
$$




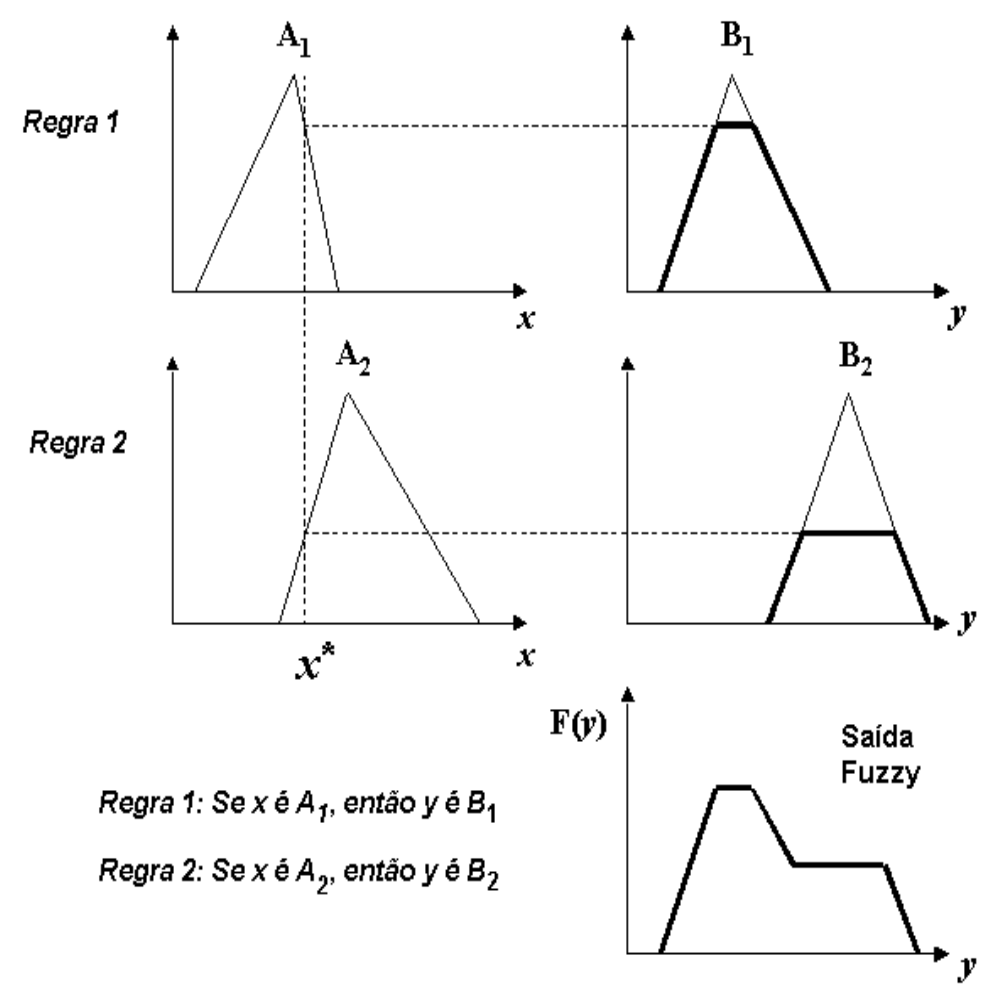

Figura 2.3: Ativação dos conjuntos e agregação do conjunto fuzzy de saída no processo de inferência tipo Mandani. Fonte:[38].

Em espaço discreto a defuzificação de centro de área é dada pela fórmula 2.2

$$
\frac{\sum_{i=0}^{N} \mu_{s}\left(X_{i}\right) * x}{\sum_{i=0}^{N} \mu_{S}\left(X_{i}\right)}
$$

\subsubsection{Diagrama de Decisão Tipo Árvore}

Um diagrama de decisão é uma estrutura em forma de árvore que basicamente representa as entradas de uma tabela de decisão afim de interpretar um conjunto de condições para execução de uma ação ou decisão.

A construção de diagramas de decisão em formato de árvore são comumente utilizadas para organização e divisão do conjunto de dados e na construção de sistemas e protocolos de suporte a decisão clínica, por exemplo o trabalho de Wetherell e Jeste (2003) que propõe um modelo de decisão em forma de arvore para demências [43] 
e o trabalho de Knopman, Boeve e Pertersen (2003), que com base nos critérios de diagnóstico estabelece uma sequência hierarquica utilizando um diagrama de decisão[44].

O procedimento de inferência sobre um diagrama de decisão se dá a partir do nó raiz que contém um teste lógico do qual se deriva os ramos para os nós filhos. A figura 2.4 apresenta um exemplo de um diagrama de decisão.

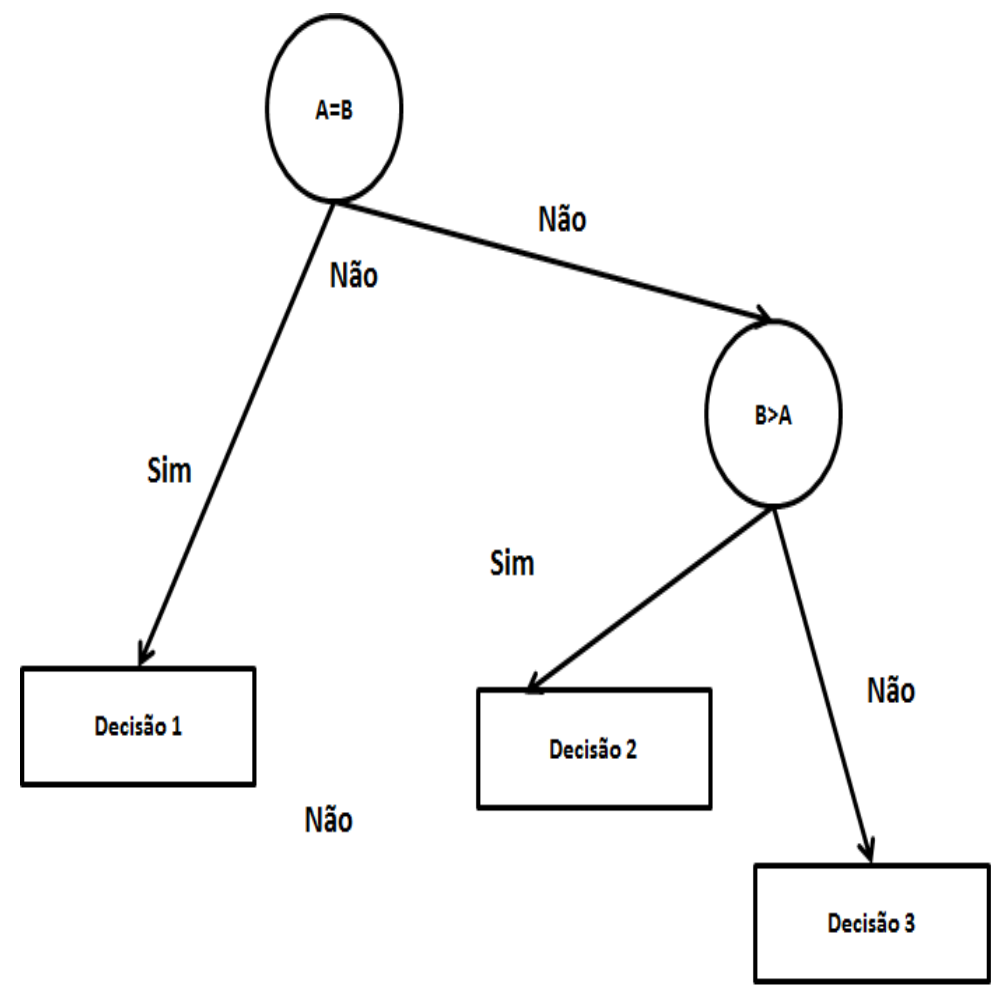

Figura 2.4: Exemplo de diagrama de decisão tipo ávore.

A principal diferença entre um fluxograma de decisão clínico e uma árvore de decisão é que a árvore de decisão pode ser estruturada com base em um banco de dados existente, utilizando algoritmos que derivam a árvore com base no valor da informação. Porém em cenários onde não existe uma base de dados formal, é necessário modelar uma estrutura de decisão com base no conhecimento especialista ou em protocolos formais existentes. 


\subsection{Análise de Neuroimagens}

Nos últimos anos com o avanço significativo da utilização de imagens no processo de diagnóstico diversos métodos computacionais vem sendo desenvolvidos para facilitar a análise de neuroimagens e identificar alterações morfológicas no cérebro [45]. Até 1984 as imagens eram bidimensionais (por exemplo Raio-X) e as pesquisas voltadas ao desenvolvimento de hardware especializado e técnicas de segmentação de imagens.

O advento das Imagens de Ressonância Magnética (fMRI) aumentou significativamente as pesquisas com o desenvolvimento de novas técnicas de análise de imagem como a segmentação por crescimento de região, modelos deformáveis e técnicas de análise de reconhecimento de padrões estatísticos dos quais podemos destacar os métodos de análise massiva univariada e métodos de análise multivariados [6, 46].

Nesta sessão abordaremos brevemente técnicas de análises estatísticas de neuroimagens que podem ser utilizadas em sistemas de apoio a decisão para classificação ou identificação de regiões discriminantes no acometimento de demências. Abordaremos três técnicas: 1) Análises massivamente univariadas utilizando o software Statistical Parametring Mapping (SPM); 2) O Modelo Discrimimante Estatistico (SDM ${ }^{2}$ ) (baseado nas técnicas de Análise de Componentes Principais $\left(\mathrm{PCA}^{3}\right)$ e na Análise de Discriminantes Lineares de Máxima Incerteza (MLDA ${ }^{4}$ ); e 3 ) As Máquinas de Suporte Vetoriais $\left(S^{5}{ }^{5}\right)$, utilizando o software PROBID.

Como as técnicas de análise de neuroimagem são propostas de forma complementar aos modelos de diagnóstico elas serão abordadas de forma breve comparando resultados

\footnotetext{
${ }^{2}$ do inglês Statistical Discriminant Model

${ }^{3}$ do inglês Principal Component Analisys

${ }^{4}$ do inglês Maximum uncertainty Linear Discriminant Analysis

${ }^{5}$ do inglês - Suport Vector Machines
} 
da aplicação das três técnicas e discutindo sua viabilidade de uso em modelos de diagnóstico assistido. As informações sobre os softwares utilizados nas análises são abordadas no capítulo 3 .

Antes de submeter um conjunto de imagens a técnicas de análise estatística, é necessário normalizar as amostras de acordo com uma referência padrão, a seguir abordaremos o pré-processamento de neuroimagens, etapa necessária antes das realizações das avaliações estatísticas.

\subsubsection{Pré processamento de Neuroimagens}

O pré-processamento tem por objetivo alinhar espacialmente as imagens eliminando as diferenças de tamanho, orientação, rotação e forma do cérebro, bem como remoção de artefatos cranianos. A normalização garante que a imagem estará alinhada a um sistema comum de coordenadas e terá as mesmas dimensões e tamanhos dos voxels.

De forma geral, inicialmente submete-se a imagem à normalização espacial afim de alinhar as imagens do estudo a uma imagem modelo definida pelo Montreal Neurological Institute (MNI), composta pela média de 152 indivíduos saudáveis e aproximadas ao espaço padrão encontrado no atlas de Talairach Tornoux [6]. Podemos citar dois protocolos amplamente utilizados em estudos de análise de neuroimagens: Morfometria Baseada em Voxel (MBV) e a Morfometria Baseada em Voxel Otimizada (MBVOtimizada).

A Morfometria Baseada em Voxel e a Morfometria Baseada em Voxel Otimizada são protocolos de pré-processamento que estabelecem uma sequência de procedimentos para normalização, segmentação e suavização de neuroimagens, afim de reduzir as variações inerentes do processo de aquisição das imagens. A principal diferença entre as 
metodologias é que o MBV utiliza uma imagem padrão para normalização, enquanto a MBV-Otimizada utiliza um template customizado criado a partir das imagens que serão utilizadas nas análises estatísticas [47, 48].

O MBV é composto por etapas de pré processamento que englobam a normalização espacial da imagem para uma referência comum, no caso o Atlas de Talairach [6]; segmentação compartimentada das substâncias cerebrais em massa branca cinza e líquido cefalorraquidiano; e suavização das imagens. Após as etapas de pré-processamento são realizadas análises estatísticas calculando-se a significância estatística de cada voxel (pvalor) através do teste t-Student [46].

Após a normalização espacial é realizada uma segmentação onde as imagens são segmentadas em massa branca, cinza e líquido cefalorraquidiano e aplicado um filtro gaussiano isotrópico com a finalidade de suavizar a imagem. A figura 2.5 apresenta o resultado da imagem original após as etapas de normalização, segmentação e suavização. Para análise com base em imagens não segmentadas, como é o caso das análises multivariadas, a extração de artefatos cranianos pode ser realizada utilizando o software $\mathrm{MRicro}^{6}$, função skull strip.

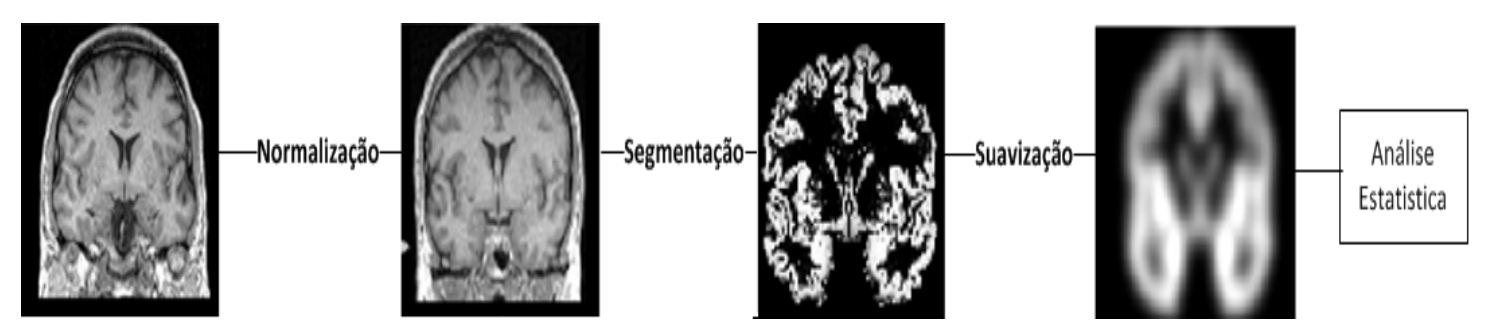

Figura 2.5: Etapas de pré-processamento para realização da análise estatistica

Após as etapas de pré-processamento são realizados testes de significância voxel a voxel com objetivo de identificar regiões discriminantes.

\footnotetext{
${ }^{6}$ Disponível em: http://www.mccauslandcenter.sc.edu/mricro/
} 


\subsubsection{Análises Massivamente Univariadas voxel a voxel}

A análise massivamente univariada de dados para neuroimagens é realizada avaliando cada voxel individualmente afim de identificar diferenças relevantes. Para tal, utiliza-se o teste t-Student, que determina a significância de cada voxel através do valor preditivo do teste (p-valor) [46].

Para realização de uma análise massivamente univariada entre grupos distintos é capturado um voxel $v$ na posição $(x, y, z)$, para cada imagem do grupo 1 e do grupo 2. Assim a depender do valor descritivo do teste ( $p$-valor) pode ser verificado se existe diferença entre as médias dos voxels dos grupos analisados.

A principal vantagem da utilização de técnicas de análises massivamente univariadas é a ampla aceitação pela comunidade médica, já que se trata de uma técnica consolidada e amplamente utilizada. Entretanto a técnica não permite, por exemplo a realização de uma análise global do cérebro [6].

A realização de uma análise global sem segmentação que possa avaliar toda a imagem traz alguns benefícios para entendimento do comportamento e evolução de patologias, pois sendo o cérebro uma estrutura complexa que não possui delimitações claras entre as regiões é esperado que uma alteração mesmo que isolada tenha um efeito global. Consequentemente as técnicas de análise multivariada, que consideram todo o conjunto de voxels, podem trazer informações adicionais sobre a doença avaliada.

\subsubsection{Análises Multivariadas}

Técnicas de análise multivariada têm sido utilizadas em estudos de neuroimagem para classificação automática de grupos distintos e identificação de diferenças discriminantes 
entre os grupos. Essas técnicas podem classificar amostras com base em informações discriminantes que nem sempre podem ser observadas por uma inspeção visual $[6,7,49]$.

As análises multivariadas de neuroimagens podem trazer informações adicionais sobre a patologia, pois avaliam toda a imagem para criar um hiperplano de separação entre os grupos, desde indivíduos classificados nos extremos (com mais características da doença) até individuos limítrofes entre os grupos.

Neste trabalho abordaremos as técnicas do SDM e do SVM como sendo técnicas que têm sido utilizadas para classificação e avaliação de diferenças morfológicas entre grupos de paciente e controle.

\subsubsection{Modelo Discriminante Estatístico - SDM}

O SDM[6] é baseado nas técnicas do PCA e do MLDA. Basicamente o SDM consiste em aplicar a análise PCA para redução da dimensionalidade dos dados, preservando as principais características do conjunto de amostras, o que traz ganhos significativos de tempo na convergência do classificador do MLDA que realiza a projeção das amostras no hiperplano de separação.

O PCA é utilizado para redução da dimensionalidade do conjunto de amostras. Para tal, é calculado um vetor que melhor aproxima as amostras e descarta-se autovetores que não apresentam pouca ou nenhuma variância. Assim podemos representar um grande conjunto de dados com dimensionalidade reduzida [6]. Um exemplo prático de redução de dimensionalidade é o fundo de uma neuroimagem que não apresenta nenhuma informação discriminante e nenhuma variância entre os voxels, logo pode ser eliminado sem comprometer o conjunto de dados. 
O MLDA é uma técnica de aprendizado supervisionado focado em maximizar as diferenças entre os grupos e tem sido utilizada em estudos de neuroimagem para a classificação e identificação de regiões discriminantes [6, 7, 49].

Como resultado da aplicação do MLDA obtemos as característica mais discriminantes de cada imagem, projetadas no espaço do MLDA para criação do hiperplano de separação entre os grupos, a definição das médias locais de cada grupo, bem como seus extremos. A imagem 2.6 mostra um exemplo do hiperplano de separação do MLDA que apresenta um exemplo da minimização do espalhamento do grupo a partir das características discriminantes (dado pelo círculo em volta das amostras) e a definição do hiperplano de separação com base nas diferenças entre os grupos.

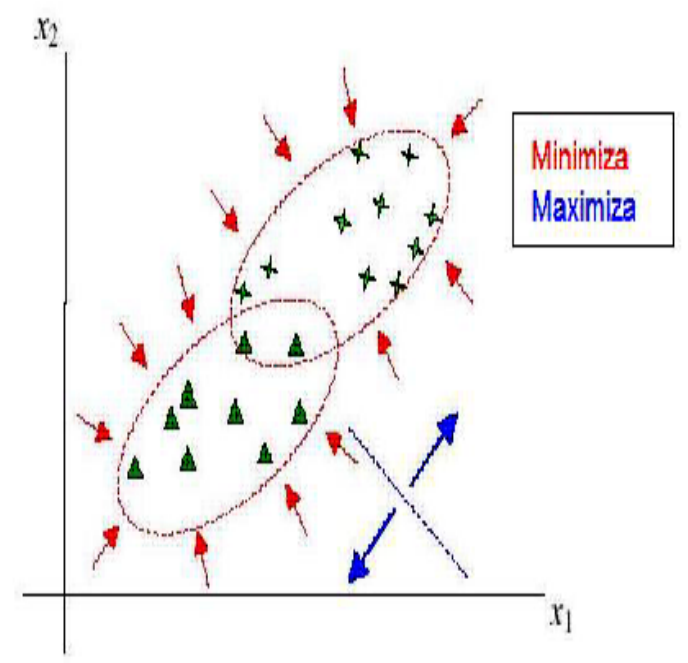

Figura 2.6: Hiperplano de separação do MLDA. Os círculos apresentam as características discriminantes de cada grupo para realização da classificação, consequentemente maximizando a separação entre os grupos.

A identificação das regiões discriminantes no SDM é realizada calculando-se as diferenças entre as imagens nos extremos do grupo. A equação 2.3 apresenta a fórmula utilizada para calcular a variação para cada ponto, onde $x_{1}$ é a imagem classificada no extremo do grupo 1 e $x_{2}$ a imagem classificada no extremo do grupo 2 . 


$$
\operatorname{diff}=\frac{x_{1}-x_{2}}{\sqrt{\sigma^{2} / N_{1}+\sigma^{2} / N_{1}}} .
$$

O valor da variância ponderada é dado por $\sigma^{2}$, calculado de acordo com a equação 2.4:

$$
\sigma^{2}=\frac{\left(N_{1}-1\right) \sigma^{2}+\left(N_{2}-2\right) \sigma^{2}}{N_{1}+N_{2}-2}
$$

\subsubsection{Máquinas de Suporte Vetorial - SVM}

O SVM é uma técnica multivariada de aprendizado supervisionado utilizada em problemas de classificação [50]. O SVM trabalha afim de maximizar o hiperplano de classificação, o que permite obter uma boa capacidade de generalização e minimização dos erros de classificação.

A classificação do SVM consiste em encontrar um hiperplano de classificação em relação a maximização dos vetores de suporte, que são calculados pelas características que mais se assemelham ao outro grupo (mais próximas do hiperplano). A imagem 2.7 apresenta um modelo de classificação do SVM: as linhas contínuas representam os vetores de suporte e a linha pontilhada representa o hiperplano de separação que maximiza a distância entre os vetores de suporte.

Neste trabalho, propomos a utilização de técnicas de análise de neuroimagem na construção de um modelo de diagnóstico assistido, mas por não ser objeto principal da pesquisa não abordaremos exaustivamente o detalhamento de cada técnica que pode ser encontrada na literatura específica.As máquinas de suporte vetorial são abordadas mais 


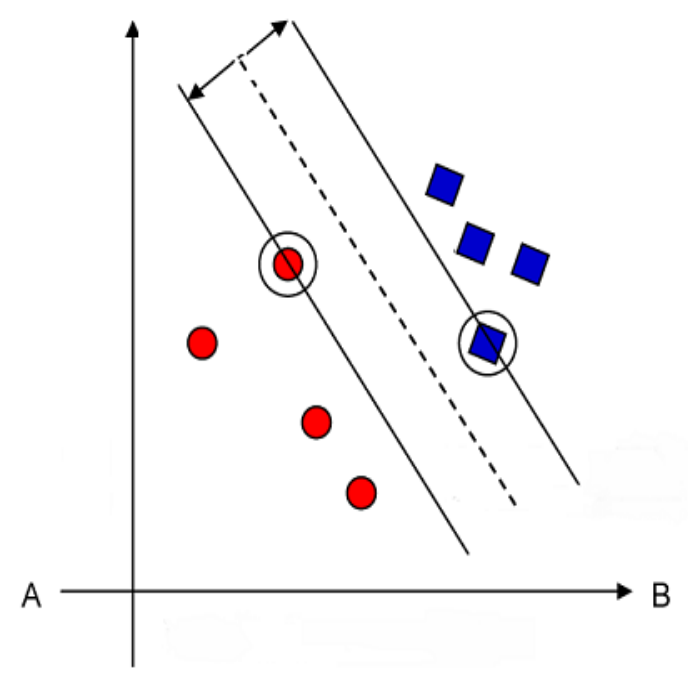

Figura 2.7: Hiperplano do classificador SVM. As linhas contínuas representam os vetores de suporte, enquanto a linha pontilhada é o hiperplano de separação, que maximiza das distâncias entre os vetores de suporte.

detalhadamente no trabalho de Vapnick [50] e as aplicações em estudos de neuroimagens nos trabalhos de Sato et al. [8], Mourão-Miranda et al. [51] e Cuingnet et al. [52]

Detalhes sobre a implantação do SDM e aplicações do MLDA, podem ser encontrado nos trabalhos de Thomaz et al.[53], Santos et al. [6], Kasparek et al. [49] e Sato et al. [7].

Uma discussão sobre a utilização do modelo linear geral para realização de análises massivamente univariadas, pode ser encontrado no trabalho de Friston et al. [46]. 


\section{Capítulo 3}

\section{Metodologia}

Nesta seção apresentamos os métodos e ferramentas que utilizamos neste trabalho. Descrevemos os modelos fuzzy criados para apoio a decisão diagnóstica; os testes cognitivos utilizados na modelagem; os banco de dados utilizados; os testes de performance realizados para análise de performance dos modelos e também as técnicas de análise de neuroimagens utilizadas.

\subsection{Modelo Computacional de apoio ao diagnóstico de demências}

Os modelos desenvolvidos neste trabalho foram criados com base em entrevistas com os especialistas do Projeto Terceira Idade - PROTER do Instituto de Psiquiatria (IPq) do Hospital das Clínicas da FMUSP onde procuramos sistematizar e formalizar o conhecimento tácito do processo de diagnóstico de demências em um modelo computacional que possa apoiar esse processo de diagnóstico. 
O modelo geral foi dividido em três sub modelos: um modelo de Comprometimento Cognitivo; um modelo de tipo de demência; e um modelo de tipo de demência. A figura 3.1 apresenta o macro fluxo da informação entre os modelos.

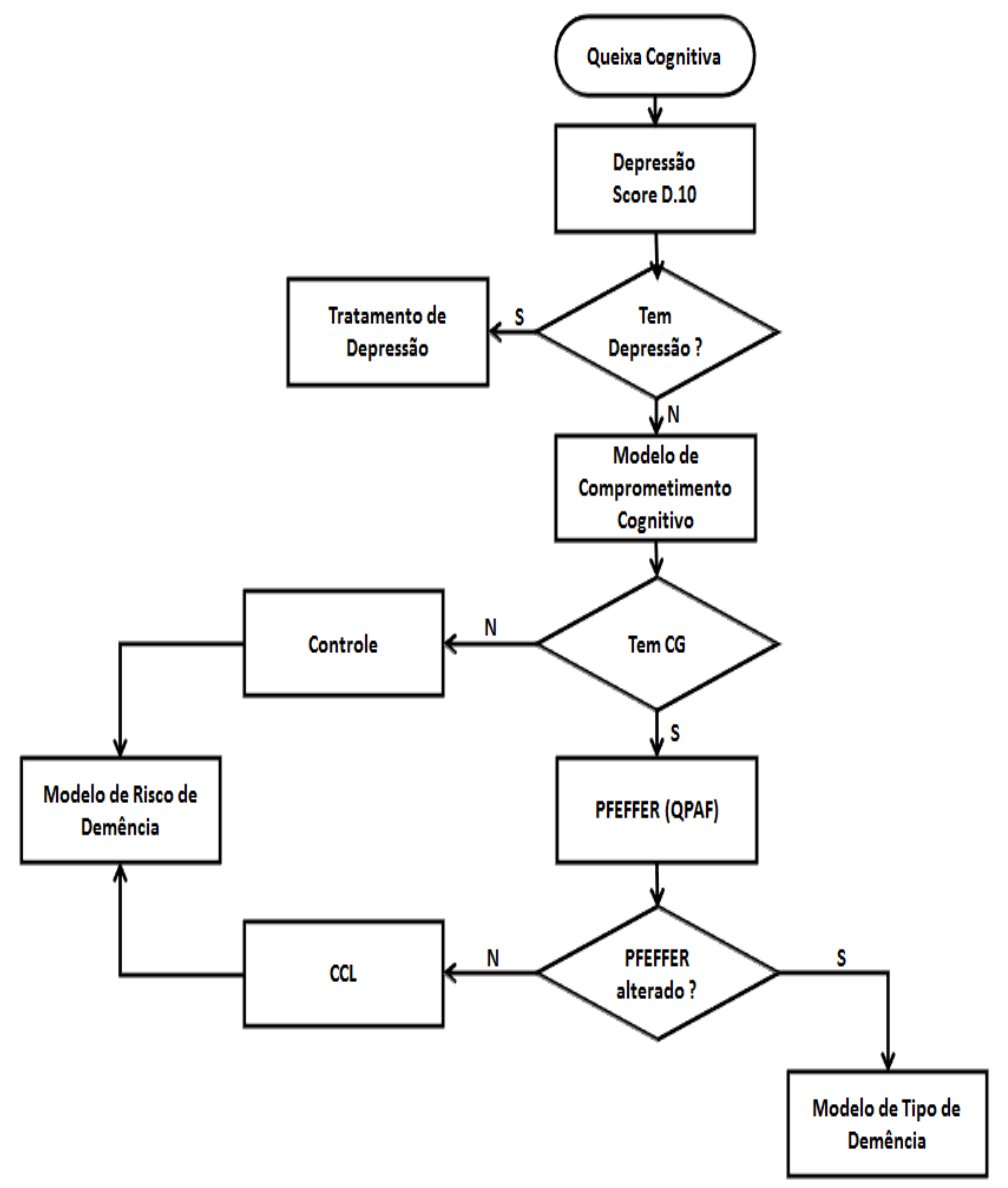

Figura 3.1: Diagrama do sistema de apoio a decisão para diagnóstico de demência.

O modelo é aplicado para indivíduos que apresentam queixa cognitiva. Neste caso a primeira decisão do sistema deverá ser se o indivíduo apresenta um quadro de depressão. A depressão é um fator de confusão para o diagnóstico de demência [54], sendo possível identificar correlações entre as duas patologias, seja presença de sintomas depressivos em pacientes com demências, deficiência cognitiva como sintoma da depressão ou a presença de síndrome demencial da depressão [55]. 
Sendo assim, é fundamental distinguir primeiramente entre depressão e síndromes demenciais [54]. O diagnóstico de depressão de acordo com o critério do DSM-IV se dá através dos seguintes fatores [18]:

- Sentir-se deprimido a maior parte do tempo (Humor deprimido);

- Perda de interesse e prazer para realizar atividades cotidianas (Anedonia) ;

- Sentir-se com culpa excessiva ou inútil (Autodepreciação) ;

- Dificuldade de concentração;

- Fadiga ou perda de energia;

- Distúrbios do sono (Hipersonia ou Hiposonia);

- Agitação ou retardo psicomotor;

- Perda ou ganho acentuado de peso; e

- Idéias recorrentes de morte ou suicídio.

A depressão em um primeiro atendimento ambulatorial pode ser verificada através de uma escala como a Geriatric Depression Screening width (GDS) [18, 56]. O ambulatório de demências do PROTER/IPq-USP considera a utilização da ecala D.10, criada e validada em trabalhos desenvolvidos no IPq.

Caso o indivíduo seja diagnosticado com depressão ele é inicialmente encaminhado para o tratamento da doença. Em contrapartida, se não houver quadro de depressão são realizados uma série de testes para mensurar se existe comprometimento cognitivo, e se existir, qual o grau de comprometimento presente. Esta avaliação é realizada a partir do modelo apresentado a seguir. 


\subsubsection{Modelo fuzzy de comprometimento cognitivo}

Para o modelo fuzzy de comprometimento cognitivo foi utilizado o Mini Exame do Estado Mental (MEEM), o teste do relógio e o teste de fluência verbal, que combinados fornecem um escore de comprometimento cognitivo. O objetivo é o desenvolvimento de um modelo que possa ser utilizado em um primeiro atendimento de forma rápida e eficaz. A figura 3.2 apresenta o fluxo do modelo criado. O MEEM [57] é um teste simples sendo provavelmente o mais utilizado mundialmente [18]. Esse teste é composto por 11 itens que avaliam a capacidade cognitiva do paciente, sendo a pontuação variando de zero (pior estado cognitivo) a 30 pontos (melhor capacidade cognitiva).

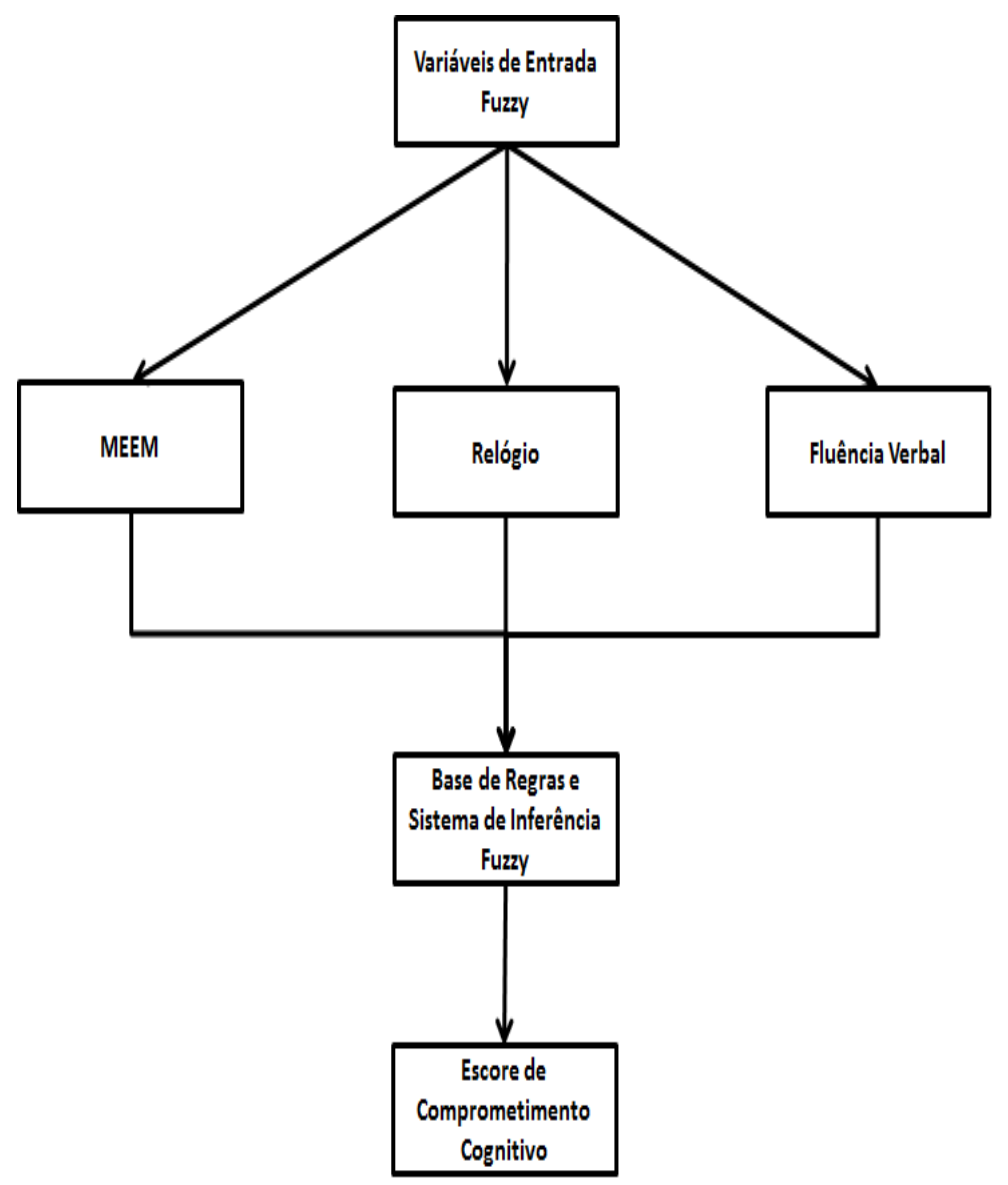

Figura 3.2: Diagrama do modelo fuzzy de comprometimento cognitivo. 
O MEEM tem por objetivo avaliar apenas as capacidades cognitivas do paciente analisando a orientação temporal e espacial; a memória de curto prazo (imediata ou atenção); a capacidade de cálculo; a praxia e habilidades de linguagem e viso-espaciais [58].

Apesar MEEM não ser um instrumento para diagnóstico de demências, ele é uma ferramenta efetiva para rastreio de perda cognitiva, sendo uma ferramenta simples e rápida já que o teste pode ser facilmente aplicado. Porém, mesmo com a versatilidade e praticidade de uso, o MEEM pode sofrer um viés causado pelo tempo de estudo do paciente, ou seja, os pontos de corte são influenciados pelos tempo de escolaridade e, consequentemente pela reserva cognitiva do indivíduo.

Em estudos realizados no Brasil são sugeridas diferentes pontuações de corte para definir a existência de dano cognitivo com base na idade e escolaridade dos indivíduos que compõem os grupos avaliados. Devido a variação dos resultados em consequência da população estudada é recomendado sempre considerar a escolaridade ao interpretar resultados do MEEM principalmente para populações com baixo nível educacional [58].

Com base nos pontos de corte estabelecidos durante as entrevistas com os especialistas, foi elaborada a variável que representa o MEEM em 4 conjuntos fuzzy representados pelos termos: grave, moderado, leve e normal. A representação gráfica das funções de pertinência pode ser vista na figura 3.3.

O teste do relógio pode fornecer um panorama do comprometimento funcional do paciente. O teste consiste em dar ao paciente um papel e um lápis para que ele desenhe um relógio analógico marcando um determinado horário solicitado pelo médico [59].

O teste do relógio é um importante instrumento de avaliação das praxias e capacidade de planejamento. È utilizado também para avaliar casos de pacientes com 


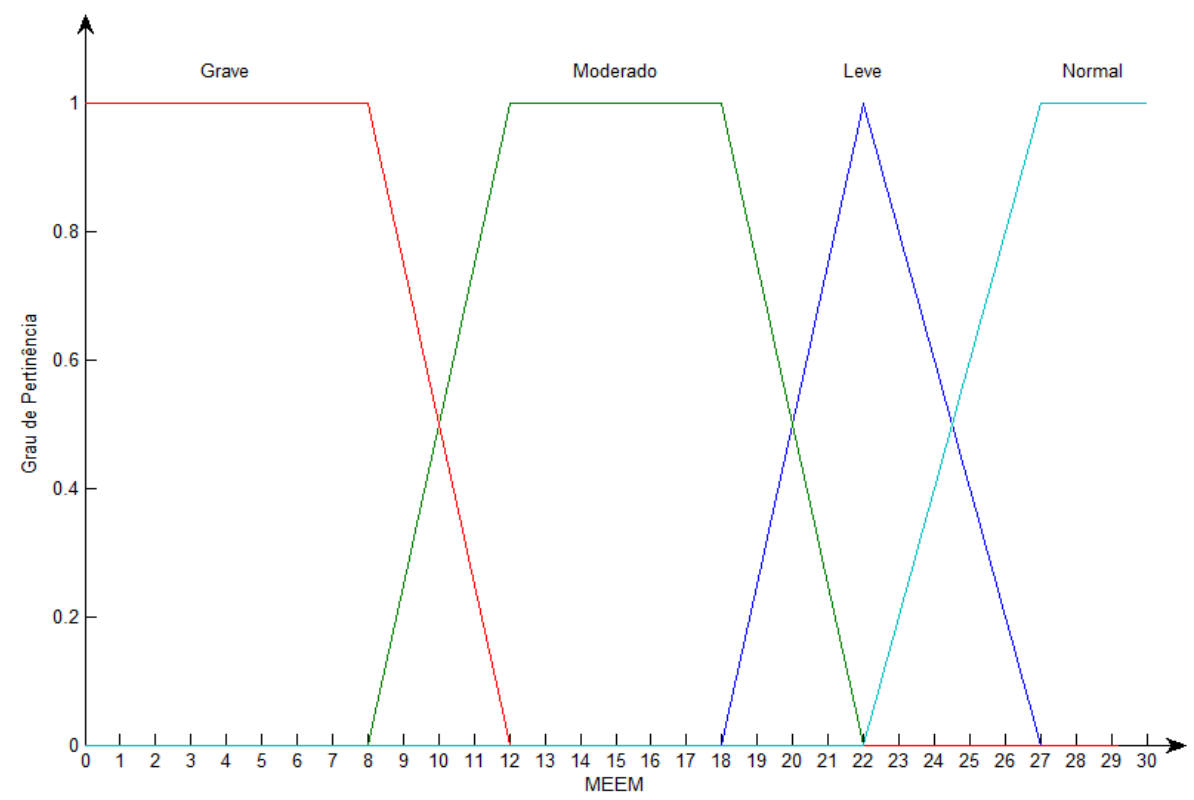

Figura 3.3: Funções de pertinência da variável linguística que representam os conjuntos fuzzy para o MEEM.

escore de MEEM considerado normal que podem apresentar comprometimento das funções executivas antes das funções de memória[60].

Existem diferentes formas de se quantificar o resultado para o teste do relógio [61]. Podemos citar o teste do relógio com escore de 5 pontos proposto por Shulmman [59] onde pontuações abaixo de três pontos devem ser investigadas. O teste do relógio de Sunderland [62] é pontuado até 10 pontos, onde pontuações abaixo de 6 devem ser investigadas. Ainda temos o relógio de quatro pontos proposto por Borson et al.[63], onde qualquer alteração deve ser considerada como uma anormalidade.

A fuzificação da variável do teste do relógio foi feita com duas funções de pertinência considerando o teste do relógio de quatro pontos, como pode ser observado na figura 3.4: ausente e presente.

O teste de fluência verbal é utilizado para verificar a existência de declínio cognitivo através de comprometimentos lexicais que possam ocorrer no início da patologia[64, 65], sendo considerado um teste com alta acurácia [60]. 


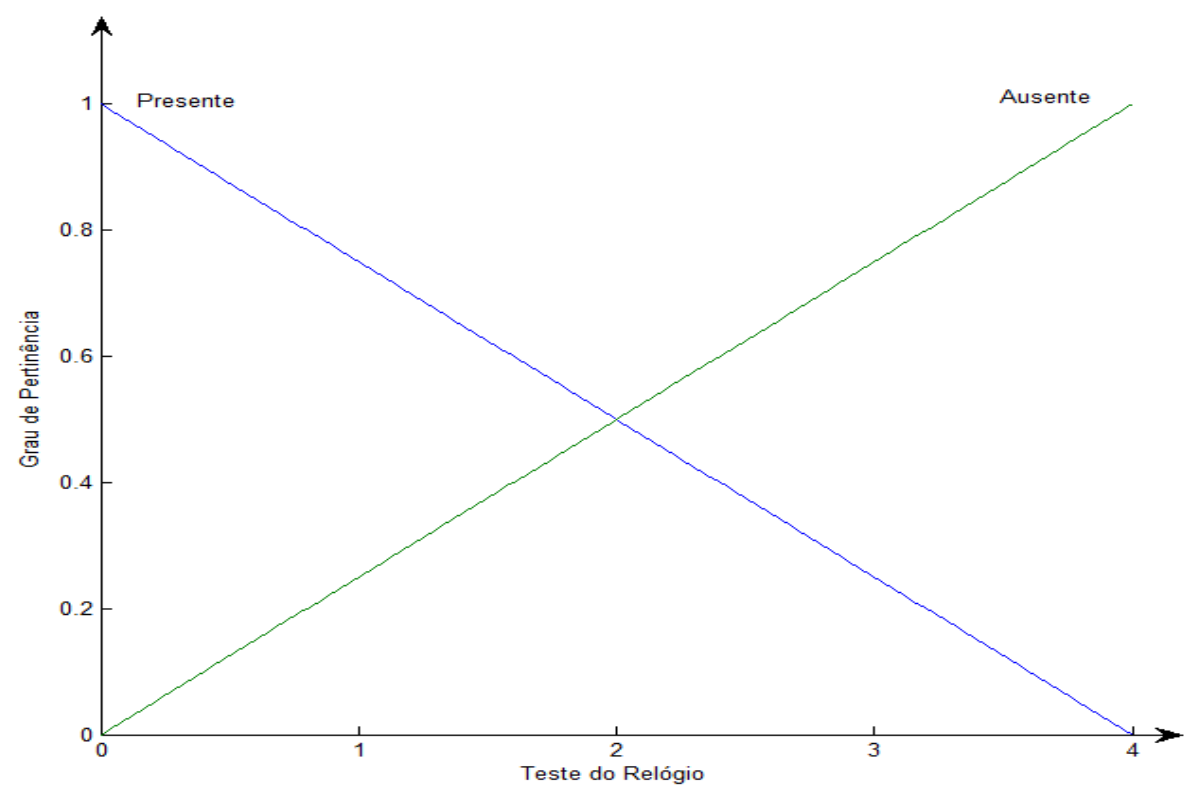

Figura 3.4: Funções de pertinência da variável linguistica fuzzy para o teste do relógio.

Neste teste o médico solicita ao indivíduo que evoque o maior número possível de palavras no período de um minuto de uma categoria pré-definida, como nome de animais, por exemplo [66]. A pontuação esperada para individuos sem compromentimento cognitivo neste teste esta na faixa de 13 a 15 pontos $[29,67,68]$.

A fuzificação da variável do teste de fluência verbal foi feita com três funções de pertinência: ausente, moderado e grave, como pode ser observado na figura 3.5

A saída do modelo é um conjunto fuzzy de possibilidade de comprometimento cognitivo pontuado no intervalo de [0-10], apresentado na figura 3.6. Essa variável possui cinco conjuntos fuzzy que classificam o paciente em normal (sem comprometimento), leve, moderado, grave e muito grave.

A base de regras é composta a partir da combinação das variáveis de entrada do sistema. Para o modelo de Comprometimento Cognitivo temos um total de 24 regras, cada qual na forma: 


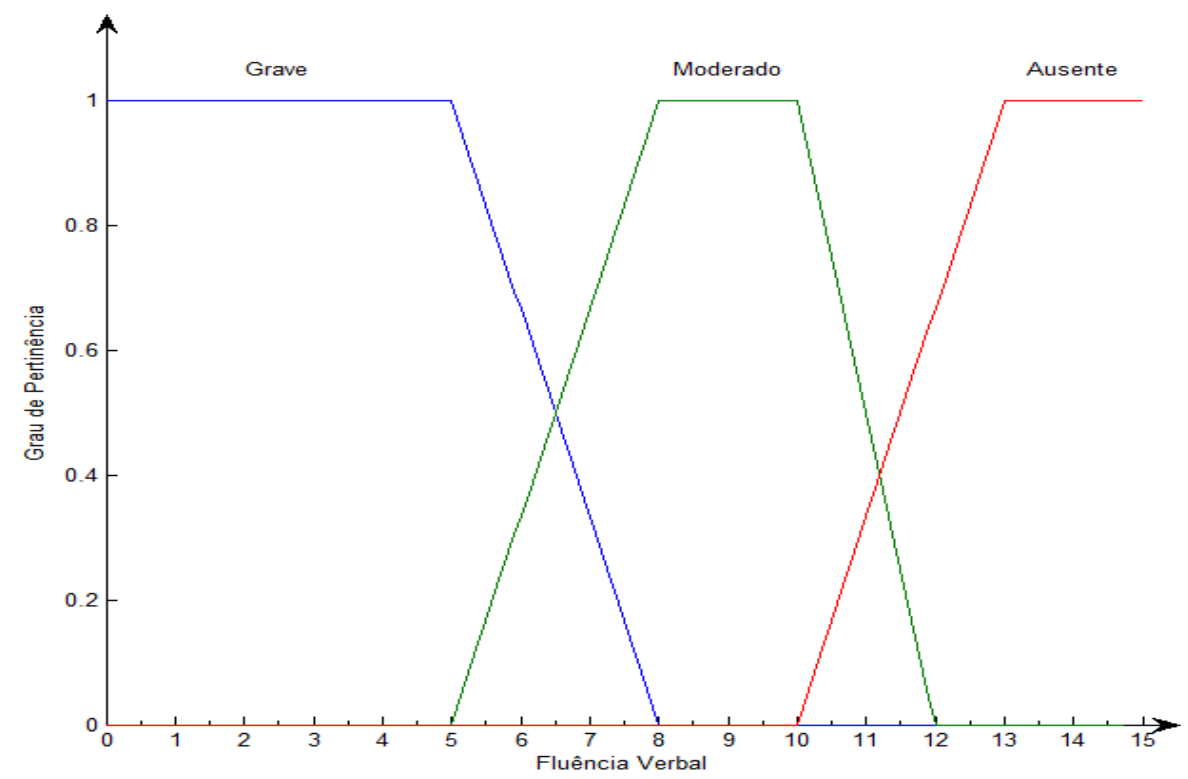

Figura 3.5: Funções de pertinência da variável linguistica fuzzy para o teste de fluência verbal.

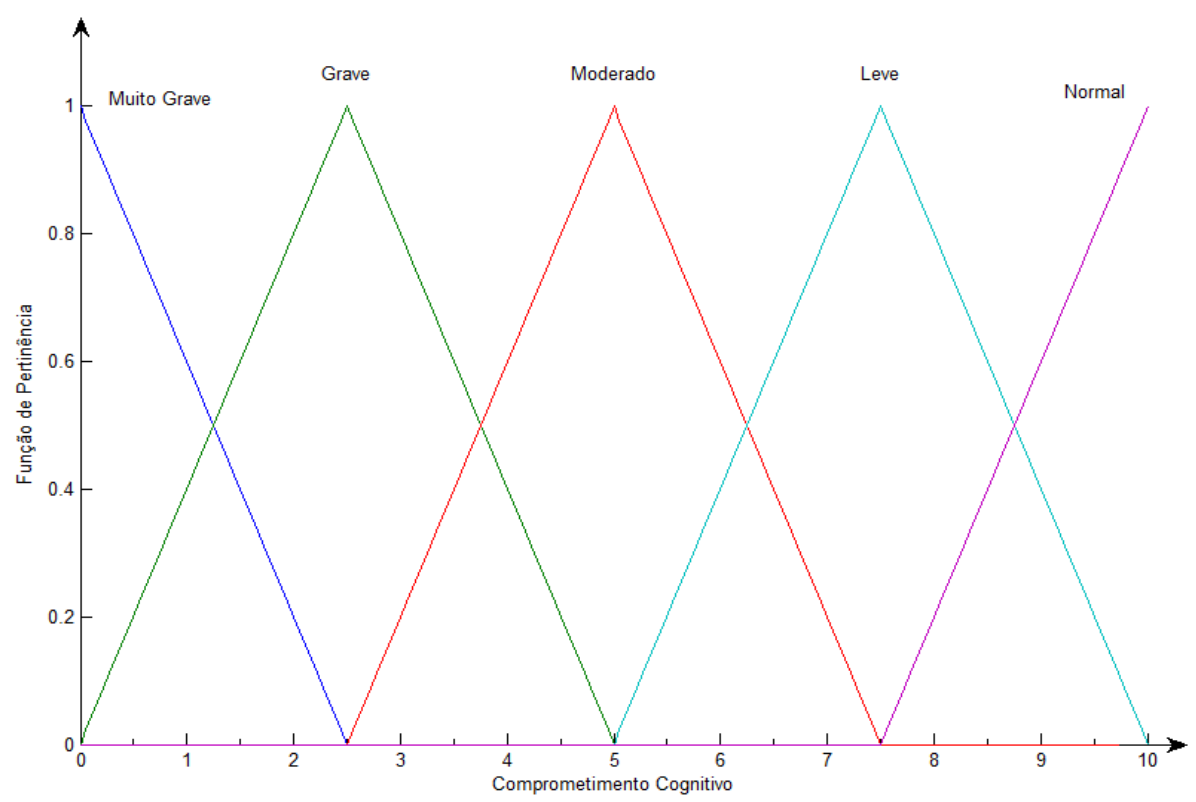

Figura 3.6: Funções de pertinência da variável de saida do modelo de comprometimento cognitivo.

SE MEMM é moderado $\mathbf{E}$ teste do relógio é presente $\mathbf{E}$ teste de fluência verbal é moderado, ENTÃO comprometimento cognitivo é grave 
Os consequentes de cada regra fuzzy foi elaborado pelos especialistas. A tabela 3.1 mostra todas as regras que compõe base de conhecimento do sistema.

Tabela 3.1: Base de regras para o modelo de compromentimento cognitivo.

\begin{tabular}{|c|c|c|c|c|}
\hline Regra & SE MEEM é & E Teste do Relógio É & E Fluência Verbal é & ENTÃO Compr.Cognitivo é \\
\hline 1 & Normal & Ausente & Ausente & Normal \\
\hline 2 & Normal & Ausente & Moderado & Normal \\
\hline 3 & Normal & Ausente & Grave & Leve \\
\hline 4 & Normal & Presente & Ausente & Leve \\
\hline 5 & Normal & Presente & Moderado & Leve \\
\hline 6 & Normal & Presente & Grave & Moderado \\
\hline 7 & Leve & Ausente & Ausente & Leve \\
\hline 8 & Leve & Ausente & Moderado & Leve \\
\hline 9 & Leve & Ausente & Grave & Leve \\
\hline 10 & Leve & Presente & Ausente & Moderado \\
\hline 11 & Leve & Presente & Moderado & Moderado \\
\hline 12 & Leve & Presente & Grave & Moderado \\
\hline 13 & Moderado & Ausente & Ausente & Moderado \\
\hline 14 & Moderado & Ausente & Moderado & Moderado \\
\hline 15 & Moderado & Ausente & Grave & Moderado \\
\hline 16 & Moderado & Presente & Ausente & Grave \\
\hline 17 & Moderado & Presente & Moderado & Grave \\
\hline 18 & Moderado & Presente & Grave & Grave \\
\hline 19 & Grave & Ausente & Ausente & Grave \\
\hline 20 & Grave & Ausente & Moderado & Grave \\
\hline 21 & Grave & Ausente & Grave & Grave \\
\hline 22 & Grave & Presente & Ausente & Muito Grave \\
\hline 23 & Grave & Presente & Moderado & Muito Grave \\
\hline 24 & Grave & Presente & Grave & Muito Grave \\
\hline
\end{tabular}

A saída do modelo de compromentimento cognitivo produz um número a partir do qual, a depender do valor o paciente é encaminhado para grupo de controle (se o valor for menor que 7,5 ) ou para a avaliação de um quadro de demência (se o valor for maior que 7,5$)$. Vide figura 3.1.

A nota de corte de 7,5 pontos foi definida em conjunto com os especialistas que participaram da criação do modelo e baseado nos valores do conjunto fuzzy de saída do modelo de comprometimento cognitivo (vide figura 3.6). Assim, abaixo de 7,5 considerase que o indivíduo tenha algum grau de comprometimento cognitivo e acima de 7,5 considera-se o indivíduo como tendo uma capacidade cognitiva normal. 
A decisão do diagnóstico do tipo de demência é dado por um quadro de comprometimento cognitivo e funcional. Para avaliar o comprometimento funcional alguns testes podem ser aplicados como o índice de Katz de Atividades Básicas da Vida Diária (ABVD) e o Questionário PFEFFER de Avaliação Funcional (QPAF) [69], que cobre a dimensão das atividades instrumentais da vida diária. Neste modelo optamos por adotar como teste de comprometimento funcional o QPAF, por ser o mais utilizado pelo grupo do PROTER/IPq-USP com o qual desenvolvemos este modelo.

A decisão acerca da presença de demência é booleana, ou seja, caso o indivíduo apresente qualquer grau de comprometimento funcional no PFEFFER, em conjunto com algum grau de comprometimento cognitivo é considerado um quadro demencial.

\subsubsection{Modelo de decisão para o tipo de demência}

A decisão do tipo de demência é feita através da análise de sintomas, sinais, histórico do paciente e o tempo de evolução da patologia $[1,18]$. O histórico indica principalmente como começou a percepção de alterações cognitivas, funcionais ou comportamentais [18].

O diagnóstico de demências é bem documentado por protocolos que listam fatores que devem ser avaliados para decisão do tipo de demência [18], sendo assim, entendemos que a melhor forma de apoiar o especialista pelo processo diagnóstico é através de uma diagrama de decisão.

O diagrama de decisão para o diagnóstico de tipo de demência foi modelado a partir de entrevistas com especialistas do PROTER/IPq-USP e com base nos protocolos de diagnóstico listados no capítulo 2. A árvore permite que o especialista, a partir das 
características comumente avaliadas nas consultas ambulatoriais, obtenha uma hipótese diagnóstica do tipo de demência.

O primeiro nó de decisão do diagrama é voltado a investigação do histórico de início da hipótese de demência. Um início com episódios de memória indica possivelmente DA ou DV, e o fluxograma de decisão deriva a partir desse nó, ramos que investigam a velocidade de evolução e a avaliação de um exame de neuroimagem.

Um início com anormalidades comportamentais pode indicar a ocorrência de DFT, DCL ou DV. A decisão é dada pela ocorrência dos sintomas e sinais dessas demências separadamente e pela avaliação de um exame de neuroimagem para identificar sinais específicos de DV ou do lobo frontal, por exemplo.

Devido a extensão do diagrama apresentaremos a representaração gráfica do modelo em três diferentes figuras. A figura 3.7 que apresenta o diagrama de decisão para sintomas iniciais identificados como relacionados a memória, que deriva fluxos decisórios para encontrar como possíveis diagnósticos DV, DA, Demência Mista (DA+DV) e DA de início precoce.

A figura 3.8 que apresenta o diagrama de decisão para sintomas iniciais identificados como relacionados a alterações comportamentais. Desse nó deriva fluxos decisórios para encontrar como possíveis diagnósticos DFT, DV, DCL e Demência Mista $(\mathrm{DFT}+\mathrm{DV})$. Caso os sintomas nao estejam relacionados a memória ou alterações de comportamento solicita-se um exame neuropsicológico ou a investigação de outras causas de demência. 


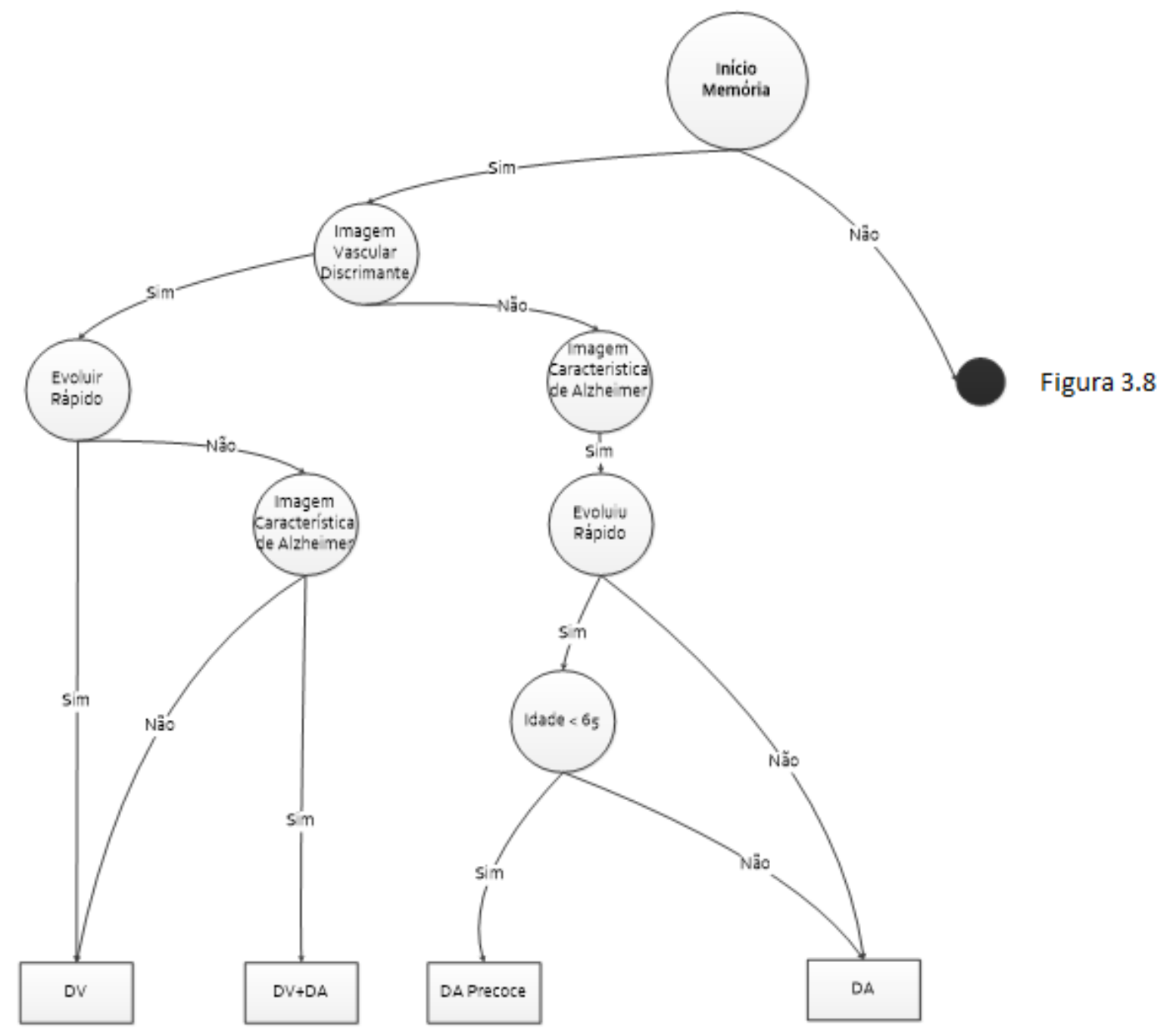

Figura 3.7: Diagrama de Decisão para o tipo de demência: A imagem apresenta o nó para sintomas iniciais relacionados a memória. 


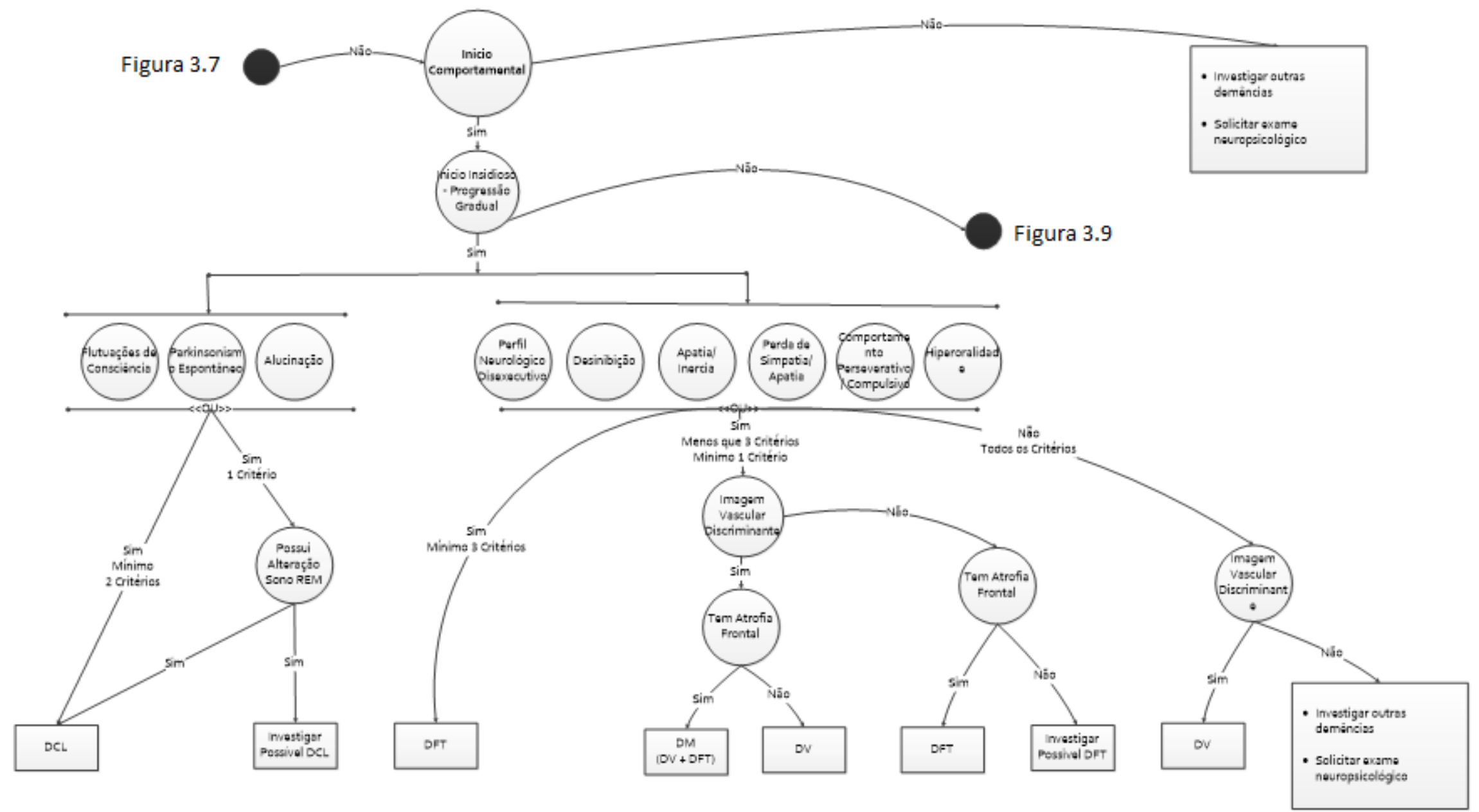

Figura 3.8: Diagrama de Decisão para o tipo de demência: A imagem apresenta o nó para sintomas iniciais relacionados a alterações comportamentais. 
A figura 3.9 apresenta o fluxo de decisão caso o início não seja insidioso e a velocidade de evolução nao seja percebida como gradual. O diagrama deriva um fluxo decisório para investigação de alterações súbitas. Desse nó deriva um diagnóstico de DV ou leva o especialista a solicitar um exame neuropsicológico ou considerar outras causas de demência.

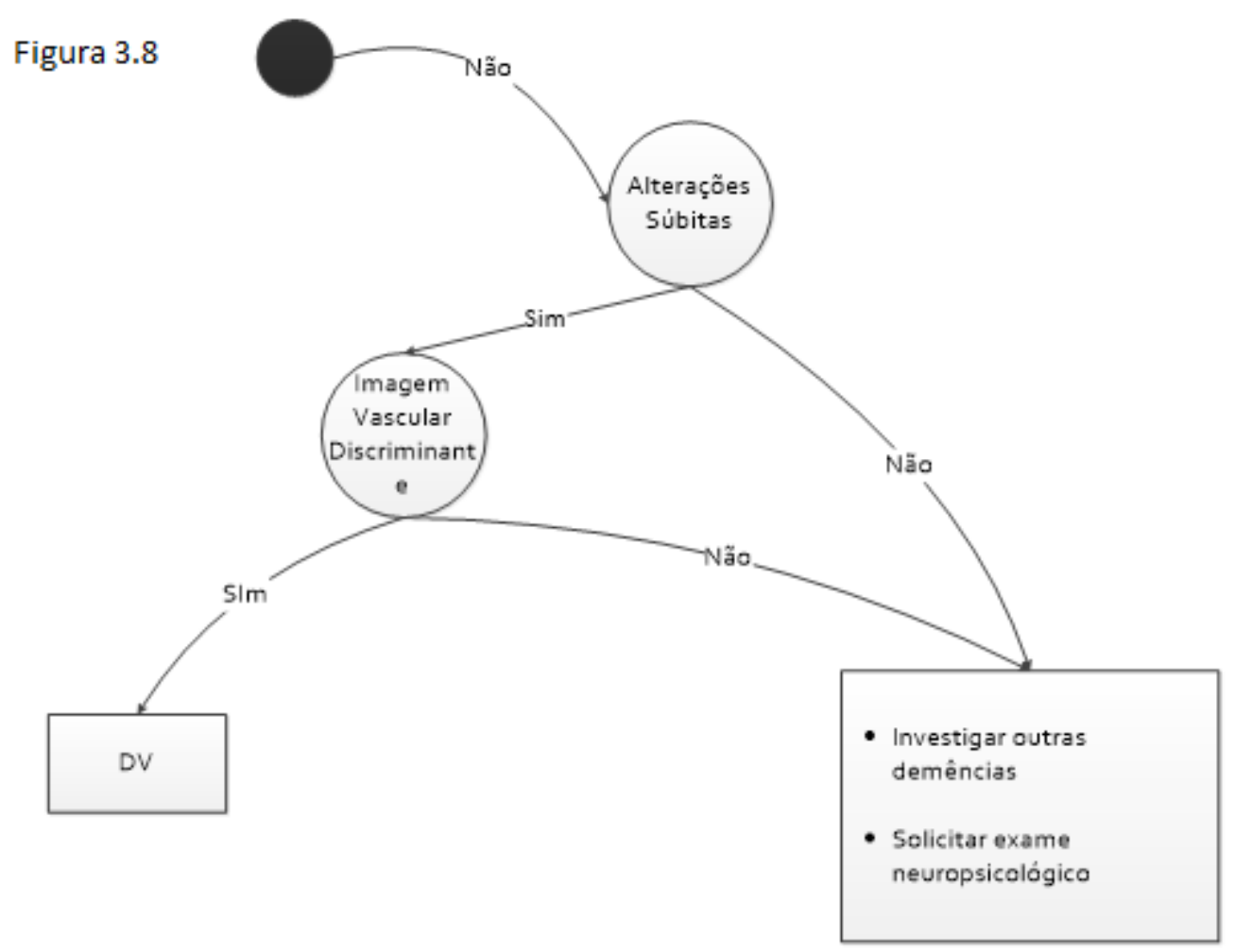

Figura 3.9: Diagrama de Decisão para o tipo de demência: A imagem apresenta o nó para alterações súbitas de comportamento.

Percebemos durante a modelagem da árvore de decisão do tipo de demência que o exame de neuroimagem é por várias vezes consultado, seja para tomada de decisão, para corroborar um diagnóstico clínico ou fornecer mais informações para o especialista sobre a evolução da patologia. Sendo assim a análise de neuroimagens através de técnicas estatísticas pode ser utilizada para avaliação de regiões discriminantes e classificação dos indivíduos em grupos de controle e pacientes. Devido a importância que a neuroimagem tem adquirido nos processos de decisão, dedicamos parte da tese ao estudo de técnicas, 
focadas na discriminação de DA. Na sessão seguinte apresentaremos brevemente as ferramentas utilizadas neste trabalho para execução das análises baseadas nas técnicas massivamente univariada, SDM e SVM, abordadas anteriormente no capítulo 2.

\subsubsection{Análise de Neuroimagens}

Foram realizadas avaliações de três diferentes técnicas abordadas no capítulo 2: 1) Análises massivamente univariadas por meio de testes de significância voxel a voxel; 2) Análise multivariada com o modelo estatístico discriminante (SDM); 3) Análise multivariada por meio da técnica de máquina de suporte vetorial (SVM).

Para realização das análises estatisticas massivamente univariadas foi utilizado o software Statistical Statistical Parametric Mapping (SPM), que além das funções de normalização e segmentação também possui testes de significância para avaliação de grupos e identificação de regiões discriminantes. Diversos trabalhos tem sido publicados utilizando o SPM [70-74], neste trabalho utilizamos o SPM $5^{1}$ para realização das etapas de pré-processamento e análise estatística.

Para realização das avaliações com o SDM utilizamos a implementação proposta no trabalho de Santos et al. [6].Para execução da classificação e análise com base no SDM é necessário submeter as imagens à normalização espacial e retirada de artefatos cranianos, sendo dispensado a segmentação por substância.

Para execução das análises com base no SVM, utilizamos o software PROBID ${ }^{2}$. O PROBID é uma implementação do SVM utilizada em estudos de neuroimagem que

\footnotetext{
${ }^{1}$ Disponível em http://www.fil.ion.ucl.ac.uk/spm/software/spm5/

${ }^{2}$ Disponível em: http://www.kcl.ac.uk/iop/depts/neuroimaging/research/ imaginganalysis/Software/PROBID . aspx
} 
traz várias funções nativas para tratamento de imagens, classificação e identificação das diferenças discrimimantes [52].

Os modelos linguísticos fuzzy tipo Mamdani foram criados utilizando o Fuzzy Tollbox disponível para Matlab ${ }^{3}$

Os softwares SPM, PROBID, a implementação do SDM e o Fuzzy Tollbox são disponiveis para Matlab. Neste trabalho foi utilizada a versão Matlab R2009b.

\subsubsection{Modelo fuzzy de risco de demência}

O modelo de Risco de desenvolver demência combina o a possibilidade de comprometimento cognitivo com fatores de risco e de proteção. A saída é uma medida de risco de desenvolvimento de demências. O diagrama do modelo é apresentado na figura 3.10

O escore de fatores de risco pode variar de 0 à 35 pontos e leva em consideração fatores de risco comumente investigado pelos médicos durante a anamnese.

Os fatores de risco foram agrupados de forma criar um questionário que possa quantificar o risco de um indivíduo vir a desenvolver uma demência. Este questionário produz uma nota e foi criado por meio de entrevistas com especialistas do PROTER/IpqUSP.

As demências no geral compartilham fatores de risco. É sabido que a idade tem um peso significativo no desenvolvimento das demências, bem como a presença de fatores como a obesidade, diabetes, tabagismo ou alcoolismo [75].

O escore de fatores de risco foi obtido através da soma simples dos valores pontuados nesse questionário, com o valor zero, indicando ausência de risco e o valor 35 indicando um máximo para presença dos fatores de risco pra demência.O questionário,

\footnotetext{
${ }^{3}$ Disponível em http://www.mathworks . com/help/fuzzy/index.html
} 


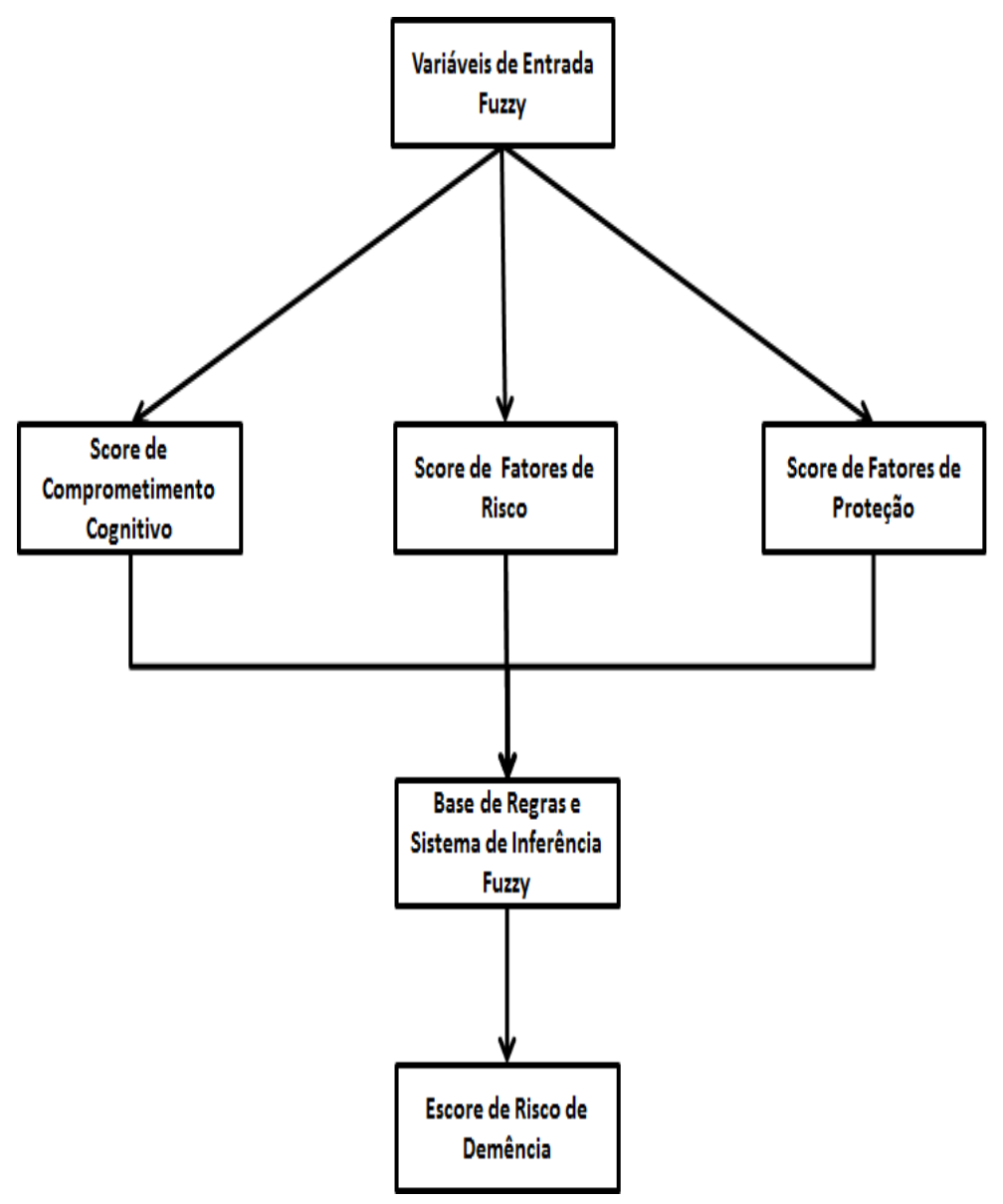

Figura 3.10: Diagrama do modelo fuzzy de risco de desenvolvimento de demência.

apresentado na tabela 3.2, leva em consideração 19 questões, com diferentes pesos atribuídos durante a modelagem com base na relevância dos fatores do ponto de vista do médico. A observação para a questão 1 indica a variação do peso em relação a idade; e para as questões 6 à 10 a observação se refere ao peso para o conjunto de questões relativas ao acompanhamento regular com o clínico.

Com base no questionário de fatores de risco foi elaborada a fuzificação dessa variável em 5 funções de pertinência: Muito Baixo, Baixo, Média, Alta e Muito Alta. A representação gráfica dessas funções de pertinência pode ser vista na figura 3.11 
Tabela 3.2: Perguntas do questionário de Fatores de Risco com peso atribuído a cada questão. $(*) O$ peso altera conforme a faixa etária: $<60$ anos - peso 0; de 60 a 70 anos peso 1 ; de 71 a 80 anos - peso 2 ; >80 anos - peso 4; $\left(^{* *}\right)$ Se marcados todos os itens o resultado do somatório das questões de 6 a 10 deve ser multiplicado por 2

\begin{tabular}{|c|c|c|}
\hline Questão & Fator & Peso \\
\hline 1 & Idade* & {$[0-4]$} \\
\hline 2 & História familiar de demência em primeiro grau & 2 \\
\hline 3 & AVC prévio ou recorrente & 3 \\
\hline 4 & Diabetes melitus tipo 2** & 2 \\
\hline 5 & Depressão Tardia & 3 \\
\hline 6 & Hipertensão arterial sistêmica** & 1 \\
\hline 7 & Hiperlipidemia** & 1 \\
\hline 8 & Obesidade** & 1 \\
\hline 9 & Tabagismo** & 1 \\
\hline 10 & Etilismo pesado** & 1 \\
\hline 11 & Síndrome de Down & 2 \\
\hline 12 & Doença de Parkinson & 2 \\
\hline 13 & Uso de medicações que podem mimetizar ou agravar quadro cognitivo & 1 \\
\hline 14 & Baixa escolaridade (<8 anos) & 1 \\
\hline 15 & Exposição a pesticidas & 1 \\
\hline 16 & Trauma crânio encefálico & 1 \\
\hline 17 & Hipotireoidismo & 1 \\
\hline 18 & Hiperhomocisteinemia & 1 \\
\hline 19 & Antecedentes psiquiátricos (transtorno afetivo bipolar principalmente) & 1 \\
\hline
\end{tabular}

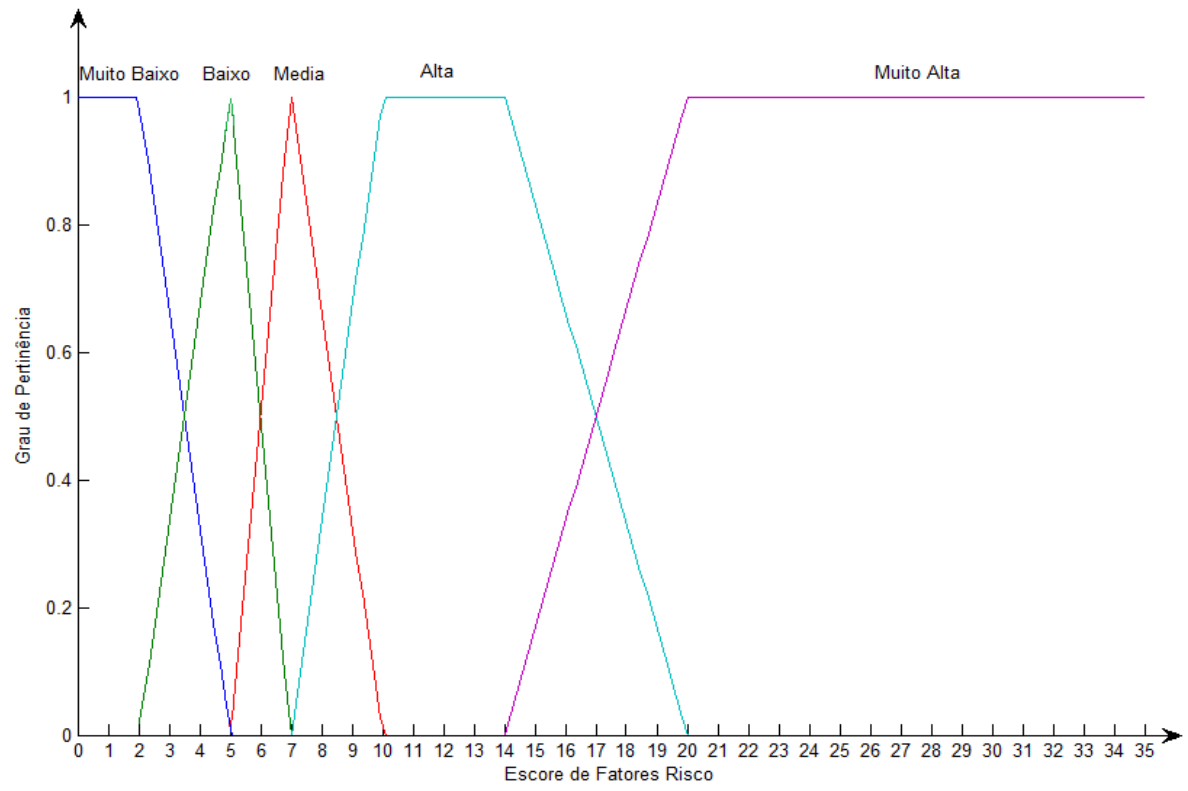

Figura 3.11: Funções de pertinência da variável linguística que representa o questionário de fatores de risco para demência.

Tão importante quando avaliar os fatores de risco para o desenvolvimento de demência, é avaliar os fatores de proteção. Assim, o escore de proteção é composto por seis questões que somam até 10 pontos. De forma análoga aos fatores de risco, os 
pesos foram atribuídos pelos médicos durante o processo de modelagem com base na relevância de cada fator.

Os fatores de proteção como esforço mental em ocupações anteriores dizem respeito a reserva cognitiva, considerada como um fator de proteção contra demências; o acompanhamento clínico regular refere-se ao controle de fatores de risco como diabetes, colesterol e AVC; e fatores como atividade física, contato social regular e atividades de lazer são considerados como fatores de proteção para demências [18, 75].A tabela 3.3 apresenta as questões relacionadas aos fatores de proteção e os pesos atribuídos a eles.

Tabela 3.3: Perguntas do questionário de Fatores de Proteção com peso atribuído a cada questão.

\begin{tabular}{|c|l|c|}
\hline Questão & Fator de proteção & Peso \\
\hline 1 & Ocupação anterior exigia certo grau de esforço mental ? & 1 \\
\hline 2 & Acompanhamento clínico regular & 2 \\
\hline 3 & Alta escolaridade & 2 \\
\hline 4 & Atividade física moderada regular & 2 \\
\hline 5 & Atividades de estímulo cognitivo regularmente & 2 \\
\hline 6 & Atividades de lazer / contato social & 1 \\
\hline
\end{tabular}

A variável fuzzy para os fatores de proteção foi modelada contendo três funções de pertinência: Proteção Baixa, Proteção Média e Proteção alta, apresentadas na figura 3.12.

A terceira variável do modelo é o comprometimento cognitivo, dado pela saída do primeiro modelo inclusive com os mesmos grupos (Muito Grave, Grave, Moderado, Leve e Normal) apresentados na figura 3.13

A saída do modelo é uma medida de possibilidade de risco de demência que varia de 0 a 10. Esta variável tem cinco funções de pertinência apresentadas na figura 3.14 de risco de desenvolver demência: Muito Baixo, Baixo, Moderado, Alto e Muito Alto. 


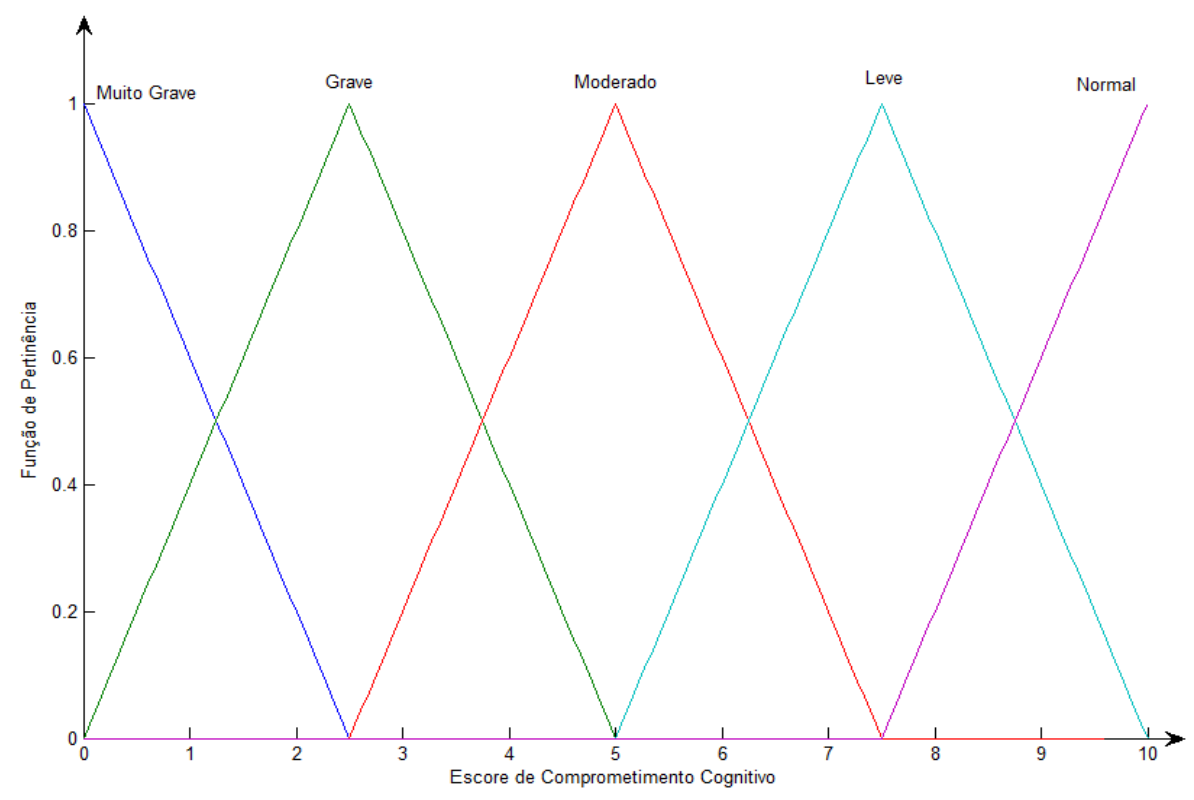

Figura 3.12: Funções de pertinência da variável linguística que representa o questionário de fatores de proteção para demência.

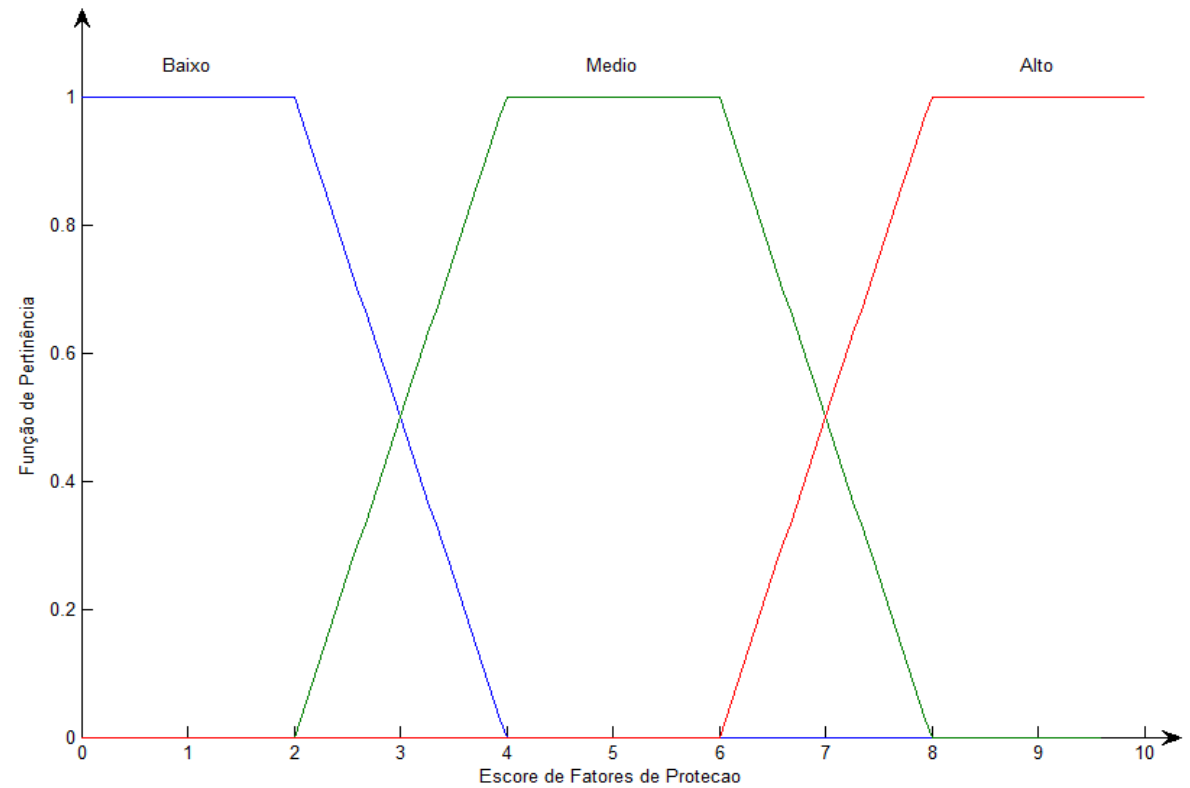

Figura 3.13: Funções de pertinência da variável que representa a variável de comprometimento cognitivo.

A base de regras do modelo linguístico é composta a partir da combinação das funções de pertinência das variáveis de entrada do modelo. Para o modelo de Risco de Demência elas tem o formato: 


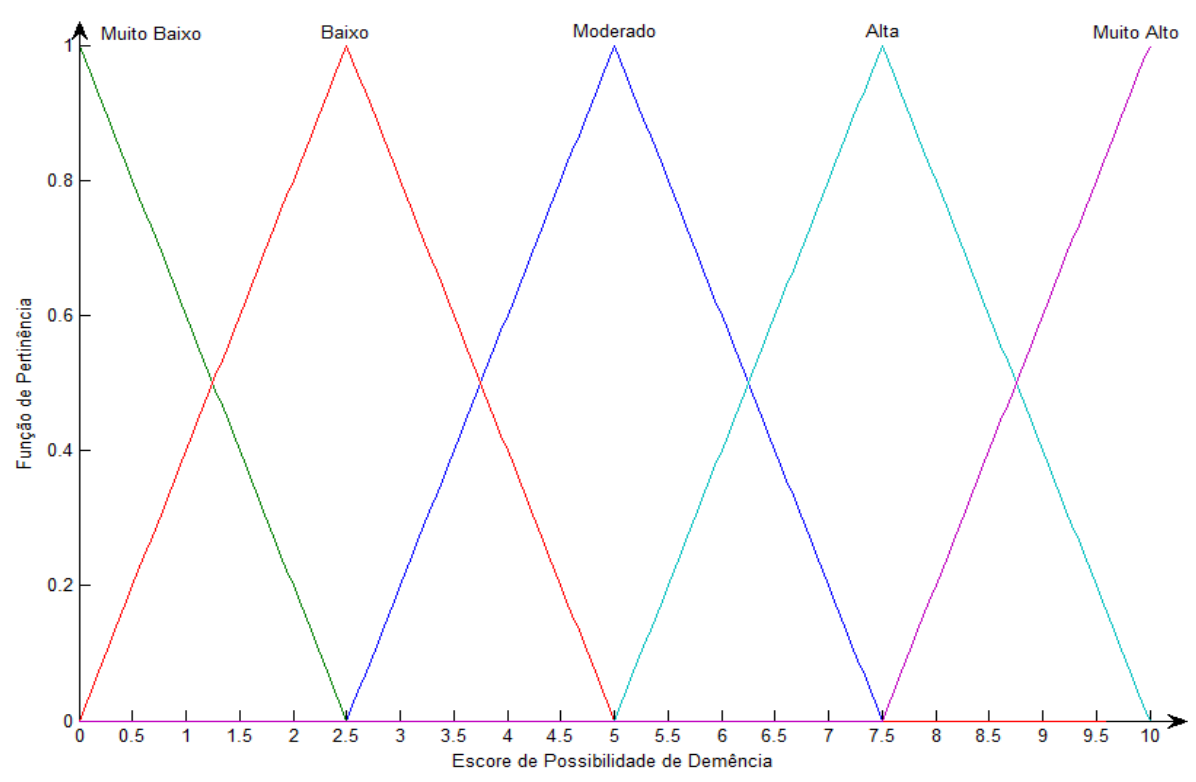

Figura 3.14: Funções de pertinência da variável de saida do modelo de risco de demência

$\mathbf{S E}$ fatores de risco é muito baixo $\mathbf{E}$ compromentimento cognitivo é muito grave $\mathbf{E}$ fatores de proteção é baixo ENTÃO risco de desenvolvimento de demência é alto.

Para o modelo de Risco de Demência temos 75 regras, que foram elaboradas com os especialistas do PROTER/IPq-USP. A tabela 3.4 mostra todas as regras que compõem a base de conhecimento do sistema.

Tabela 3.4: Regras para o modelo de Risco de Demência

\begin{tabular}{|c|c|c|c|c|}
\hline Regra & SE Risco é & E Comp.Cog. é & E Fat. Prot. é & ENTÃo Risco Dem. é \\
\hline 1 & Muito Baixo & Normal & Baixo & muito baixo \\
\hline 2 & Muito Baixo & Normal & Media & muto baixo \\
\hline 3 & Muito Baixo & Normal & Alta & muito baixo \\
\hline 4 & Muito Baixo & Leve & Baixo & baixo \\
\hline 5 & Muito Baixo & Leve & Media & baixo \\
\hline 6 & Muito Baixo & Leve & Alta & muito baixo \\
\hline
\end{tabular}




\begin{tabular}{|c|c|c|c|c|}
\hline 7 & Muito Baixo & Moderado & Baixo & moderado \\
\hline 8 & Muito Baixo & Moderado & Media & moderado \\
\hline 9 & Muito Baixo & Moderado & Alta & moderado \\
\hline 10 & Muito Baixo & Grave & Baixo & alto \\
\hline 11 & Muito Baixo & Grave & Media & alto \\
\hline 12 & Muito Baixo & Grave & Alta & alto \\
\hline 13 & Muito Baixo & Muito Grave & Baixo & alto \\
\hline 14 & Muito Baixo & Muito Grave & Media & alto \\
\hline 15 & Muito Baixo & Muito Grave & Alta & alto \\
\hline 16 & Baixa & Leve & Baixo & baixo \\
\hline 17 & Baixa & Leve & Media & baixo \\
\hline 18 & Baixa & Leve & Alta & baixo \\
\hline 19 & Baixa & Normal & Baixo & baixo \\
\hline 20 & Baixa & Normal & Media & baixo \\
\hline 21 & Baixa & Normal & Alta & muito baixo \\
\hline 22 & Baixa & Moderado & Baixo & moderado \\
\hline 23 & Baixa & Moderado & Media & moderado \\
\hline 24 & Baixa & Moderado & Alta & moderado \\
\hline 25 & Baixa & Grave & Alta & alto \\
\hline 26 & Baixa & Grave & Media & alto \\
\hline 27 & Baixa & Grave & Baixo & alto \\
\hline 28 & Baixa & Muito Grave & Baixo & alto \\
\hline 29 & Baixa & Muito Grave & Media & alto \\
\hline
\end{tabular}




\begin{tabular}{|c|c|c|c|c|}
\hline 30 & Baixa & Muito Grave & Alta & alto \\
\hline 31 & Medio & Normal & Baixo & baixo \\
\hline 32 & Medio & Normal & Media & baixo \\
\hline 33 & Medio & Normal & Alta & baixo \\
\hline 34 & Medio & Leve & Baixo & moderado \\
\hline 35 & Medio & Leve & Media & moderado \\
\hline 36 & Medio & Leve & Alta & baixo \\
\hline 37 & Medio & Moderado & Baixo & alto \\
\hline 38 & Medio & Moderado & Media & alto \\
\hline 39 & Medio & Moderado & Alta & moderado \\
\hline 40 & Medio & Grave & Baixo & alto \\
\hline 41 & Medio & Grave & Media & alto \\
\hline 42 & Medio & Grave & Alta & alto \\
\hline 43 & Medio & Muito Grave & Baixo & alto \\
\hline 44 & Medio & Muito Grave & Media & alto \\
\hline 45 & Medio & Muito Grave & Alta & alto \\
\hline 46 & Alta & Normal & Baixo & moderado \\
\hline 47 & Alta & Normal & Media & moderado \\
\hline 48 & Alta & Normal & Alta & baixo \\
\hline 49 & Alta & Leve & Baixo & alto \\
\hline 50 & Alta & Leve & Media & alto \\
\hline 51 & Alta & Leve & Alta & moderado \\
\hline 52 & Alta & Moderado & Baixo & alto \\
\hline
\end{tabular}




\begin{tabular}{|c|c|c|c|c|}
\hline 53 & Alta & Moderado & Media & alto \\
\hline 54 & Alta & Moderado & Alta & moderado \\
\hline 55 & Alta & Grave & Baixo & muito alto \\
\hline 56 & Alta & Grave & Media & muito alto \\
\hline 57 & Alta & Grave & Alta & alto \\
\hline 58 & Alta & Muito Grave & Baixo & muito alto \\
\hline 59 & Alta & Muito Grave & Media & muito alto \\
\hline 60 & Alta & Muito Grave & Alta & muito alto \\
\hline 61 & Muito Alta & Normal & Baixo & alto \\
\hline 62 & Muito Alta & Normal & Media & alto \\
\hline 63 & Muito Alta & Normal & Alta & moderado \\
\hline 64 & Muito Alta & Leve & Baixo & alto \\
\hline 65 & Muito Alta & Leve & Media & alto \\
\hline 66 & Muito Alta & Leve & Alta & moderado \\
\hline 67 & Muito Alta & Moderado & Baixo & muito alto \\
\hline 68 & Muito Alta & Moderado & Media & muito alto \\
\hline 69 & Muito Alta & Moderado & Alta & alto \\
\hline 70 & Muito Alta & Grave & Baixo & muito alto \\
\hline 71 & Muito Alta & Grave & Media & muito alto \\
\hline 72 & Muito Alta & Grave & Alta & muito alto \\
\hline 73 & Muito Alta & Muito Grave & Baixo & muito alto \\
\hline 74 & Muito Alta & Muito Grave & Media & muito alto \\
\hline 75 & Muito Alta & Muito Grave & Alta & muito alto \\
\hline
\end{tabular}




\subsection{Bancos de dados para testes e análise dos mode-}

\section{los}

Esta seção descreve os bancos de dados hipotéticos, reais e de neuroimagens utilizados para realização de testes e análises dos modelos propostos neste trabalho

\subsubsection{Banco de dados hipotético para avaliação do modelo de Comprometimento Cognitivo}

O modelo de comprometimento cognitivo foi refinado com uma base de dados hipotética de 40 casos, contendo escores de MEEM, Teste do Relógio e Fluência Verbal. Maiores detalhes sobre as base de dados hipotética utilizada para testes do modelo de Compromentimento cognitivo podem ser observadas no Apêndice $A$.

A aferição dos casos da base hipotética foi realizada através de uma escala visual analógica (EVA) $[76,77]$ com intervalo de zero a dez, onde os extremos da escala são referentes aos grupos extremos do modelo (nesse caso, normal próximo do 0 e muito grave próximo de dez). O especialista avaliava o caso e marcava em uma régua a posição a qual ele indica ser adequada para aquele paciente. A escala é posteriormente medida para atribuir a nota do especialista àquele caso. A figura 3.15 apresenta o modelo da escala de aferição da base hipotética. A análise de performance do modelo de comprometimento cognitivo foi realizada calculando-se a quantidade de erros e acertos do modelo em relação aos especialistas, o Índice de Concordância Kappa, o coeficiente de correlação de Spearman. 
Muito Grave | Normal

Figura 3.15: Escala visual analógica contínua para aferição da nota para os casos da base de dados hipotética

\subsubsection{Banco de dados real para análise de performance do modelo de Comprometimento Cognitivo}

Para o modelo de Comprometimento Cognitivo foi realizado um teste com a base de dados reais do PROTER/IPq-USP com 60 casos, contendo escores de MEEM, Teste do Relógio e Fluência Verbal. O apêndice A apresenta mais detalhes sobre a base de dados do PROTER/IPq-USP utilizada no modelo de compromentimento cognitivo.

A análise dos resultados do modelo de comprometimento cognitivo para a base de dados com casos reais foi realizada através do Índice de Concordância Kappa, coeficiente de correlação de Spearman e a curva ROC.

\subsubsection{Análise do modelo de Tipo de Demência}

O modelo de árvore decisória para o tipo de demência foi refinado com uma base de dados de 49 casos. Para essa avaliação foi criada uma tabela que contém informações como tipo de início (Memória ou inicio insidioso), achados na neuroimagem (imagem característica da doença), velocidade da evolução (evolução rápida ou lenta) entre outros critérios. O especialista avaliou o caso e escolheu marcando um $X$ na opção que ele acredita ser a hipótese diagnóstica daquele caso. A figura 3.16 apresenta um exemplo do formulário modelo utilizado para testes dos caminhos do diagrama de decisão. 


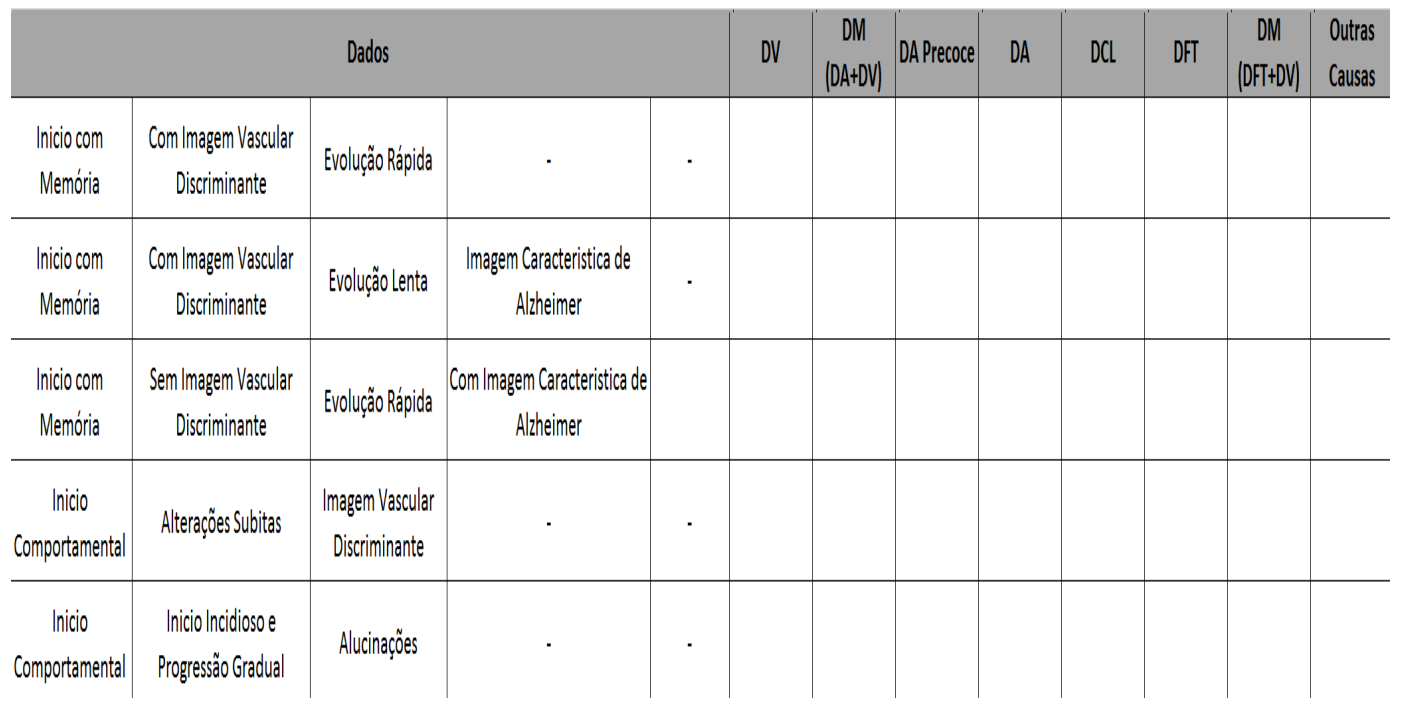

Figura 3.16: Exemplo do Formulário utilizado para teste dos caminhos de decisão do Modelo de Tipo de Demência

A análise do modelo para tipo de demência foi realizada calculando a taxa de erros e acertos dos especialistas em optar pelo caminho correto da árvore dado as informações dos nós. Infelizmente não foi possível a execução de outras aferições devido a ausência de dados reais adequados.

\subsubsection{Banco de dados hipotético para avaliação do modelo de Risco de Demência}

O modelo de Risco de Demência foi testado com uma base de dados contendo 30 casos hipotéticos. Os casos têm informações de comprometimento cognitivo e fatores de risco e de proteção presentes nos questionários criados com os especialistas.

A tabela 3.5 apresenta o resumo dos casos presentes na base de dados hipotética de fatores de risco e proteção (percentual das respostas positivas e negativas para cada fator). A média de idade da base de dados é de 73 anos \pm 9 anos.

Para o modelo de risco de demência a análise de performance foi realizada a partir da análise de percentual de erros além do coeficiente de correlação de Spearman. 
Tabela 3.5: Resumo dos casos gerados para base hipotética com base nos questionários de Risco e Proteção.

\begin{tabular}{|c|c|c|}
\hline Fator & $\%$ Casos Positivos & $\%$ Casos Negativos \\
\hline História familiar de demência primeiro grau & $36,7 \%$ & $63,3 \%$ \\
\hline AVC prévio ou recorrente & $43,3 \%$ & $56,7 \%$ \\
\hline Diabetes melitus tipo 2 & $56,7 \%$ & $43,3 \%$ \\
\hline Depressão Tardia & $56,7 \%$ & $43,3 \%$ \\
\hline Hipertensão arterial sistêmica & $60,0 \%$ & $40,0 \%$ \\
\hline Hiperlipidemia & $50,0 \%$ & $50,0 \%$ \\
\hline Obesidade & $60,0 \%$ & $40,0 \%$ \\
\hline Tabagismo & $36,7 \%$ & $63,3 \%$ \\
\hline Etilismo pesado & $63,3 \%$ & $36,7 \%$ \\
\hline Síndrome de Down & $26,7 \%$ & $73,3 \%$ \\
\hline Doença de Parkinson & $20,0 \%$ & $80,0 \%$ \\
\hline Uso de medicações que podem mimetizar ou agravar quadro cognitivo & $46,7 \%$ & $53,3 \%$ \\
\hline Baixa escolaridade ( $<8$ anos) & $56,7 \%$ & $43,3 \%$ \\
\hline Exposição a pesticidas & $56,7 \%$ & $43,3 \%$ \\
\hline Trauma crânio encefálico & $46,7 \%$ & $53,3 \%$ \\
\hline Hipotireoidismo & $53,3 \%$ & $46,7 \%$ \\
\hline Hiperhomocisteinemia & $53,3 \%$ & $46,7 \%$ \\
\hline Antecedentes psiquiátricos (transtorno afetivo bipolar principalmente) & $40,0 \%$ & $60,0 \%$ \\
\hline Ocupação anterior que exigia certo grau de esforço mental & $63,3 \%$ & $36,7 \%$ \\
\hline Acompanhamento clínico regular & $43,3 \%$ & $56,7 \%$ \\
\hline Alta escolaridade & $43,3 \%$ & $56,7 \%$ \\
\hline Atividade física moderada regular & $43,3 \%$ & $56,7 \%$ \\
\hline Atividades de estímulo cognitivo regularmente & $63,3 \%$ & $36,7 \%$ \\
\hline Atividades de lazer/ contato social & $60,0 \%$ & $40,0 \%$ \\
\hline
\end{tabular}

Também devido a inexistência de uma base de dados real, não pode ser calculado a curva ROC do modelo.

Assim como no modelo de comprometimento cognitivo, a aferição da base hipotética foi realizada pelos especialistas através de uma escala de diferencial semântica contínua:0 para risco muito baixo e 10 para risco muito alto.

\subsubsection{Banco de dados real para análises de neuroimagem}

Para os testes dos modelos de análise de neuroimagem, foram utilizada as bases de dados da Alzheimer's Disease Neuroimage Initiative (ADNI) do Open Access Series of Imaging Studies (OASIS) e do Hospital das Clínicas - FMUSP. A tabela 3.6 apresenta um resumo dos dados das neuroimagens utilizados para as avaliações.

Todas as bases contém com valores do Clinical Dementia Rate (CDR) para classificar o grau de demência ou comprometimento cognitivo. O CDR é um teste 
Tabela 3.6: Distribuição demográfica da base de dados de neuroimagens - $\mathrm{N}$ - Número de imagens, $\mathrm{H}$ - Número de Homens, M - Numero de mulheres, \% HC - percentual das imagens que pertencem ao banco de dados do Hospital das Clinicas, \% ADNI - percentual de imagens que pertencem ao banco de dados do ADNI, \% Oasis - percentual das imagens que pertencem a base de dados do OASIS, Idade - Média da Idade e desvio padrão dos individuos, MEEM Média e desvio padrão do MEEM e CDR - Nota no CDR

\begin{tabular}{|c|c|c|c|c|c|c|c|c|c|}
\hline Grupo & $\mathbf{N}$ & \% HC & \% Oasis & \%ADNI & H & M & Idade & MEEM & CDR \\
\hline Paciente & 47 & $28 \%$ & $21 \%$ & $28 \%$ & 25 & 22 & $77( \pm 8)$ & $22( \pm 3)$ & $1-97 \% ; 2-3 \%$ \\
\hline Controle & 47 & $26 \%$ & $74 \%$ & $0 \%$ & 14 & 33 & $68( \pm 14)$ & $29( \pm 1)$ & $0-100 \%$ \\
\hline
\end{tabular}

amplamente utilizado para classificação de demência composto por valores que variam de 0 a 3, a interpretação do escore do CDR é apresentada na tabela 3.7

Tabela 3.7: Interpretação dos escores do CDR

\begin{tabular}{|c|c|}
\hline CDR & Classificação \\
\hline 0 & Indivíduo Saudável \\
\hline 0.5 & Demência Questionável \\
\hline 1 & Demência Leve \\
\hline 2 & Demência Moderada \\
\hline 3 & Demência Grave \\
\hline
\end{tabular}

O Alzheimer's Disease Neuroimage Initiative (ADNI) é uma base de dados de neuroimagens disponível ao público acesso mediante cadastro. Existem mais de 200 artigos científicos publicados utilizando o ADNI [78]. O ADNI tem um banco de imagens disponíveis no qual utiliza como principal critério de classificação dos invíduos o valor do CDR (uma nota de CDR igual a 0 indica indivíduo normal), sendo:

- Indivíduos são considerados controle com idade até 70 anos e nota de corte no CDR igual a 0;

- Indivíduos são considerados com comprometimento cognitivo leve se o valor do CDR é igual a 0,5 com queixa de perda de memória e ausência de demência comprovada ; e 
- Indivíduos considerados com diagnóstico de DA com CDR acima de 0,5 e que cumprem os critérios clínicos do diagnóstico de DA.

O Open Access Series of Imaging Studies (OASIS) é uma base de dados de acesso livre com imagens disponíveis de indivíduos saudáveis e doentes entre 18 e 96 anos de idade diagnosticados com algum grau de demência. O OASIS tem notas de corte no CDR que variam entre 0,$5 ; 1$ e 2 [79].

O banco de dados disponibilizado pelo Hospital das Clínicas - HC-FMUSP é composta por 28 neuroimagens sendo 14 indivíduos de normais e 14 indivíduos doentes com notas de CDR variando de 0 a 2 .

A análise de performance do modelo das análises de neuroimagem é dada pela sensibilidade, especificidade e acurácia da classificação. Para a análise das regiões encontradas pelos modelos, buscamos na literatura científica, através de um estudo de revisão bibliográfica, correpondências afim de corroborar os achados. 


\section{Capítulo 4}

\section{Resultados}

Os modelos foram avaliados pelo grupo de especialistas do PROTER/IPq-USP. O primeiro modelo foi refinado utilizando uma base hipotética de 40 casos contendo valores do MEEM, Teste do Relógio e Fluência Verbal e aplicado em uma base de dados real do PROTER/IPq-USP com 60 casos. Para o primeiro modelo foi medido o percentual de erro dos especialistas, índice de concordância kappa, correlação de spearman e a curva ROC.

Para o modelo de tipo de demência foram realizados os testes dos caminhos com três especialistas. Devido a ausência de base de dados com as informações necessárias o modelo não foi testado com uma base real.

O terceiro modelo, de Risco de Demência foi testado usando uma base hipotética com 30 casos e submetido a testes com três especialistas. Da mesma forma que o diagrama de decisão de demência o modelo não pode ser testado com casos reais devido a ausência de base de dados. Para o terceiro modelo foi medida o percentual de erros dos especialistas e a correlação de spearman entre as notas do modelo e dos especialistas. 


\subsection{Resultados do modelo de Comprometimento Cog-}

\section{nitivo}

Para o banco de dados de casos hipotéticos (40 casos). O modelo classificou 33 casos $(82,5 \%)$ como comprometimento cognitivo e 7 casos $(17,5 \%)$ como indivíduos normais. O modelo foi submetido a avaliação de cinco especialistas e obtivemos um erro que variou de $10 \%$ (4 casos) para os especialistas 1 e 2; 7,5\% (3 erros) para os especialista 3 e 5 ; e $15 \%$ de erro (6 erros) para o especialista 4 . A tabela 4.1 apresenta os erros, acertos e percentual de casos classificados incorretamente pelo modelo.

Tabela 4.1: Quantidade total de erros, acertos e percentual de erro do modelo de comprometimento cognitivo em relação aos cinco especialistas, para o banco hipotético com 40 casos.

\begin{tabular}{|l|c|c|c|c|c|}
\hline & Especialista 1 & Especialista 2 & Especialista 3 & Especialista 4 & Especialista 5 \\
\hline Erros & 4 & 4 & 3 & 6 & 3 \\
\hline Acertos & 36 & 36 & 37 & 34 & 37 \\
\hline$\%$ Erro & 10 & 10 & 7,5 & 15 & 7,5 \\
\hline
\end{tabular}

\subsection{1 Índice de Concordância Kappa}

Para calcular o índice Kappa primeiramente foi estabelecida uma nota de corte para divisão dos grupos. A nota de corte de 7,5 pontos foi definida em conjunto com os especialistas que participaram da criação do modelo como abordado anteriormente no capítulo 3.

O índice de concordância Kappa entre os especialistas e o modelo apresentarou um valor de concordância substancial para quatro dos cinco especialistas testados. Quando avaliamos o índice de concordância Kappa entre os especialistas percebemos índices maiores, mas com variação de 0,59 a 0,91. A tabela 4.2 apresenta os resultados dos 
índices de concordância Kappa do modelo de comprometimento cognitivo considerando o banco hipotético

Tabela 4.2: Índice de concordância Kappa entre os especialistas e o modelo e entre os especialistas.

\begin{tabular}{|l|c|c|c|c|c|c|}
\hline & Modelo & Esp. \# 1 & Esp. \# 2 & Esp. \# 3 & Esp. \# 4 & Esp. \# 5 \\
\hline Modelo & 1 & 0,65 & 0,69 & 0,72 & 0,48 & 0,75 \\
\hline Esp. \#1 & - & 1 & 0,84 & 0,91 & 0,83 & 0,75 \\
\hline Esp. \# 2 & - & - & 1 & 0,76 & 0,69 & 0,78 \\
\hline Esp. \# 3 & - & - & - & 1 & 0,72 & 0,82 \\
\hline Esp. \# 4 & - & - & - & - & 1 & 0,59 \\
\hline Esp. \# 5 & - & - & - & - & - & 1 \\
\hline
\end{tabular}

Percebem-se dois casos (caso 13 e 36) onde o modelo não tem acordo com nenhum dos especialistas. No restante dos casos a concordância é parcial, como vemos na tabela 4.3.

Tabela 4.3: Casos da base hipotética com com discordância entre especialistas e modelo. $O$ campo Classif. apresenta o grupo no qual o caso foi classificado, sendo classificação 0 para presença de compromentimento cognitivo e 1 para indivíduo normal

\begin{tabular}{|c|c|c|c|c|c|c|c|c|}
\hline Item & Caso 1 & Caso 2 & Caso 7 & Caso 11 & Caso 13* & Caso 27 & Caso 34 & Caso 36* \\
\hline MEEM & 24 & 19 & 23 & 22 & 23 & 26 & 27 & 26 \\
\hline Teste do Relógio & 4 & 2 & 1 & 2 & 0 & 3 & 2 & 2 \\
\hline Fluência & 9 & 7 & 9 & 8 & 9 & 13 & 9 & 9 \\
\hline Nota Modelo & 6,25 & 4,53 & 6,25 & 6,25 & 7,50 & 8,38 & 7,50 & 6,76 \\
\hline Nota Esp. \# 1 & 7,75 & 4,83 & 6,58 & 4,17 & 4,17 & 6,83 & 8,33 & 8,17 \\
\hline Nota Esp. \# 2 & 8,57 & 5,83 & 7,62 & 6,79 & 6,31 & 9,40 & 9,52 & 9,40 \\
\hline Nota Esp. \# 3 & 7,37 & 2,11 & 5,09 & 6,58 & 5,18 & 5,96 & 8,33 & 7,89 \\
\hline Nota Esp. \# 4 & 9,47 & 7,63 & 7,46 & 6,93 & 5,79 & 5,88 & 4,74 & 7,72 \\
\hline Nota Esp. \# 5 & 7,46 & 2,54 & 4,91 & 7,54 & 2,37 & 8,77 & 8,68 & 7,72 \\
\hline Classif. Modelo & 0 & 0 & 0 & 0 & 1 & 1 & 1 & 0 \\
\hline Classif. Esp. \# 1 & 1 & 0 & 0 & 0 & 0 & 0 & 1 & 1 \\
\hline Classif. Esp. \# 2 & 1 & 0 & 1 & 0 & 0 & 1 & 1 & 1 \\
\hline Classif. Esp. \# 3 & 0 & 0 & 0 & 0 & 0 & 0 & 1 & 1 \\
\hline Classif. Esp. \# 4 & 1 & 1 & 0 & 0 & 0 & 0 & 0 & 1 \\
\hline Classif. Esp. \# 5 & 0 & 0 & 0 & 1 & 0 & 1 & 1 & 1 \\
\hline
\end{tabular}

Os casos classificados incorretamente tem uma grande variação nos valores dos testes do MEEM (de 19 a 27 pontos), Fluência Verbal (de 7 a 13 pontos) e no Teste do Relógio (de 0 a 4 pontos), o que não indica que apenas uma variável ou a regra esteja causando esses erros de classificação. No entanto quando avaliamos o escore gerado pelo modelo de comprometimento cognitivo (vide figura 4.1) percebemos um intervalo de notas onde o modelo apresenta desacordo com os especialistas que varia entre 4,53 
a 8,38 pontos para todos os casos, e 6,76 e 7,50 pontos para os casos totalmente discordantes.

Como a base hipotética leva em consideração apenas os valores das variáveis fuzzy de entrada não é possível aprofundar a análise, o que será feito utilizando a base de dados real do PROTER/IPq-USP, contudo vemos que o caso 13 e 36 tiveram uma nota próxima do limite, sendo que o caso 13 possui um valor relativamente baixo de MEEM e o caso 36 um escore de dois pontos no teste de relógio e limítrofe no MEEM, apesar do desempenho razoável na fluência.

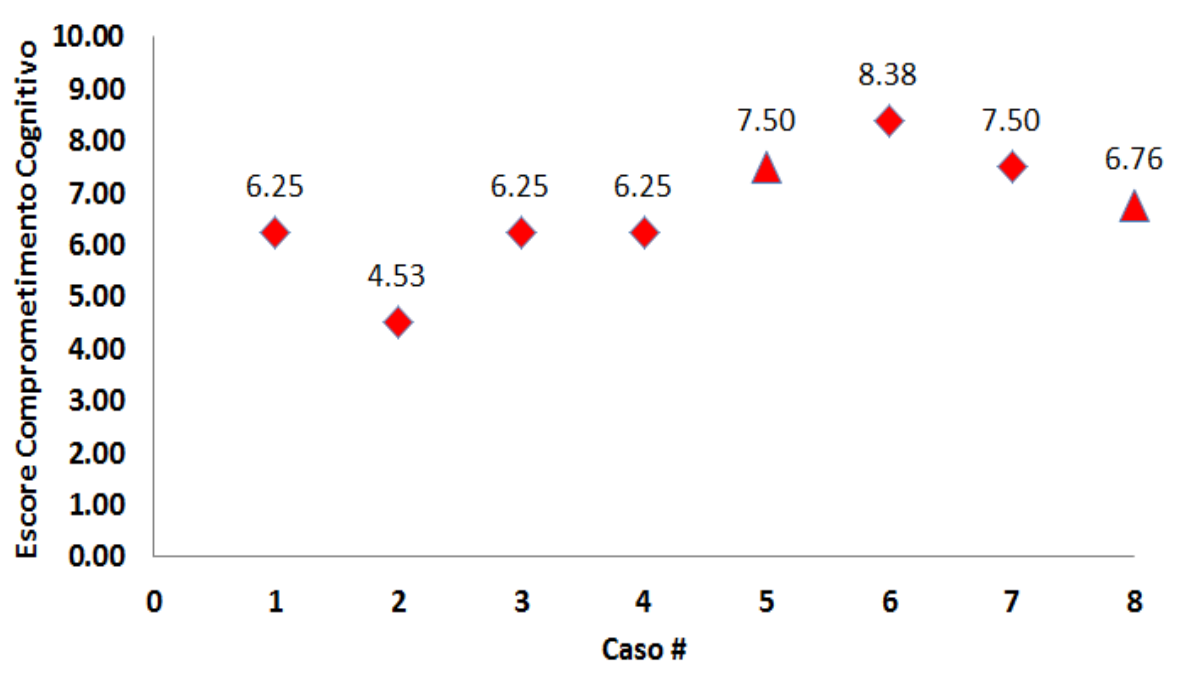

Figura 4.1: Espalhamento das notas de comprometimento cognitivo da base hipotética para os casos discordantes com o modelo onde são projetadas as notas de todos os casos discordantes. Os pontos triangulares $(\Delta)$ são os casos totalmente discordantes entre especialistas e modelo.

O modelo de comprometimento cognitivo também foi comparado com a média da nota atribuída pelos especialistas. O resultado foi de 36 acertos e 4 erros $(10 \%$ de erro) e um índice de concordância Kappa de 0,65. Os 4 casos com discordância em relação a média estão listados na tabela 4.4. No geral ao avaliarmos a média os casos discordantes apresentaram menos variação do teste do MEEM e do escore de fluência verbal mas ainda uma variação grande para o teste do relógio. 
Tabela 4.4: Casos discordantes em relação a média dos especialistas e o modelo, sendo classificação 0 para presença de compromentimento cognitivo e 1 para indivíduo normal

\begin{tabular}{|l|c|c|c|c|}
\hline Item & Caso 1 & Caso 13 & Caso 27 & Caso 36 \\
\hline MEEM & 24 & 23 & 26 & 26 \\
\hline Teste do Relógio & 4 & 0 & 3 & 2 \\
\hline Fluência & 9 & 9 & 13 & 9 \\
\hline Nota do Modelo & 6,25 & 7,5 & 8,38 & 6,76 \\
\hline Nota Média dos Esp. & 8,12 & 4,76 & 7,37 & 8,18 \\
\hline Classif. do Modelo & 0 & 1 & 1 & 0 \\
\hline Classif. da Média dos Esp. & 1 & 0 & 0 & 1 \\
\hline
\end{tabular}

\subsubsection{Correlação das notas do modelo versus notas dos especi-}

\section{alistas}

A correlação entre os valores numéricos da saída do modelo e dos valores de EVA dos especialistas foi calculada usando a correlação de Spearman. A correlação entre as notas dadas pelos especialistas entre si variou no intervalo de 0,79 e 0,97 . Para o modelo obtivemos correspondência acima de 0,86 para 4 especialistas exceto por um caso (Especialista 4) que obteve 0,83 de correlação com o modelo, como podemos observar na tabela 4.5.

Tabela 4.5: Correlação de Spearman entre as notas atribuídas pelos especialistas e pelo modelo.

\begin{tabular}{|l|c|c|c|c|c|c|}
\hline & Modelo & Esp. 1 & Esp. 2 & Esp. 3 & Esp. 4 & Esp. 5 \\
\hline Modelo & 1 & 0,89 & 0,89 & 0,90 & 0,83 & 0,86 \\
\hline Especialista 1 & - & 1 & 0,97 & 0,92 & 0,88 & 0,92 \\
\hline Especialista 2 & - & - & 1 & 0,92 & 0,88 & 0,91 \\
\hline Especialista 3 & - & - & - & 1 & 0,87 & 0,87 \\
\hline Especialista 4 & - & - & - & - & 1 & 0,79 \\
\hline Especialista 5 & - & - & - & - & - & 1 \\
\hline
\end{tabular}

Adicionalmente, realizamos uma comparação da média dos especialistas com o modelo. A média pode ser entendida como uma espécie de consenso entre os especialistas. Comparando a média dos especialistas com o modelo obtivemos um correlação de Spearman de 0,91. 


\subsubsection{Resultados do modelo com a Base de Dados do PROTER/IPq-}

\section{USP}

Após o modelo ter sido testado em dados hipotéticos, este foi submetido a um banco de dados reais com 60 casos para análise de desempenho. As notas do modelo foram comparadas com os valores do CDR (descritos anteriormente na tabela 3.7).

Da mesma forma em relação a base hipotética, para calcular o índice de concordância Kappa e o percentual de erros foi utilizada a nota de corte para as notas do modelo de 7,50 (maior ou igual a 7,50 considerado sem comprometimento cognitivo) e os valores de CDR acima de 0 foram considerados como indivíduo com comprometimento cognitivo. Obtivemos como resultado para 60 casos, 8 erros $(13,33 \%)$ e um índice de concordância Kappa de 0,67 com o modelo.

Os casos classificados incorretamente foram listados na tabela 4.6. Nestes casos, como anteriormente na avaliação do modelo hipotético, temos uma variação entre os resultados de MEEM (variações de 22 a 28 pontos), Fluência Verbal (variações de 2 a 5 pontos) e Teste do Relógio (variações de 1 a 3 pontos).

Tabela 4.6: Casos classificados incorretamente pelo modelo em relação ao CDR.

\begin{tabular}{|l|c|c|c|c|c|c|c|c|}
\hline \multicolumn{1}{|c|}{ Item } & Caso 7 & Caso 24 & Caso 28 & Caso 43 & Caso 52 & Caso 55 & Caso 94 & Caso 98 \\
\hline MEEM & 27 & 26 & 26 & 24 & 23 & 22 & 28 & 26 \\
\hline Teste do Relógio & 2 & 2 & 1 & 1 & 2 & 2 & 2 & 3 \\
\hline Fluência & 3 & 2 & 3 & 2 & 5 & 3 & 4 & 3 \\
\hline Escolaridade & 5 & 8 & 0 & 2 & 4 & 2 & 8 & 4 \\
\hline Nota Modelo & 6,59 & 6,59 & 5,91 & 5,95 & 5,64 & 5,00 & 6,59 & 6,90 \\
\hline CDR & 0 & 0 & 0 & 0 & 0 & 0 & 0 & 0 \\
\hline Grupo do Modelo & 1 & 1 & 1 & 1 & 1 & 1 & 1 & 1 \\
\hline
\end{tabular}

Todos os casos incorretamente classificados foram de indivíduos considerados pelo escore do CDR como sem compromentimento cognitivo, e assim como nos testes 
realizados com a base hipotética, não temos uma variável ou regra que pudemos identificar como geradoras dos erros de classificação.

Porém, é sabido que testes de cognição são afetados diretamente pela escolaridade. A figura 4.2 apresenta o espalhamento do tempo de escolaridade dos casos apresentados na tabela 4.6 em relação a nota atribuída no modelo.

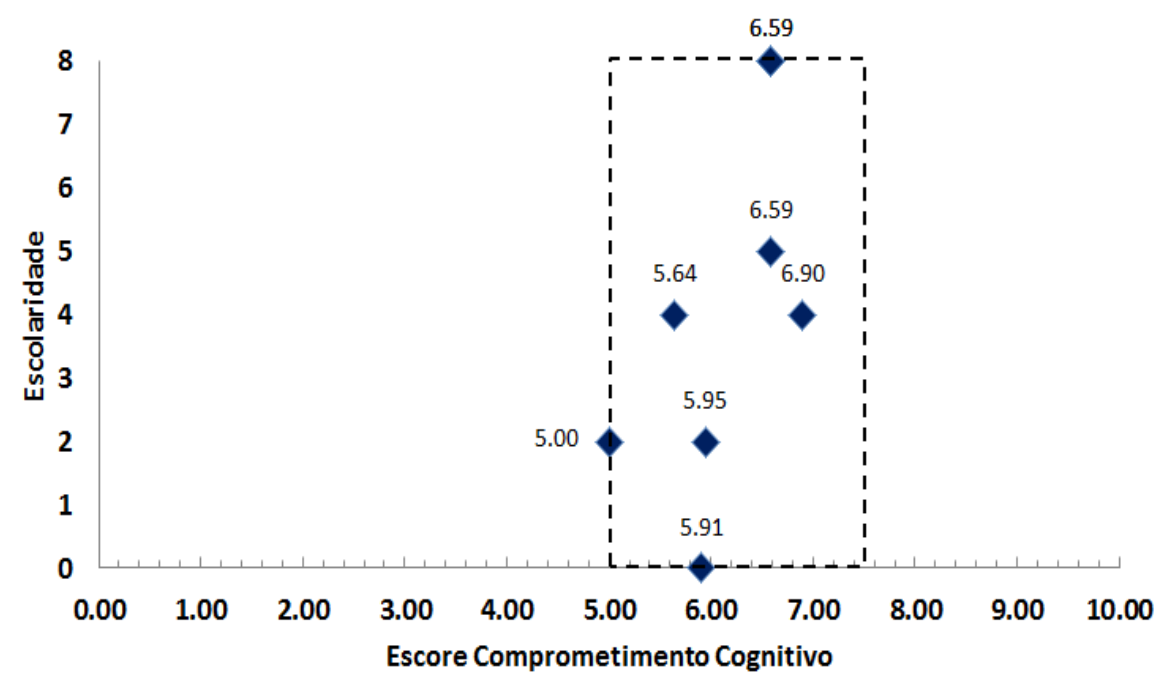

Figura 4.2: Espalhamento das notas do modelo de comprometimento cognitivo versus escolaridade.

A escolaridade é uma variável importante para entender a classificação incorreta do modelo de compromentimento cognitivo. Para os casos classificados incorretamente temos uma média de 4 anos \pm 3 anos, o que justifica as pontuações baixas em alguns dos testes de cognição.

Nestes casos o intervalo de notas atribuídas pelo modelo para o banco de dados reais $(5,0$ a 6,90$)$ é próximo do intervalo observado nos testes realizados com a base hipotética (mais especificamente de 6,76 a 7,50 pontos para os casos totalmente discordantes), o que indica um intervalo de saída onde a escolaridade deve ser avaliada para tomada de decisão. Esse intervalo foi apresentado ao grupo de especialistas do PROTER/IPq-USP e ajustado pelos grupo para um intervalo de 5,0 a 7,50 pontos. 


\subsubsection{Curva ROC do modelo de Comprometimento Cognitivo}

A curva ROC (sensibilidade versus 1-especificidade) foi calculada utilizando o escore do CDR como padrão ouro. Para o cálculo foi estabelecido que todo indivíduo com escore de CDR maior que 0 e nota no escore do modelo de comprometimento cognitivo menor que 7,5 fossem considerados como pertencentes ao grupo de indivíduos com comprometimento cognitivo. A imagem 4.3 apresenta a curva ROC, onde obtivemos uma área sob a curva de 0.80 .

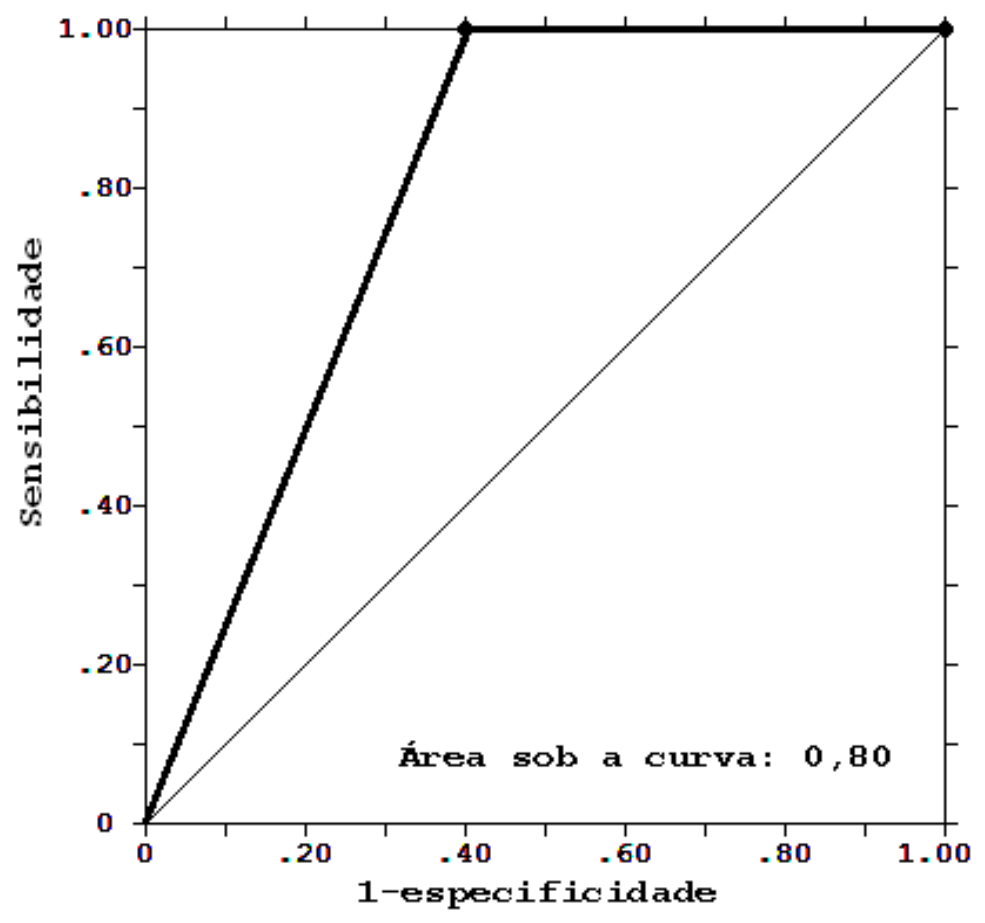

Figura 4.3: Curva ROC do modelo de comprometimento cognitivo pelo padrão do CDR.

\subsection{Resultados do modelo de tipo de demência}

Para a árvore de decisão de tipo de demência foram realizados testes dos caminhos de cada ramo da árvore com uma base hipotética com 53 casos. Estes casos foram avaliados 
por três especialistas. A Tabela 4.7 apresenta os resultados de cada especialista (acertos, erros e percentual de erros).

Tabela 4.7: Índice de erros, acertos e percentual de erros do diagrama de decisão de tipo de demência.

\begin{tabular}{|l|c|c|c|}
\hline & Especialista 1 & Especialista 2 & Especialista 3 \\
\hline Erros & 1 & 9 & 7 \\
\hline Acertos & 48 & 40 & 42 \\
\hline$\%$ Erros & 2,40 & 18,33 & 14,28 \\
\hline
\end{tabular}

O especialista 2 apresentou a maior índice de erros, sendo que grande parte dos testes de caminhos classificados como incorretos na análise do especialista ao optar por "investigação de outras causas de demência"(5 erros). A tabela 4.9 apresenta os casos classificados incorretamente.

Tabela 4.8: Casos classificados incorretamente pelos especialistas, a coluna "resultado do diagrama" indica o caminho modelado no diagrama de decisão, e a coluna "escolha do especialista" indica o caminho escolhido pelo especialista.

\begin{tabular}{|c|c|c|c|c|c|c|c|c|}
\hline \multirow{2}{*}{$\frac{\text { Caso\# }}{3}$} & \multirow{2}{*}{$\begin{array}{c}\text { Esp \# } \\
2\end{array}$} & \multirow{2}{*}{$\begin{array}{c}\begin{array}{c}\text { Tipo de } \\
\text { Início }\end{array} \\
\begin{array}{c}\text { Inicio com } \\
\text { Memória }\end{array}\end{array}$} & \multicolumn{4}{|c|}{ Dados } & \multirow{2}{*}{$\begin{array}{c}\begin{array}{c}\text { Resultado } \\
\text { Diagrama }\end{array} \\
\text { DV }\end{array}$} & \multirow{2}{*}{$\begin{array}{c}\begin{array}{c}\text { Resultado } \\
\text { Especialista }\end{array} \\
\text { DA+DV }\end{array}$} \\
\hline & & & $\begin{array}{l}\text { Com Imagem } \\
\text { Vascular } \\
\text { Discriminante }\end{array}$ & $\begin{array}{l}\text { Evolução } \\
\text { Rápida }\end{array}$ & - & - & & \\
\hline 5 & 1 e 2 & $\begin{array}{l}\text { Inicio com } \\
\text { Memória }\end{array}$ & $\begin{array}{c}\text { Com Imagem } \\
\text { Vascular } \\
\text { Discriminante }\end{array}$ & $\begin{array}{l}\text { Evolução } \\
\text { Lenta }\end{array}$ & $\begin{array}{c}\text { Sem Imagem } \\
\text { Caracteristica de } \\
\text { Alzheimer }\end{array}$ & - & DV & $\mathrm{DA}+\mathrm{DV}$ \\
\hline 9 & 2 & $\begin{array}{l}\text { Inicio com } \\
\text { Memória }\end{array}$ & $\begin{array}{c}\text { Sem Imagem } \\
\text { Vascular } \\
\text { Discriminante }\end{array}$ & $\begin{array}{l}\text { Evolução } \\
\text { Rápida }\end{array}$ & $\begin{array}{l}\text { Com Imagem } \\
\text { Caracteristica de } \\
\text { Alzheimer }\end{array}$ & $<60$ Anos & $\begin{array}{c}\text { DA } \\
\text { Precoce }\end{array}$ & $\begin{array}{l}\text { Outras } \\
\text { Causas }\end{array}$ \\
\hline 13 & 3 & $\begin{array}{c}\text { Inicio } \\
\text { Comportamental }\end{array}$ & $\begin{array}{l}\text { Inicio com } \\
\text { Alterações } \\
\text { Subitas }\end{array}$ & $\begin{array}{c}\text { Imagem } \\
\text { Vascular } \\
\text { Discriminante }\end{array}$ & - & - & DV & $\mathrm{DFT}+\mathrm{DV}$ \\
\hline 14 & 3 & $\begin{array}{c}\text { Inicio } \\
\text { Comportamental }\end{array}$ & $\begin{array}{l}\text { Inicio com } \\
\text { Alterações } \\
\text { Subitas }\end{array}$ & $\begin{array}{l}\text { Sem Imagem } \\
\text { Vascular } \\
\text { Discriminante }\end{array}$ & - & - & $\begin{array}{l}\text { Outras } \\
\text { Causas }\end{array}$ & DFT \\
\hline 19 & 2 & $\begin{array}{c}\text { Inicio } \\
\text { Comportamental }\end{array}$ & $\begin{array}{l}\text { Inicio Incidioso e } \\
\text { Progressão } \\
\text { Gradual }\end{array}$ & $\begin{array}{l}\text { Flutuações de } \\
\text { Consciencia }\end{array}$ & - & - & $\mathrm{DCL}$ & Outras Causas \\
\hline 22 & 2 & $\begin{array}{c}\text { Inicio } \\
\text { Comportamental }\end{array}$ & $\begin{array}{l}\text { Inicio Incidioso e } \\
\text { Progressão } \\
\text { Gradual }\end{array}$ & $\begin{array}{l}\text { Flutuações de } \\
\text { Consciencia }\end{array}$ & $\begin{array}{l}\text { Alterações no } \\
\text { Sono REM }\end{array}$ & - & $\mathrm{DCL}$ & $\begin{array}{l}\text { Outras } \\
\text { Causas }\end{array}$ \\
\hline 28 & 2 & $\begin{array}{c}\text { Inicio } \\
\text { Comportamental }\end{array}$ & $\begin{array}{l}\text { Inicio Incidioso e } \\
\text { Progressão } \\
\text { Gradual }\end{array}$ & $\begin{array}{c}\text { Perfil } \\
\text { Neurológico } \\
\text { Disexecutivo }\end{array}$ & $\begin{array}{l}\text { Imagem Vascular } \\
\text { Discriminante }\end{array}$ & $\begin{array}{l}\text { Tem Atrofia } \\
\text { Frontal }\end{array}$ & $\mathrm{DFT}+\mathrm{DV}$ & $\begin{array}{l}\text { Outras } \\
\text { Causas }\end{array}$ \\
\hline 30 & 2 & $\begin{array}{c}\text { Inicio } \\
\text { Comportamental }\end{array}$ & $\begin{array}{c}\text { Inicio Incidioso e } \\
\text { Progressão } \\
\text { Gradual }\end{array}$ & Desinibição & $\begin{array}{c}\text { Imagem } \\
\text { Vascular } \\
\text { Discriminante }\end{array}$ & $\begin{array}{l}\text { Tem Atrofia } \\
\text { Frontal }\end{array}$ & $\mathrm{DFT}+\mathrm{DV}$ & DFT \\
\hline 31 & 3 & $\begin{array}{c}\text { Inicio } \\
\text { Comportamental }\end{array}$ & $\begin{array}{l}\text { Inicio Incidioso e } \\
\text { Progressão } \\
\text { Gradual }\end{array}$ & Desinibição & $\begin{array}{c}\text { Imagem } \\
\text { Vascular } \\
\text { Discriminante }\end{array}$ & $\begin{array}{c}\text { Não tem } \\
\text { Atrofia Frontal }\end{array}$ & DV & $\mathrm{DFT}+\mathrm{DV}$ \\
\hline 34 & 3 & $\begin{array}{c}\text { Inicio } \\
\text { Comportamental }\end{array}$ & $\begin{array}{c}\text { Inicio Incidioso e } \\
\text { Progressão } \\
\text { Gradual }\end{array}$ & $\begin{array}{l}\text { Perda de } \\
\text { Simpatia }\end{array}$ & $\begin{array}{c}\text { Imagem } \\
\text { Vascular } \\
\text { Discriminante }\end{array}$ & $\begin{array}{l}\text { Tem Atrofia } \\
\text { Frontal }\end{array}$ & $\mathrm{DFT}+\mathrm{DV}$ & DFT \\
\hline 36 & 3 & $\begin{array}{c}\text { Inicio } \\
\text { Comportamental }\end{array}$ & $\begin{array}{l}\text { Inicio Incidioso e } \\
\text { Progressão } \\
\text { Gradual }\end{array}$ & $\begin{array}{l}\text { Comportamento } \\
\text { perseverativo }\end{array}$ & $\begin{array}{c}\text { Imagem } \\
\text { Vascular } \\
\text { Discriminante }\end{array}$ & $\begin{array}{l}\text { Tem Atrofia } \\
\text { Frontal }\end{array}$ & $\mathrm{DFT}+\mathrm{DV}$ & DFT \\
\hline 38 & 3 & $\begin{array}{c}\text { Inicio } \\
\text { Comportamental }\end{array}$ & $\begin{array}{l}\text { Inicio Incidioso e } \\
\text { Progressão } \\
\text { Gradual }\end{array}$ & Hiperoralidade & $\begin{array}{c}\text { Imagem } \\
\text { Vascular } \\
\text { Discriminante }\end{array}$ & $\begin{array}{l}\text { Tem Atrofia } \\
\text { Frontal }\end{array}$ & $\mathrm{DFT}+\mathrm{DV}$ & DFT \\
\hline 47 & 2 & $\begin{array}{c}\text { Inicio } \\
\text { Comportamental }\end{array}$ & $\begin{array}{c}\text { Inicio Incidioso e } \\
\text { Progressão } \\
\text { Gradual }\end{array}$ & $\begin{array}{l}\text { Perda de } \\
\text { Simpatia }\end{array}$ & $\begin{array}{c}\text { Sem Imagem } \\
\text { Vascular } \\
\text { Discriminante }\end{array}$ & $\begin{array}{l}\text { Não Possui } \\
\text { Atrofia Frontal }\end{array}$ & DFT & $\begin{array}{l}\text { Outras } \\
\text { Causas }\end{array}$ \\
\hline 53 & 3 & $\begin{array}{c}\text { Inicio } \\
\text { Comportamental }\end{array}$ & $\begin{array}{l}\text { Inicio Incidioso e } \\
\text { Progressão Gradual }\end{array}$ & - & $\begin{array}{c}\text { Sem Imagem } \\
\text { Vascular } \\
\text { Discriminante }\end{array}$ & $\begin{array}{l}\text { Não tem } \\
\text { Atrofia Frontal }\end{array}$ & $\begin{array}{l}\text { Outras } \\
\text { Causas }\end{array}$ & DFT \\
\hline
\end{tabular}




\subsection{Resultados das Análises Estatísticas de Neuroi-}

\section{magens}

Foram avaliadas três técnicas de análise de neuroimagens abordadas anteriormente no capítulo 2 através dos softwares abordados no capítulo 3 . Foi realizada uma comparação entre a identificação de regiões discriminantes para as três técnicas; e para as técnicas multivariadas (SDM e SVM) foram avaliados adicionalmente os hiperplanos de classificação de cada técnica.

As imagens foram normalizadas e segmentadas utilizando o SPM 5. A normalização espacial foi realizada com base no template do ICBM e segmentadas por substância (massa cinza, massa branca e liquido cefalorraquidiano), todas as imagens foram submetidas a etapa de suavização utilizando a um filtro gaussiano com kernel de 12-mm full-width at half-maximum (FWHM).

\subsubsection{Resultados dos Classificadores Estatísticos}

Após a normalização e retirada de artefatos, as imagens foram submetidas aos classificadores estatísticos do SDM (utilizando o MLDA) e do SVM. O SVM teve resultados de sensibilidade e especificidade com menor variação. Enquanto o MLDA apresentou um maior índice de sensibilidade e maior acurácia. A tabela 4.9 apresenta os resultados dos classificadores.

Tabela 4.9: Sensibilidade, especificidade e acurácia dos classificadores multivariados do SDM e SVM.

\begin{tabular}{|l|c|c|c|}
\hline Técnica & Sensibilidade & Especificidade & Acurácia \\
\hline Statistical Discriminant Model (SDM/MLDA) & $100 \%$ & $74,46 \%$ & $87,23 \%$ \\
\hline Support Vector Machines (SVM) & $80,85 \%$ & $82,98 \%$ & $81,91 \%$ \\
\hline
\end{tabular}


O hiperplano de separação dos classificadores pode ser vistos na figuras 4.4 para o SDM/MLDA e na figura 4.5 para o SVM.

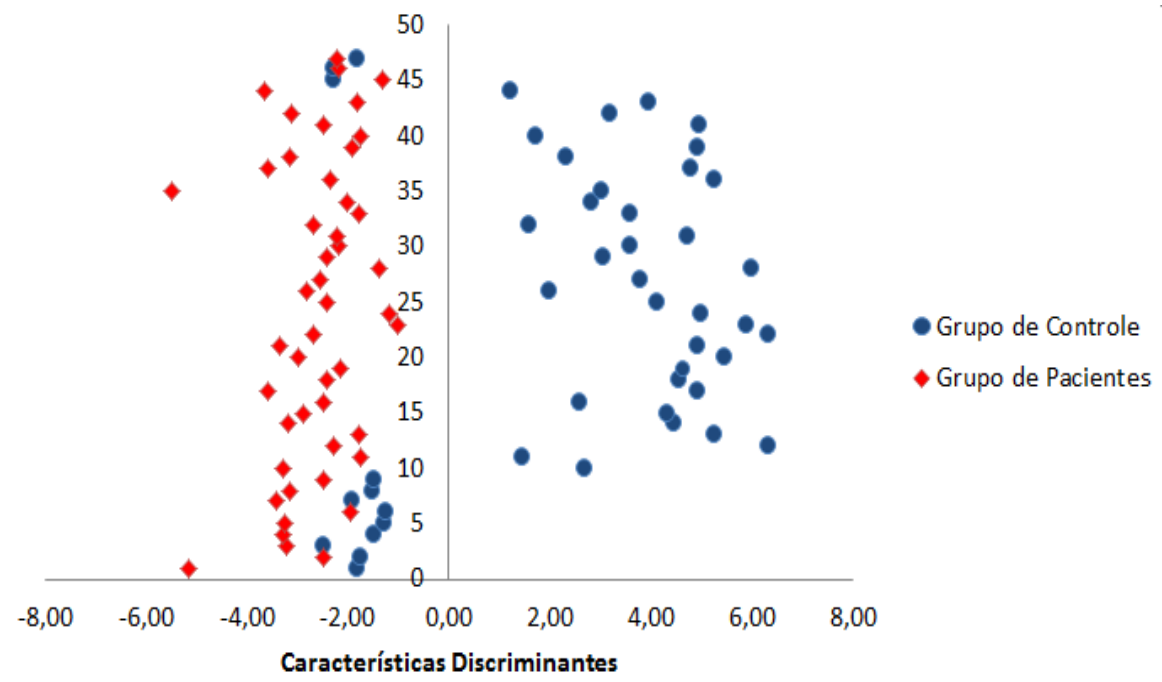

Figura 4.4: Hiperplano de separação resultante da classificação do MLDA.

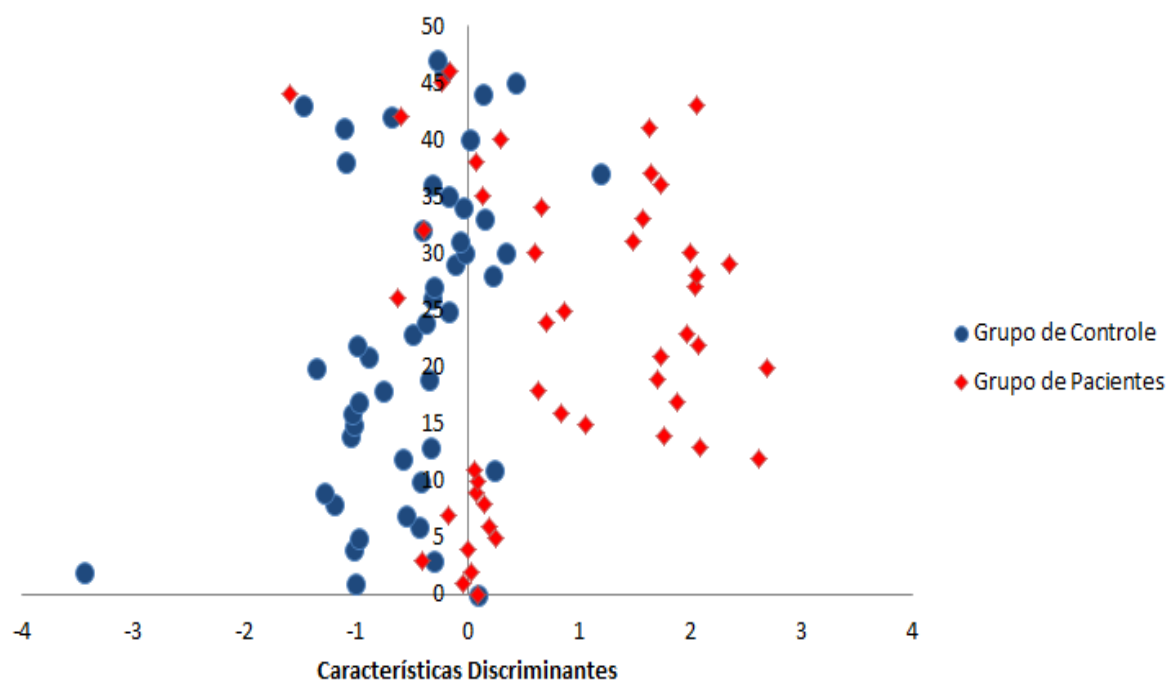

Figura 4.5: Hiperplano de separação resultante da classificação do SVM

O SDM é baseado na técnica do MLDA que trabalha o espalhamento no hiperplano maximizando as diferenças entre os grupos, em contrapartida o SVM busca maximizar a classificação. Essa característica do SDM permite conseguir classificações melhores quando lidamos com dados que contém muitas informações, como é o caso das neuroimagens. 
Devido ao fato do SDM trabalhar maximizando as diferenças entre os grupos, é possível admitir que variáveis clínicas possam ser melhor representadas. A figura 4.6 apresenta os hiperplanos do MLDA e do SVM agrupados com base no MEEM e na idade. Podemos perceber que o agrupamento do SDM é mais eficiente para representar algumas variáveis clínicas, o que faz dessa técnica um importante recurso não apenas para classificação de grupos de neuroimagens mas também para avaliações de características clínicas em conjunto com a imagem, tornando-o uma poderosa ferramenta de apoio ao diagnóstico de DA.

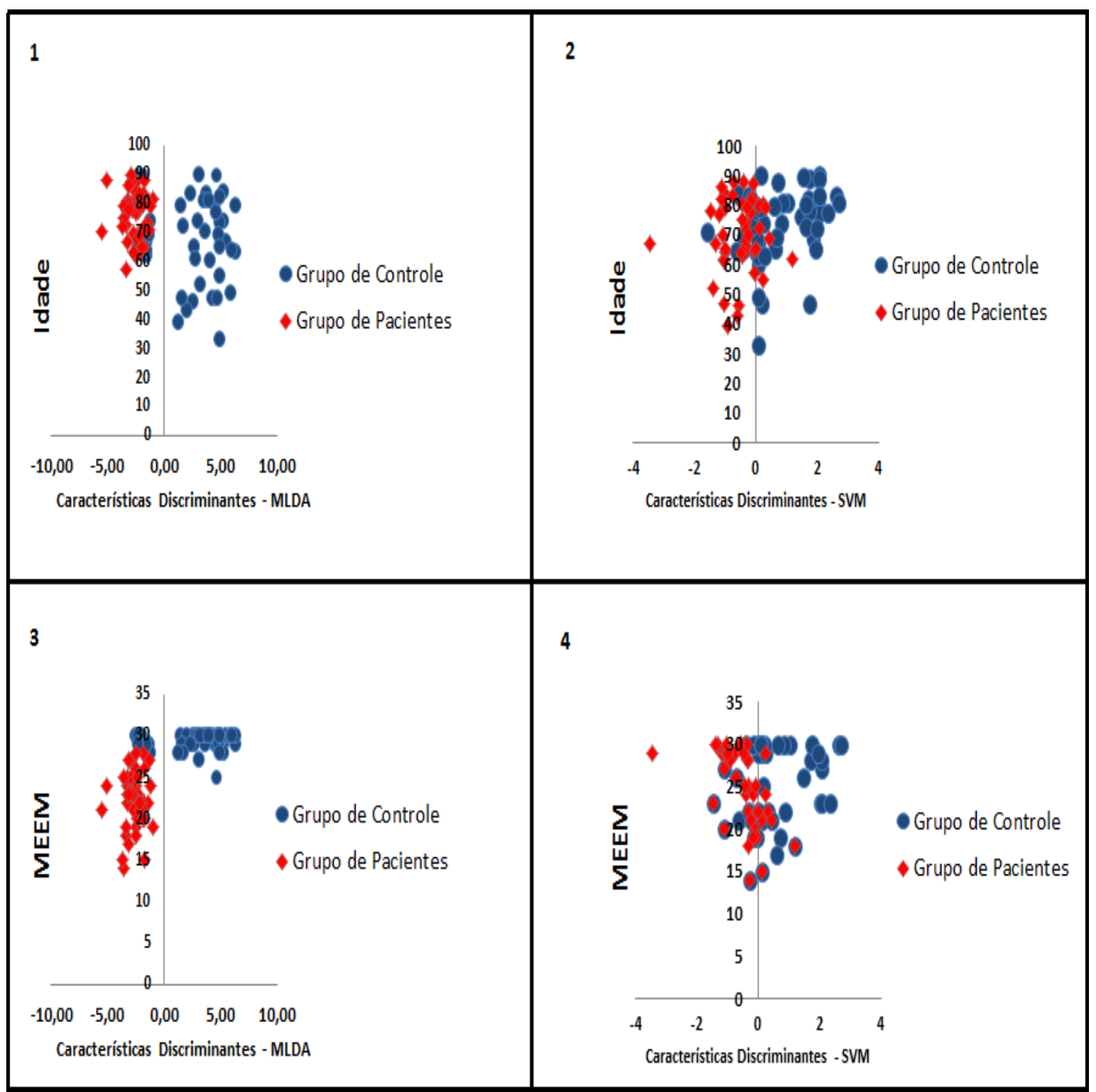

Figura 4.6: Hiperplanos de separação dos classificadores do MLDA (quadros 1 e 3) e do SVM (quadros 2 e 4) agrupados por indicadores clínicos de idade e MEEM. 


\subsubsection{Identificação de regiões discriminantes}

Para identificação de regiões discriminantes foram avaliadas três técnicas. As técnicas multivariadas (SDM e SVM) e a análise massivamente univariada utilizando o SPM.

As imagens resultantes das análises estatísticas são sobrepostas em uma imagem de indivíduo saudável. A figura 4.7 apresenta as diferenças entre as comparações estatísticas do SDM (a), SVM (b) e do SPM (c), onde podemos perceber a diferença entre as técnicas multivariadas ( $a$ e b) em relação aos modelo massivamente univariados.

a)

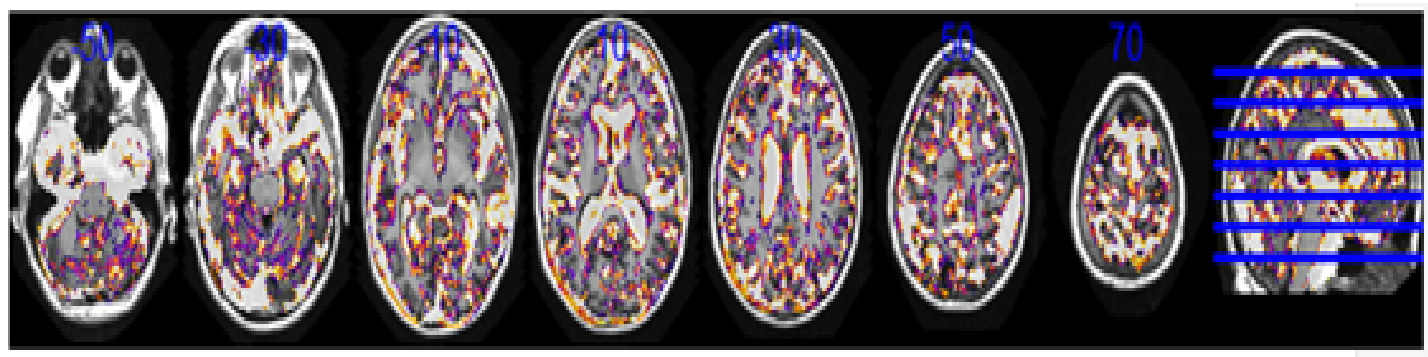

b)

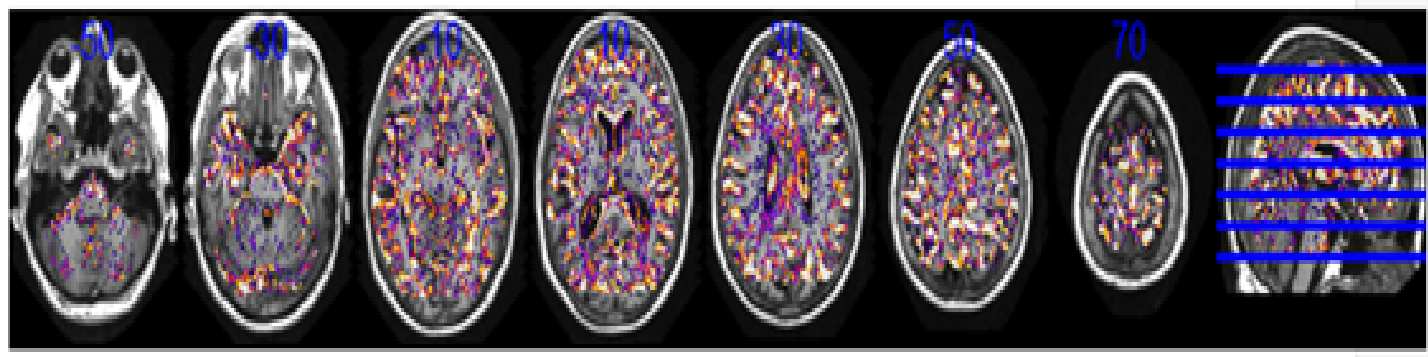

c)

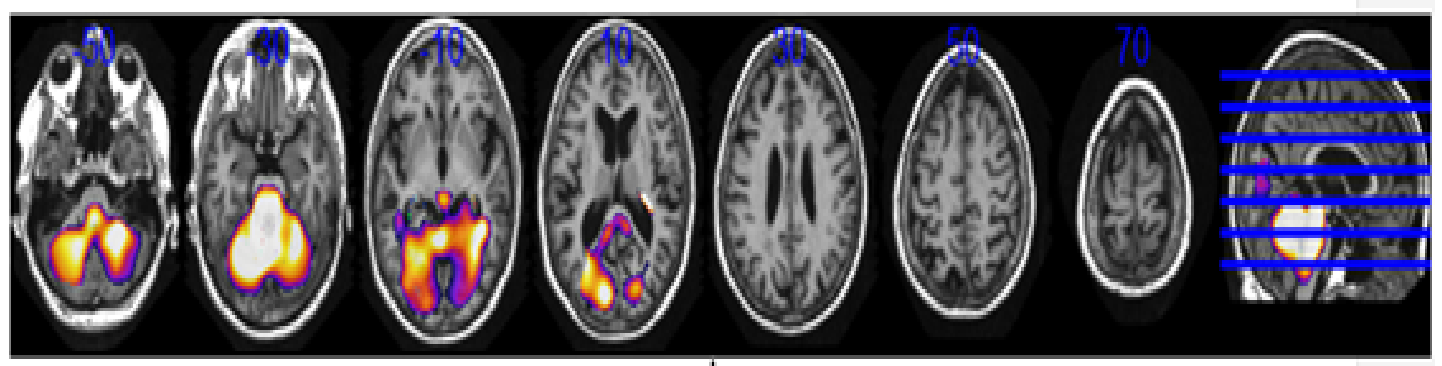

Figura 4.7: Diferença entre o grupo de controle e o grupo de pacientes das técnicas multivariadas do SDM e SVM e utilizando a análise massivamente univariada do SPM : a)Diferenças entre as médias dos grupos utilizando o SDM; b) Diferenças das imagens médias utilizando o SVM; e c) Diferenças da análise massivamente univariada utilizando o software SPM 
A imagem resultante da sobreposição é então segmentada utilizando modelos deformáveis [6], afim de isolar os voxels das regiões ativadas. A figura 4.8 apresenta a segmentação dos grupos de voxel ativados como discriminantes.
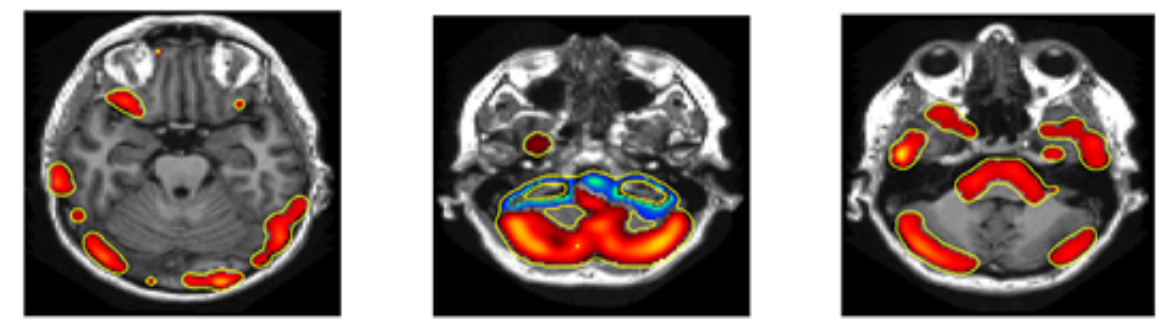

Figura 4.8: Exemplo da segmentação por fatias da imagem das regiões ativadas utilizando modelos deformavéis

As coordenadas dos voxels ativados e segmentados são então mapeadas para coordenadas do atlas de Talairach. Adicionalmente procuramos suporte na literatura para os achados após a segmentação. O tamanho das regiões (dado pela soma dos voxels que a compõe) e a referência na literatura que suporta o achado são apresentados na tabela 4.10 .

O SDM ativou mais voxels como discriminantes que o SVM e o SPM, e tanto o SDM quanto o SVM (técnicas multivariadas) ativaram uma quantidade maior de voxels quando comparados com o SPM, como podemos observar na figura 4.9. A ativação de mais voxels se dá principalmente devido aos métodos multivariados trabalharam com a análise global das diferenças.

\subsection{Resultados para o Modelo de Risco de Demência}

O terceiro modelo de Risco de Demência foi avaliado por 3 especialistas utilizando uma base hipotética de 30 casos. Nessa avaliação foi medida o percentual de erros dos especialistas e a correlação de Spearman. 
Tabela 4.10: Regiões estatisticamente relevantes identificadas pelas análises dos modelos do SDM, SVM e pela análise univariada utilizando o SPM

\begin{tabular}{|c|c|c|c|c|}
\hline Regiões & $\begin{array}{c}\text { Tamanho } \\
\text { da Região SDM }\end{array}$ & $\begin{array}{c}\text { Tamanho } \\
\text { da Região SVM }\end{array}$ & $\begin{array}{c}\text { Tamanho } \\
\text { da Região SPM }\end{array}$ & $\begin{array}{l}\text { Referência na } \\
\text { Literatura }\end{array}$ \\
\hline Lobo Anterior & 8251 & 5196 & 6090 & [80-83] \\
\hline $\begin{array}{l}\text { Tonsila } \\
\text { Cerebelar }\end{array}$ & 4193 & 1111 & 0 & [84] \\
\hline Culmen & 6325 & 4049 & 0 & [81-83] \\
\hline Cuneus & 825 & 179 & 0 & [85-91] \\
\hline Declive & 5475 & 2943 & 0 & \multirow{2}{*}[82,90,92]{} \\
\hline $\begin{array}{l}\text { Declive de } \\
\text { Vermis }\end{array}$ & 173 & 120 & 0 & \\
\hline Extra-Nuclear & 10403 & 9011 & 0 & {$[80,90,93-95]$} \\
\hline $\begin{array}{l}\text { Giro Frontal } \\
\text { Inferior }\end{array}$ & 5587 & 3370 & 1348 & {$[83,84,91,94,96-99]$} \\
\hline $\begin{array}{l}\text { Giro Occipital } \\
\text { Inferior }\end{array}$ & 1758 & 1662 & 0 & [89] \\
\hline $\begin{array}{l}\text { Lobo Inferior } \\
\text { Semi Lunar }\end{array}$ & 1256 & 847 & 4410 & {$[52,70,80,100]$} \\
\hline Lobo Limbico & 17926 & 16547 & 3904 & {$[52,70,80,101-103]$} \\
\hline Giro Lingual & 4678 & 4681 & 355 & {$[89,90,97,104-106]$} \\
\hline Mesencefalo & 3513 & 1565 & 1032 & {$[107]$} \\
\hline $\begin{array}{l}\text { Giro occipital } \\
\text { médio }\end{array}$ & 5321 & 3986 & 1082 & {$[80,98,108,109]$} \\
\hline Nódulo & 179 & 58 & 0 & - \\
\hline Lobo Occipital & 21160 & 21982 & 6697 & {$[30,84,86,87,97,107,108]$} \\
\hline Giro Orbital & 212 & 0 & 984 & {$[52,70,80]$} \\
\hline $\begin{array}{l}\text { Lobo } \\
\text { Paracentral }\end{array}$ & 1763 & 2067 & 1399 & {$[101]$} \\
\hline $\begin{array}{l}\text { Giro } \\
\text { Parahipocampal }\end{array}$ & 5060 & 3417 & 0 & {$[80,101]$} \\
\hline $\begin{array}{l}\text { Giro } \\
\text { Pós-Central }\end{array}$ & 5865 & 5130 & 206 & {$[83,86,95,96,109,110]$} \\
\hline $\begin{array}{l}\text { Lobo } \\
\text { Posterior }\end{array}$ & 16824 & 7071 & 9943 & {$[80,82,84,90,92,95]$} \\
\hline Precuneus & 6913 & 10691 & 411 & {$[80,87,94,97,98]$} \\
\hline Pirâmide & 1918 & 691 & 25 & {$[88,96,109]$} \\
\hline $\begin{array}{l}\text { Pirâmide de } \\
\text { Vermis }\end{array}$ & 81 & 47 & 1043 & {$[70,80,101,110]$} \\
\hline Giro Rectal & 825 & 179 & 1346 & - \\
\hline $\begin{array}{l}\text { Giro } \\
\text { Subcalosal }\end{array}$ & 664 & 391 & 179 & {$[8,83,90,91]$} \\
\hline Lobo Parietal Superior & 1986 & 2106 & 0 & {$[7,80,89,96,98,106]$} \\
\hline $\begin{array}{l}\text { Giro Temporal } \\
\text { Superior }\end{array}$ & 8722 & 7199 & 57 & {$[84,87,88,92,96-98,105,109]$} \\
\hline Tuber & 2304 & 980 & 56 & - \\
\hline Uvula & 1283 & 293 & 3441 & {$[70,101]$} \\
\hline
\end{tabular}




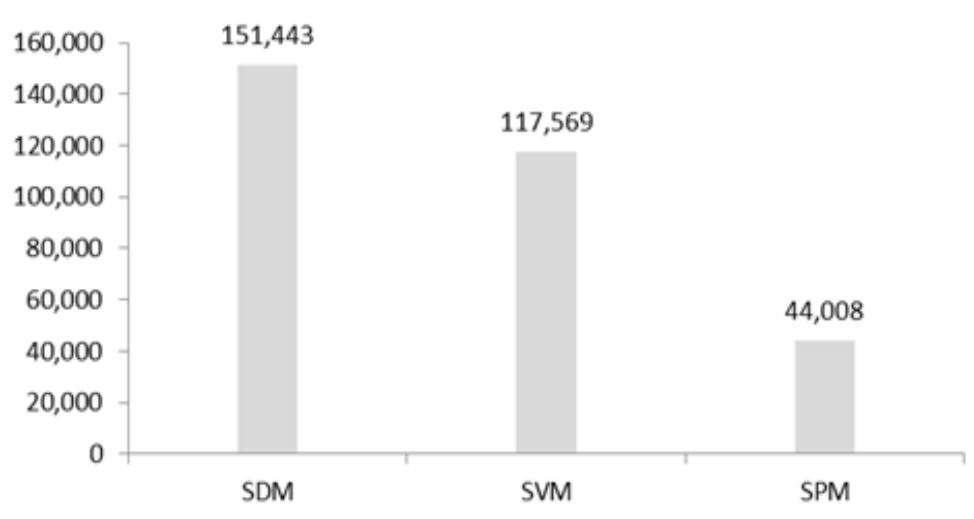

Figura 4.9: Quantidade total de voxels ativados nas técnicas do SDM, SVM e SPM

De forma análoga aos modelos anteriores foram estabelecidas notas de corte para definir os grupos com apoio dos especialistas do Proter/IPq-USP, basicamente definindo um corte clássico nas notas de 0 a 10 ao qual cada grupo pertence. Os grupos são especificados abaixo na tabela 4.11 .

Tabela 4.11: Definição dos intervalos dos grupos para o modelo de Risco de Demência.

\begin{tabular}{|c|c|c|}
\hline Intervalo & Grupo & Risco \\
\hline de 0 a 1,50 & Grupo 1 & Muito Baixo \\
\hline de 1,51 a 3,50 & Grupo 2 & Baixo \\
\hline de 3,51 a 6,0 & Grupo 3 & Moderado \\
\hline de 6,01 a 7,49 & Grupo 4 & Alto \\
\hline de 7,50 a 10,00 & Grupo 5 & Muito Alto \\
\hline
\end{tabular}

O Modelo foi testado por três especialistas e obtivemos 4 erros $(13,33 \%)$ para o especialista 1; 6 erros (20\%) para o especialista 2; e 5 erros $(16,67 \%)$ para o especialista 3. A tabela 4.12 apresenta os erros, acertos e o percentual de casos classificados incorretamente pelo modelos em relação aos três especialistas.

Tabela 4.12: Quantidade total de erros, acertos e percentual de erro do modelo de Risco de Demência em relação aos especialistas

\begin{tabular}{|l|c|c|c|}
\hline & Especialista 1 & Especialista 2 & Especialista 3 \\
\hline Erros & 4 & 6 & 5 \\
\hline Acertos & 26 & 24 & 25 \\
\hline$\%$ Erros & 13,33 & 20,00 & 16,67 \\
\hline
\end{tabular}


Para o modelo de risco não pode ser calculado o índice de concordância Kappa, pois as notas atribuídas pelo modelo não cobrem todos os grupos conforme podemos observar na figura 4.10, onde podemos ver uma concentração de notas na faixa de 6,00 a 9,00 pontos o que limita a avaliação de concordância.

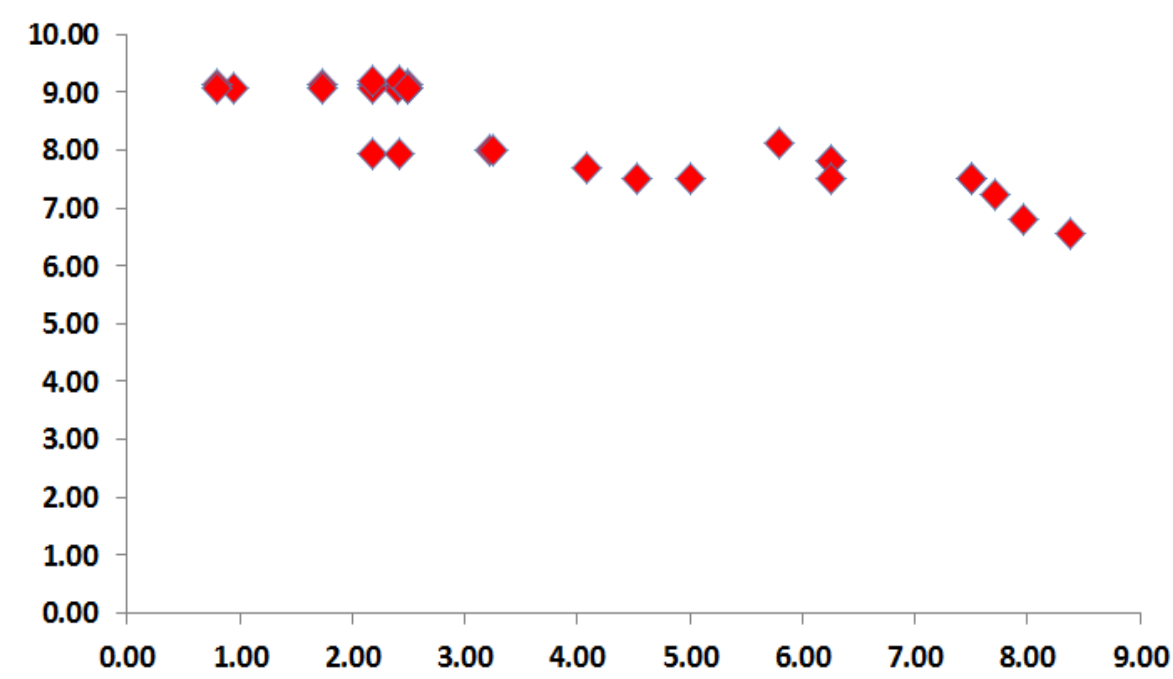

Figura 4.10: Espalhamento das notas do modelo de risco de demência. A concentração de notas do modelo abaixo de 6,50 pontos limita a avaliação de concordância Kappa

Entre os casos que possuem alguma discordância com o modelo apenas dois casos (caso 9 e caso 27) são totalmente discordantes. Os casos que tiveram alguma discordância com o modelo de risco de demência estão listados na tabela 4.13

Tabela 4.13: Casos discordantes entre especialistas e o modelo de Risco de Demência. O asterisco $\left({ }^{*}\right)$ marca os casos totalmente discordantes

\begin{tabular}{|l|c|c|c|c|c|c|c|c|}
\hline \multicolumn{1}{|c|}{ Item } & Caso 1 & Caso 3 & Caso 7 & Caso 8 & Caso 9 * & Caso 14 & Caso 19 & Caso 27* \\
\hline Nota Fatores de Risco & 31 & 12 & 20 & 15 & 11 & 13 & 20 & 12 \\
\hline Nota Fatores de Proteção & 0 & 5 & 2 & 3 & 3 & 3 & 5 & 4 \\
\hline Escore de Comp, Cognitivo & 6,25 & 7,71 & 6,25 & 7,97 & 7,50 & 3,22 & 5,79 & 8,38 \\
\hline Escore Risco de Demência & 7,82 & 7,22 & 7,82 & 6,80 & 7,50 & 8,01 & 8,12 & 6,55 \\
\hline Nota Especialista 1 & 9,23 & 7,58 & 7,36 & 6,15 & 0,55 & 7,36 & 6,15 & 2,75 \\
\hline Nota Especialista 2 & 7,40 & 6,56 & 8,33 & 5,31 & 0,52 & 9,06 & 8,44 & 4,06 \\
\hline Nota Especialista 3 & 9,23 & 7,69 & 7,47 & 6,15 & 2,86 & 7,91 & 6,15 & 2,86 \\
\hline Grupo Modelo & 5 & 4 & 5 & 4 & 5 & 5 & 5 & 4 \\
\hline Grupo Esp. \#1 & 5 & 5 & 4 & 4 & 1 & 4 & 4 & 2 \\
\hline Grupo Esp. \#2 & 4 & 4 & 5 & 3 & 1 & 5 & 5 & 3 \\
\hline Grupo Esp. \#3 & 5 & 5 & 4 & 4 & 2 & 5 & 4 & 2 \\
\hline
\end{tabular}




\subsubsection{Correlação das notas do modelo de risco de demência com}

\section{as notas dos especialistas}

Obtivemos uma correlação acima de 0,63 para o especialista 1 e 3, e 0,69 para o especialista 2. A tabela 4.14 apresenta a correlação de Spearman entre os especialistas e o modelo.

Tabela 4.14: Correlação de Spearman entre o modelo e os especialistas.

\begin{tabular}{|l|c|c|c|c|}
\hline \multicolumn{1}{|c|}{} & Modelo & Esp. 1 & Esp. 2 & Esp. 3 \\
\hline Modelo & 1 & 0,632 & 0,690 & 0,632 \\
\hline Especialista 1 & - & 1 & 0,792 & 0,991 \\
\hline Especialista 2 & - & - & 1 & 0,787 \\
\hline Especialista 3 & - & - & - & 1 \\
\hline
\end{tabular}

Novamente foi apurada a correlação e o índice de acertos da média da nota dos especialistas com o modelo. Obtivemos $13,33 \%$ de erro (4 erros), e uma correlação de Spearman entre a média das notas atribuídas pelos especialistas e o modelo de 0,688. A tabela 4.15 apresenta os casos que apresentam discordância com a média dos especialistas.

Tabela 4.15: Casos discordantes entre a média dos especialistas e o modelo

\begin{tabular}{|l|c|c|c|c|}
\hline \multicolumn{1}{|c|}{ Item } & Caso 8 & Caso 9* & Caso 19 & Caso 27* \\
\hline Nota dos Fatores de Risco & 15 & 11 & 20 & 12 \\
\hline Nota dos Fatores de Proteção & 3 & 3 & 5 & 4 \\
\hline Escore de Comprometimento Cognitivo & 7,97 & 7,50 & 5,79 & 8,38 \\
\hline Saida Modelo de Risco de Demência & 6,80 & 7,50 & 8,12 & 6,55 \\
\hline Nota Média dos Especialistas & 5,87 & 1,31 & 6,91 & 3,22 \\
\hline Classif. Modelo & 4 & 5 & 5 & 4 \\
\hline Classif. Nota Média Esp. & 3 & 1 & 4 & 2 \\
\hline
\end{tabular}




\section{Capítulo 5}

\section{Discussão}

A modelagem proposta para construção de um sistema de apoio ao diagnóstico de demência é composto pela integração de diferentes abordagens, e para essa finalidade foram desenvolvidos 3 modelos. O primeiro modelo de Comprometimento Cognitivo é baseado na teoria dos conjuntos fuzzy e integra três testes amplamente utilizados pelos especialistas: o Mini Exame do Estado Mental (MEEM); o teste do relógio; e o teste de fluência verbal.

Para decisão do tipo de demência foi desenvolvida um diagrama de decisão tipo árvore, baseada na experiência do médico e nos protocolos de diagnóstico, junto ao estudo de neuroimagens onde avaliamos técnicas de análise multivariadas e massivamente univarida.

Para avaliação do risco de desenvolvimento de demência foi proposto um modelo fuzzy levando em consideração uma série de informações, tanto de risco quanto de proteção, agregadas ao nível de comprometimento cognitivo.

Nos testes com a base hipotética para o modelo de comprometimento cognitivo obtivemos uma taxa de erro de $7,5 \%$ a $10 \%$, exceto pelo especialista 3 que teve $15 \%$, 
e apresentou um nível de concordância substancial (de 0,60-0,79) no índice Kappa. A análise de concordância Kappa requer que os pacientes sejam categorizados em grupos, porém a nota de corte, por melhor que seja, muitas vezes separa indivíduos com notas muito próximas em grupos distintos, aumentando a discordância entre os juízes. A correlação de Spearman entre as notas também foi significativa (o menor valor foi de 0,82 para o especialista 4), o que demonstra que quando consideramos os valores numéricos obtemos um nível maior de concordância com os especialistas. Isso se dá devido a natureza contínua do fenômeno, ou seja, o declínio no comprometimento cognitivo é percebido continuamente.

Esse modelo quando testado em uma base de dados real, comparado com os resultados do CDR, apresentou resultados bem próximos ao teste com a base hipotética, com uma taxa de erro de 13\% (8 erros) e um índice Kappa de concordância substancial (entre 0,60 e 0,79$)$.

Existe uma faixa de valores de saída do modelo de Comprometimento Cognitivo onde a escolaridade passa a ser importante. De fato, é sabido que a escolaridade afeta o desempenho em testes cognitivos [58], porém quando os valores de saída são baixos ou altos a escolaridade não é tão relevante quanto quando temos valores intermediários.

Percebemos isso claramente nos gráficos de espalhamento das figuras 4.1 e 4.2 onde as notas de comprometimento cognitivo dos casos classificados incorretamente estavam no intervalo definido pelos especialistas. Portanto para escores de comprometimento cognitivo altos ou baixos não há necessidade de avaliação da escolaridade. Entretanto, quando os valores estão no intervalo de 5,50 a 7,50 pontos a escolaridade deve ser avaliada, em conjunto com as notas do modelo, visando uma decisão mais acurada em relação ao comprometimento cognitivo. 
Os resultados obtidos foram bons, apontando para a possibilidade deste modelo de comprometimento cognitivo ser utilizado tanto no treinamento dos especialistas como em triagens de pacientes, funcionando como um sistema de apoio a decisão médica.

O segundo modelo, de decisão de tipo de demência, foi criado utilizando um diagrama de decisão com base em entrevistas realizadas com os especialistas e em protocolos de diagnóstico. Para esse modelo foram realizados os testes dos caminhos de decisão por três especialistas e obtivemos bons resultados com os percentuais de erros para o especialista 1 de 2,0\%, para o especialista 2 de $18,36 \%$ e para o especialista 3 de $14,2 \%$.

Apesar do especialista 2 apresentar uma taxa de erro mais alta, mais da metade dos casos (6 erros) foram causados pela opção de outras causas de demência, enquanto três erros causados por escolhas de diagnóstico incorreto. Por outro lado, o especialista 3 em dois casos não optou por investigar outras causas e em três casos não optou pela demência mista (DFT + DV). É esperado que quanto mais experiente for o especialista, mais seguro ele será para decidir por um diagnóstico possível. Por outro lado, quanto menos experiente ele for mais facilmente ele optará por continuar investigando o caso, buscando mais informações que lhe confiram segurança na sua tomada de decisão. Contudo, o modelo precisa ainda ser refinado, adicionando se necessário outras informações que possam sustentar melhor a decisão dos especialistas.

Muitos nós do diagrama de decisão requerem a avaliação de um exame de neuroimagem. Não foi foco desse trabalho um estudo mais profundo de técnicas de análise de imagens, porém, do aqui apresentado, vemos que a possibilidade de integrar o modelo de tipo de demência a um procedimento automatizado de técnicas de análise de neuroimagens consiste ainda em importante desafio, particularmente quando 
o objetivo é utilizar o modelo de suporte ao diagnóstico em tempo real nos ambulatórios. Estudos de avaliação de neuroimagens têm sido publicados com objetivo de classificar as neuroimagens em grupos e identificar regiões discriminantes. Entretanto apesar da importância da neuroimagem no apoio ao diagnóstico de demências, sabemos que as neuroimagens são um complemento importante para o diagnóstico mas não condição suficiente para defini-lo.

Este foi um ponto amplamente discutido durante as entrevistas com os especialistas, e por várias vezes foi reforçado que a inexistência de uma imagem que corrobore o diagnóstico não altera a conduta terapêutica indicada para o paciente. Da mesma forma, a existência de uma imagem que indique alguma alteração morfológica despercebida nos testes clínicos não deve influenciar totalmente o diagnóstico.

A idéia inicial durante o desenvolvimento do modelo de tipo de demência era propor uma integração total de uma técnica de análise de neuroimagem com os modelos. Entretanto percebemos que durante a consulta, quando em poder do exame de neuroimagem, o médico procura por alterações específicas que indiquem uma imagem característica de determinada demência, que possa corroborar com sua hipótese diagnóstica ou levá-lo a outra hipótese.

Essa característica do atendimento torna difícil a concepção de modelos integrados com técnicas complexas de análise de neuroimagem, por exemplo, durante um atendimento ambulatorial. Como o objetivo deste trabalho foi criar um modelo que possa ser desenvolvido e utilizado em ambulatório, a integração de um modelo complexo de análise de neuroimagens pode não ser viável ainda.

Entretanto as técnicas de analise de neuroimagem podem ser utilizadas em um momento posterior ao atendimento, para identificação de alterações morfológicas. Os 
classificadores multivariados podem ser utilizados para acompanhar a evolução do paciente com o objetivo de predição da ocorrência de demência ou de seguimento do paciente no contexto de progressão clínica da doença.

No que tange a identificação de regiões discriminantes, tanto as técnicas multivariadas quanto a análise massivamente univariada identificaram regiões com correspondência na literatura, porém as técnicas multivariadas do SDM e o SVM ativaram mais voxels em relação a análise massivamente univariada, isso se dá basicamente devido a técnicas multivariadas avaliarem toda a imagem e não voxels isoladamente. Sendo o cérebro uma estrutura complexa, o aumento ou diminuição em determinadas regiões pode influenciar diretamente em outras regiões durante a evolução da patologia. Assim, as técnicas multivariadas se mostram uma alternativa viável para uma análise global dos efeitos de doenças que tem alterações globais como Alzheimer, por exemplo.

A característica de maximizar as diferenças para realizar a classificação permitiu que o SDM encontre mais regiões discriminantes como observamos na imagem 4.7. A maximização das diferenças entre os grupos também permitiu que o SDM encontrasse nos testes realizados neste trabalho os melhores valores de acurácia com alta sensibilidade e especificidade em relação ao classificador multivariado do SVM, bem como uma melhor classificação dos indicadores clínicos [6, 49, 53].

Os modelos de análise multimodal podem realizar a classificação considerando indicadores clínicos. Esses modelos têm sido propostos com objetivo de identificar a tendência do paciente desenvolver ou não demência (especificamente DA) [111]. Esses trabalhos levam em consideração biomarcadores, como beta-amilóide e tau, para predição da evolução da patologia. Apesar do bom índice de conversão apresentado pelos biomarcadores em análises multimodais [112], a utilização desses dados requer a 
realização de exames específicos e nem sempre acessíveis a maioria da população e não consideram fatores de risco comumente avaliados pelo médicos e listados em estudos de risco de demência, como o CAIDE $[75,113]$

No decorrer do trabalho, sentimos a necessidade de elaborar um modelo que auxiliasse na avaliação e seguimento de pacientes que não foram classificados com demência, mas que por algum motivo chegaram ao ambulatório de psiquiatria. Esses dados foram utilizados na criação do modelo de risco de demência, que integra os fatores de risco, proteção e comprometimento cognitivo, tendo como resultado um escore único que possa representar o risco de desenvolvimento da doença. Esse tipo de abordagem também pode ser util para averiguação de risco de pacientes em consultórios geriatricos.

Podemos citar como exemplo de um escore para risco de desenvolvimento de demência o CAIDE $[75,113]$. O CAIDE criado pelo consorcio entre a University of Eastern Finland, o The National Institute of Health and Welfare e o Aging Research Center - Karolinska Institutet e foi desenvolvido com base em um estudo com 1449 indivíduos examinados na meia idade e reexaminados após 20 anos. Neste estudo uma série de fatores de risco e proteção foram apontados, como listado na tabela 5.1. Esses fatores estão em concordância com os levantados neste trabalho como vemos na tabela 3.2.

Tabela 5.1: Fatores de Risco e proteção do CAID

\begin{tabular}{|l|l|}
\hline \multicolumn{1}{|c|}{ Fatores de Risco } & \multicolumn{1}{c|}{ Fatores de Proteção } \\
\hline Hipertensão & Alta Educação \\
\hline Hipercolesterolemia & Atividades Fisicas \\
\hline Obesidade & Atividades Sociais \\
\hline Diabetes Mellitus & Dieta livre de Gorduras Saturadas \\
\hline Gorduras Saturadas na Dieta & Café \\
\hline Consumo de Álcool em Excesso & Estatinas \\
\hline Homocisteina & \\
\hline Fumo & \\
\hline Doenças Respiratórias & \\
\hline
\end{tabular}


Foram publicados alguns estudos de predição e risco de demência com base no CAIDE, associando o risco de demência ao diabetes [113] e risco vasculares [114]. O Estudo publicado por Kim et al. [115] conclui que o escore pode predizer de forma significativa a demência com base na Idade, baixa educação, hipertensão, hipercolesterolêmia e obesidade.

Entretanto, as relações entre os fatores de risco e a evolução da demência é tipicamente fuzzy, e muitas vezes não se pode afirmar uma relação direta entre fatores de risco e a ocorrência de demência, como o estudo publicado por Kivipelto et al. [75] que indica que baixos níveis de colesterol sérico podem ser marcadores de Alzheimer; e o estudo publicado por Crane et al. [116] que indica a correlação entre níveis de açúcar e demência mesmo em indivíduos sem diabetes.

O modelo de risco de demência foi desenvolvido com base em um escore de risco, um escore de proteção e o escore de comprometimento cognitivo. O modelo foi criado através de entrevistas com os especialistas e como resultado obtivemos apenas uma variação de 4 a 6 casos discordantes do modelo, sendo apenas 2 casos em total discordância. Entretanto não foi possível realizar uma analise de desempenho do modelo devido a ausência de um banco de dados com casos reais e com diagnóstico fechado da doença.

Uma limitação quando observamos os resultados do modelo de Risco de Demência é o fato dos escores resultantes da base hipotética terem se concentrado acima do valor 6,5. Isso ocorreu apesar dos valores das variáveis do modelo - fatores de risco, de proteção e escore de comprometimento cognitivo, terem coberto todo o espaço de medidas da entrada. De fato é complexo criar um banco de dados hipotético que cubra todo o espaço de saída quando este depende de variáveis que passam por um processo de 
inferência, como é o caso deste modelo. Ainda podemos citar o fato de que o objetivo do modelo é ser utilizado para seguimento do paciente e mensuração de risco, o que implica que dificilmente teríamos um indivíduo real sem nenhum fator de risco associado. Assim entendemos que apesar da concentração de notas acima de 6,50 o modelo foi submetido a um teste próximo da realidade de um ambulatório. Porém, é importante ressaltar que este modelo carece ainda de refinamento e de análise de performance a partir de um banco de dados real.

A ausência de base completa de dados foi uma das principais dificuldades encontradas no desenvolvimento deste trabalho. Para os testes dos primeiro modelo contamos com uma base de dados real do Proter/IPq-USP que permitiu maior acurácia nos resultados e uma análise mais assertiva, principalmente para identificar a escolaridade como uma variável de confusão do modelo.

Para a árvore de decisão de tipo de demência também não foi possível realizar análises com uma base real. Entretanto para as análises de neuroimagem de DA foi possível utilizar os bancos de dados do ADNI, OASIS e do Hospital das Clínicas.

O modelo de risco de demência também não pode ser avaliado com uma base de dados real. Este modelo apresenta um grande potencial de ser refinado, podendo ser incrementado a partir de estudos de meta-análise e acompanhamento dos pacientes.

A implementação desses modelos em um sistema computacional permitirá a utilização destes na rotina ambulatorial, o que pode auxiliar na elaboração de um banco de dados com as características necessárias para os aprimoramentos aqui apontados, bem como fornecer subsídios para estudos futuros. 


\section{Capítulo 6}

\section{Conclusão}

Neste trabalho nos propomos a criação de modelos matemáticos que possam auxiliar o especialista médico no diagnóstico de demências. A abordagem de utilizar mais de um tipo de modelo (modelos linguísticos fuzzy tipo Mamdani e um diagrama de decisão) é devido a característica do processo de diagnóstico, que passa pela avaliação do domínio cognitivo, pela identificação do tipo de demência e pelo mapeamento de fatores de risco e proteção que possam levar ao aparecimento da doença.

A escolha de uma abordagem utilizando modelos linguísticos fuzzy do tipo Mamdani se mostrou adequada para o tratamento de incertezas de identificação de compromentimento cognitivo. O modelo de Compromentimento Cognitivo se baseou nos testes comumente utilizados pelos médicos e obteve bons resultados, o que permite que o modelo seja implementado e utilizado em atendimentos ambulatoriais.

Para identificação do tipo de demência optamos pela criação de um diagrama de decisão. Este modelo de Decisão de Tipo de Demência apresentou resultados promissores, e sua utilização nos atendimentos ambulatoriais permitirá o seu aprimoramento. 
O modelo linguístico fuzzy para avaliar o Risco de Demência, trouxe uma abordagem diferente das publicadas até então para avaliar fatores de risco e proteção. As abordagens de mensuração de risco geralmente se dão por um escore de risco como o CAIDE $[75,113]$ ou com base em exames de neuroimagem [117]. Propomos neste modelo avaliar os fatores de risco e proteção comumente avaliados pelos médicos em conjunto com o nível de comprometimento cognitivo, gerando uma saída que indique o risco do indivíduo desenvolver demência no futuro. Obtivemos nesse modelo resultados promissores no que tange ao índice de erros e correlação de Spearman entre as notas do modelo e especialistas, porém o modelo precisa ser refinado para atingir um nível maior de concordância com os especialistas.

Inicialmente a idéia deste trabalho era propor modelos de apoio ao diagnóstico completamente integrado a técnicas de análise de neuroimagem. Entretanto durante o desenvolvimento dos modelos percebemos uma dificuldade em integrar modelos que devem apoiar uma rotina dinâmica de atendimento ambulatorial com análises complexas de neuroimagem. Assim, os exames de neuroimagem conservam sua importância para o diagnóstico, mas a utilização das técnicas de análise de neuroimagem, mesmo que por um sistema, parecem distante da realidade do médico que realiza um atendimento ambulatorial. Esta observação não descarta o uso de análises de neuroimagem no processo de diagnóstico, porém limita seu uso para um momento posterior ao atendimento. Sendo assim, as avaliações de neuroimagem podem fornecer uma importante visão da evolução do paciente.

As técnicas avaliadas foram ao encontro dos resultados descritos na literatura, porém as técnicas multivariadas, além de ativar mais regiões discriminantes por avaliarem toda a imagem, contam com classificadores estatísticos que podem ser utilizados em 
conjunto com dados clínicos tornando a análise mais efetiva. Esses classificadores podem inclusive trabalhar com notas de risco atribuídas a neuroimagens criando um sistema de classificação multimodal, que pode ser um caminho promissor a ser seguido.

A principal dificuldade encontrada foi a ausência de base de dados reais adequada aos modelos, por esse motivo, dois modelos foram testados com uma base hipotética.

Essas considerações nos abrem algumas possibilidades de trabalho futuros:

\section{Implementação computacional dos modelos.}

Desenvolver computacionalmente e implantar os modelos para uso no PROTER/IPqUSP, ou qualquer outro setor de triagens psiquiátricas.

\section{Testes e validações dos modelos com base de dados real.}

Com a implementação dos sistemas em um processo de apoio ao diagnóstico pode-se alimentar uma base de dados estruturada que pode ser utilizada para refinamento dos modelos com dados reais.

3. Análise multimodal baseado em neuroimagens e no modelo de risco de desenvolver demência.

Integrar dados dos classificadores estatísticos utilizados em técnicas de analise de neuroimagem pode aprimorar o escore de risco de desenvolvimento de demência, por exemplo, os escores de risco de demência pode compor a classificação do hiperplano de separação das imagens $[111,112]$, ou mesmo o valor discriminante da neuroimagem estar associada a uma medida de risco para compor o valor da nota de fatores de risco.

\section{4. Árvore de decisão paraconsistente.}

A lógica paraconsistente anotada (LPA), permite que proposições sejam acompa- 
nhadas de uma pontuação entre 0 e 1 que expressa o grau de crença e descrença na proposição. Os modelos baseados em lógica paraconsistente tem sido utilizados em sistemas de diagnóstico assistido $[9-11,118]$ e seu uso é possível em uma estrutura de árvore de decisão atribuindo graus de crença e descrença para cada nó da árvore. Esse certamente seria um bom aprimoramento do modelo elaborado. 


\section{Referências Bibliográficas}

[1] American Psychiatric Association. Diagnostic and statistical manual of mental disorders. Technical report, American Psychiatric Association., 2000.

[2] Massad E, Burattini MN, Coutinho FAB, Struchiner CJ. A fuzzy model in HIV/AIDS epidemiology: Predicting the clinical course basing on HIV viral load. In Proceedings of Soft Computing SOCO, 1997.

[3] Ortega NRS. Aplicação da Teoria de Conjuntos Fuzzy a Problemas da Biomedicina. PhD thesis, Instituto de Física da Universidade São Paulo, 2001.

[4] Lopes WA, Barros LC. Modelagem fuzzy de diagnóstico médico e monitoramento do tratamento da pneumonia. Biomatemática, 15:77-96, 2005.

[5] Tanaka, H. Estudo da perfusão e ventilação pulmonar em imagens de tomografia de impedância elétrica através de modelagem fuzzy. PhD thesis, Faculdade de Medicina da Universidade de São Paulo, 2007.

[6] Santos PE, Thomaz CE, Nunes dos Santos D, Freire R, Sato JR, Louzã M, Sallet P, Busatto G, Gattaz WF. Exploring the knowledge contained in neuroimages: Statistical discriminant analysis and automatic segmentation of the most significant changes. Artificial Intelligence in Medicine, 49:105 115, 2010. 
[7] Sato JR, Thomaz CE, Cardoso EF, Fujita A, Martin G, Amaro E. Hyperplane navigation: a method to set individual scores in fMRI group datasets. Neuroimage, 42(4):1473-80, 2008.

[8] Sato JR, Fujita A, Thomaz CE, Martin MGM, Mourão-Miranda J, Brammer MJ, Junior EA. Evaluating SVM and MLDA in the extraction of discriminant regions for mental state prediction. Neurolmage, 46:105114, 2009.

[9] Filho JIS, Holms G, Hurtado GV, Garcia DV. Analysis and diagnosis of cardiovascular diseases through the paraconsistent annotated logic. Studies in Computational Intelligence, 199:295-303, 2009.

[10] ABE JM, Nakamatsu K. Paraconsistent artificial neural networks and pattern recognition: Speech production recognition and cephalometric analysis. Intelligent Systems Reference Library, 29:365-382, 2012.

[11] ABE JM, LOPES HFS, Nakamatsu K . Improving EEG analysis by using paraconsistent artificial neural networks. Knowledge-Based Intelligent Information and Engineering Systems, 5178:466-473, 2008.

[12] Nunes dos Santos D, Thomaz CE, Sato JR, Louzã P, Sallet PC, Busatto G Santos PE, Freire R. Qualitative Spatio-Temporal Representation and Reasoning: Trends and Future Directions. IGI GLOBAL, 2011.

[13] Shen D,Wee Chong-Yaw , Zhang D, Zhou L, Yap Pew-Thian,. Machine learning techniques for ad/mci diagnosis and prognosis. Machine Learning in Healthcare Informatics, 56:147-179, 2014. 
[14] Lindgren H. DMSS a Dementia Management and Support System for providing Tailored Advice in the Dementia Workup. Technical report, UMINF - Umeå University, Sweden, 2010.

[15] Hibino S Nagata E, Matsubara M, Fukagawa K, Shirataki T, Honda H, Kobaiashi T. Fuzzy neural network model for assessment of alzheimer-type dementia. Journal of Chemical Engeneering of Japan, 34:936-942, 2001.

[16] Cho Po-Chuan, Chen Wen-Hui. A double layer dementia diagnosis system using machine learning techniques. Engineering Applications of Neural Networks, 311:402-412, 2012.

[17] Obi JC, Imainvan AA. Decision support system for the intelligent identification of alzheimer using neuro fuzzy logic. International Journal on Soft Computing, 2:25-38, 2011.

[18] Blay SL, Laks J, Bottino CMC. Demência e transtornos congnitivos em idosos. Guanabara Koogan, 2006.

[19] Filho GB. Fisiopatologia dos Transtornos Psiquiátricos. Atheneu, 2007.

[20] Bottino CMC, Cid CG, Camargo CHP. Depressão e Demência no Idoso Tratamento Psicológico e Farmacológico, chapter Avaliação Neuropsicológica, pages 121-140. Lemos Editorial, 1997.

[21] Aprahamian I, Martinelli JE, Yassuda MS. Doença de alzheimer: revisão da epidemiologia e diagnóstico. Rev Bras Clin Med, 7:27:35, 2009.

[22] Alzheimers Disease International. Relatório sobre a doença de Alzheimer no mundo. Technical report, Alzheimers Disease International, 2009. 
[23] Maurer K, Volk S, Gerbaldo H. Auguste D and alzheimers disease. The Lancet, 349:1546-1549, 1997.

[24] Petersen R. Guia da Clínica Mayo sobre o Mal de Alzheimer. Anima, 2006.

[25] Herrera Jr E, Caramelli P, Silveira ASB, Nitrini R. Epidemiologic survey of dementia in a community-dwelling brazilian population. Alzheimers Disease \& Associated Disordes, 16:103-108, 2002.

[26] World Health Organization. Clinical descriptions and diagnostic guidelines. Technical report, World Health Organization, 2012.

[27] McKhann G, Drachman D, Folstein M, Katzman R, Price D, Stadlan EM. Clinical diagnosis of Alzheimer's disease: report of the NINCDS-ADRDA work group under the auspices of department of health and human services task force on Alzheimer's disease. Neurology, 34 (7):939-44, 1984.

[28] Nitrini R, Caramelli P, Bottino CMC, Damasceno BP, Brucki SMD, Anghinah R. Diagnóstico da doença de alzheimer no brasil. Arq Neuropsiquiatr, 63(3-A):713719,2005

[29] Ministério da Saude. Envelhecimento e saúde da pessoa idosa.

[30] Forlenza OV, Diniz BS, Gattaz WF. Diagnosis and biomarkers of predementia in Alzheimers disease. BMC Medicine, 8:89, 2010.

[31] Pantoni L, Inzitari D. Hachinski's ischemic score and the diagnosis of vascular dementia: a review. Ital J Neurol Sci., 14(7):539-46, 1993. 
[32] O'Brien JT, Erkinjuntti T, Reisberg B, Roman G, Sawada T, Pantoni L, Bowler JV, Ballard C, DeCarli C, Gorelick PB, Rockwood K, Burns A, Gauthier S , DeKoskyl STO'Brien JT, Erkinjuntti T, Reisberg B , Roman G , Sawada T , Pantoni L, Bowler JV, Ballard C, DeCarli C, Gorelick PB, Rockwood K, Burns A, Gauthier S, DeKoskyl ST. Vascular cognitive impairment. The Lancet Neurology, $2: 89-98,2003$.

[33] Caixeta, L. Demência frontotemporal subdiagnosticada. Arq. Neuro-Psiquiatr, 63( 1 ):186-186, 2005.

[34] Pasquier F. New behavioural variant FTD criteria and clinical practice. Rev Neurol (Paris)., 169(10):799-805, 2013.

[35] Konenko, I. Machine learning for medical diagnosis: History, state of the art and perspective. Artificial Intelligence in Medicine, 23(1):89-109, 2001.

[36] Sim I, Gorman P, Greenes RA, Haynes RB, Kaplan B, Lehmann B, Tang PC. Clinical decision support systems for the practice of evidence-based medicine. $J$ Am Med Inform Assoc, 8(6):527534, 2001.

[37] Silva R. LEPIDUS: Sistema especialista em medicina geral. PhD thesis, Faculdade de Filosofia, Ciencias e Letras de Ribeirão Preto - Universidade de São Paulo, 2001.

[38] Ortega NRS. Teoria dos conjuntos fuzzy em saúde: Desenvolvimento de sistemas e tomada de decisão, 2010.

[39] Peña-Reyes CA. Evolutionary fuzzy modeling human diagnostic decisions. Ann N Y Acad Sci., 1090:190-211., 2004. 
[40] Zadeh LA. Fuzzy sets. Information and Control, 8:338-353, 1965.

[41] Barros LC, Bassanezi RC. Tópicos de Lógica Fuzzy e Biomatemática. IMECC, 2010.

[42] Massad E, Ortega NRS, de Barros LC, Struchiner CJ. Fuzzy Logic in Action: Applications in Epidemiology and Beyond. Springer-Verlag, 2008.

[43] Wetherell JL, Jeste DV. Diagnostic decision tree in dementia. Dialogues Clin Neurosci., 5(1):4447, 2003.

[44] Knopman DS,Boeve BF, Petersen RC. Essentials of the proper diagnoses of mild cognitive impairment, dementia, and major subtypes of dementia. Mayo Clin Proc, 78:1290-308, 2003.

[45] Desikan RS, Cabral HJ, Settecase F, Hess CP, Dillon WP, Glastonbury CM, Weiner MW, Schmansky NJ, Salat DH, Fischl B, Alzheimer's Disease Neuroimaging Initiative. Automated MRI measures predict progression to Alzheimers disease. Neurobiol Aging, Aug,31(8):1364-74, 2010.

[46] Friston KJ, Holmes AP, Worsley KJ, Poline JB, Frith C, Frackowiak RSJ. Statistical parametric maps in functional imaging: A general linear approach. Human Brain Mapping, 2:189210, 1995.

[47] Ashburner J, Friston KJ. Comments and controversies: Why voxel based morphometry should be used. Neurolmage, 14:12381243, 2001.

[48] Friston KJ, Ashburner J, Mechelli A, Price CJ. Voxel-based morphometry of the human brain: Methods and applications. Current Medical Imaging Reviews, 1:105 113, 2005. 
[49] Kasparek T, Thomaz CE, Sato JR, Schwarz D, Janousova E, Marecek R, Prikryl R, Vanicek J, Fujita A, Ceskova E. Maximum-uncertainty linear discrimination analysis of first-episode schizophrenia subjects. Psychiatry Research: Neuroimaging, 191:174181, 2011.

[50] Vapnik VN. Statistical learning theory. Wiley, 1998.

[51] Mourão-Miranda J, Reinders AATS, Rocha-Rego V, Lappin J, Rondina J, Morgan C, Morgan KD, Fearon P, Jones PB, Doody GA, Murray RM, Kapur S, Dazzan P. Individualized prediction of illness course at the first psychotic episode: a support vector machine MRI study. Psychol Med, 42(5):10371047, 2012.

[52] Cuingnet R, Gerardin E, Tessieras J, Auzias G, Lehéricy S, Habert MO, Chupin M, Benali H, Colliot O, Alzheimer's Disease Neuroimaging Initiative. Automatic classification of patients with alzheimer's disease from structural MRI: a comparison of ten methods using the ADNI database. Neuroimage, 56(2):766-81, 2011.

[53] Thomaz CE, Kitani EC, GILLIES DF. A maximum uncertainty lda-based approach for limited sample size problems - with application to face recognition. Journal of the Brazilian Computer Society, 12:7-18, 2006.

[54] Gallucci NJ, Tamellini MG, Forlenza OV. Diagnóstico diferencial das demências. Rev Psiq Clín, 32(3):119-30, 2005.

[55] Taveira A, Azevedo AP, Sougey EB. Pseudo-pseudodemência. Rev Psiq Clín, 28(3), 2001. 
[56] Yesavage JA, Brink TL, Rose TL, Lum O, Huang V, Adey M, Leirer VO. Development and validation of a geriatric depression screening scale. J Psychiatr Res., 17(1):37-49, 1982-1983.

[57] Folstein MF, Folstein SE, McHugh PR. Mini- Mental State: a practical method for grading the cognitive state of patients for the clinician. J Psychiatr Res, 12:189-198, 1975.

[58] Chaves MLF. Testes de avaliação cognitiva: Mini-exame do estado mental neurologia cognitiva e do envelhecimento da ABN, 2006-2008.

[59] Shulman KI. Clock-drawing: is it the ideal cognitive screening test ? Int J Geriatr Psychiatry, 15:548-561, 2005.

[60] Nitrini R, Lefévre B, Mathias S, Caramelli P, Carrilho PE, Sauaia N, Massad E, Takiguti C, Silva IO, Porto CS, Magila MC, Scaff M. Testes neuropsicológicos de aplicação simples para o diagnostico de demência. Arq Neuropsiquiatr, 52(4):457465, 1994.

[61] Pinto E,Peters R. Literature review of the clock drawing test as a tool for cognitive screening. Dement Geriatr Cogn Disord, 27:201-213, 2009.

[62] Sunderland T, Hill JL, Mellow AM, Lawlor BA, Gundersheimer J, Newhouse PA, Grafman JH. Clock drawing in Alzheimer's disease. a novel measure of dementia severity. J Am Geriatr Soc., 37(8):725-729., 1989.

[63] Borson S, Brush M, Gil E, Scanlan J, Vitalino P, Chen J, Cashman J, Sta Maria MM, Barnhart R, Roques J. The clock drawing test: utility for dementia detection in multiethnic elders. J Gerontol Med Sci, 54(11):M534-40, 1999. 
[64] Hollveg P, Hamdan AC. Avaliação neuropsicológica em idosos. RBCEH, Passo Fundo, 5(2):110-123, 2008.

[65] Haves MLF, Godinho CC, Porto CS, Mansur L, Carthery-Goulart MT, Yassuda MS, Beato R. Doença de alzheimer - avaliação cognitiva, comportamental e funcional. Dement Neuropsychol, 5:21-33, 2011.

[66] Dozzibruki SM,Malheiros SMF, Okamoto IH, Bertolucci PHF,. Dados normativos para o teste de fluência verbal categoria animais em nosso meio. Arq. Neuropsiquiatr, 55(1):56-61, 1997.

[67] Silva TBL, Yassuda MS, Guimarães VV, Florindo AA. Fluência verbal e variáveis sociodemográficas no processo de envelhecimento: um estudo epidemiológico. Psicol. Reflex., 24(4), 2011.

[68] Rodrigues AB, Yamashita ET, Chiappetta ALML. Teste de fluência verbal no adulto e no idoso: Verificação da aprendizagem verbal. Rev CEFAC, 10(4):443451, 2008.

[69] Santos AA, Pavarini SCI. Funcionalidade de idosos com alterações cognitivas em diferentes contextos de vulnerabilidade social. Acta Paul Enferm, 24(4):520-6, 2011.

[70] Almeida OA, Castro CC, Camargo CHP, Cid CG, Buchpiguel CA, Furuie S, Bottino CMC, Busatto GF, Garrido GEJ . A voxel-based morphometry study of temporal lobe gray matter reductions in Alzheimers disease. Neurobiology of Aging, 2:22131, 2003. 
[71] Karas GB, Burton EJ, Rombouts SA, van Schijndel RA, O'Brien JT, Scheltens Ph, McKeith IG, Williams D, Ballard C, Barkhof F. A comprehensive study of gray matter loss in patients with alzheimers disease using optimized voxel-based morphometry. Neurolmage, 18(4)::895 907, 2003.

[72] Karas GB, Scheltens P, Rombouts SA, Visser PJ, van Schijndel RA, Fox NC, Barkhof F. Global and local gray matter loss in mild cognitive impairment and alzheimers disease. Neurolmage, 23(2)::708 716, 2004.

[73] Kawachi T, Ishii K, Sakamoto S, Sasaki M, Mori T, Yamashita F, Matsuda H, Mori E. Comparison of the diagnostic performance of FDG-PET and VBM-MRI in very mild Alzheimers disease. European Journal of Nuclear Medicine and Molecular Imaging, 7:801 809, 2006.

[74] Duran FL, Zampieri FG, Bottino CC, Buchpiguel CA, Busatto GF. Voxel-based investigations of regional cerebral blood ow abnormalities in alzheimers disease using a single-detector spect system. Clinics, 62:377 384, 2007.

[75] Kivipelto M, Ngandu T, Laatikainen T, Winblad B, Soininen H, Tuomilehto J. Risk score for the prediction of dementia risk in 20 years among middle aged people: a longitudinal, population-based study. Lancet Neurol, 5(9):735-41, 2006.

[76] Lansing RW, Moosavi SH, Banzett RB. Measurement of dyspnea: word labeled visual analog scale vs. verbal ordinal scale. Respir Physiol Neurobiol, 134(2):77-83, 2003.

[77] Scott J, Huskisson EC. Graphic representation of pain. Pain, 2(2):175-84, 1976. 
[78] Aisen PS Beckett LA Cairns NJ Green RC Harvey D Jack CR Jagust W Liu E Morris JC Petersen RC Saykin AJ Schmidt ME Shaw L Siuciak JA Soares H Toga AW Trojanowski JQ; Alzheimers Disease Neuroimaging Initiative. Weiner MW, Veitch DP. The alzheimers disease neuroimaging initiative: a review of papers published since its inception. Elsevier, 8:S1S68, 2012.

[79] Marcus DS, Wang TH, Parker J, Csernansky JG, Morris JC, Buckner RL. Open access series of imaging studies (OASIS): cross-sectional MRI data in young, middle aged, nondemented, and demented older adults. J Cogn Neurosci, 19(9):1498507, 2007.

[80] Schwindt GC, Black SE. Functional imaging studies of episodic memory in Alzheimer's disease: a quantitative meta-analysis. Neuroimage, 45(1):181-90, 2009.

[81] Brambati SM, Ogar J, Neuhaus J, Miller BL, Gorno-Tempini ML. Reading disorders in primary progressive aphasia: a behavioral and neuroimaging study. Neuropsychologia, 47(8-9):1893-900, 2009.

[82] Raji CA, Lopez OL, Kuller LH, Carmichael OT, Becker JT. Age, Alzheimer disease, and brain structure. Neurology, 73(22):1899-905, 2009.

[83] Sabbagh MN Baxter LC, Sparks DL, Johnson SC, Lenoski B, Lopez JE, Connor DJ. Relationship of cognitive measures and gray and white matter in Alzheimer's disease. J Alzheimers Dis., 9(3):253-60, 2006. 
[84] Hoefer M, Allison SC, Schauer GF, Neuhaus JM, Hall J, Dang JN, Weiner MW, Miller BL, Rosen HJ. Fear conditioning in frontotemporal lobar degeneration and Alzheimer's disease. Brain., 131(Pt 6):131(Pt 6), 2008.

[85] Buck BH, Black SE, Behrmann M, Caldwell C, Bronskill MJ. Spatial- and objectbased attentional deficits in alzheimer's disease. relationship to HMPAO-SPECT measures of parietal perfusion. Brain, 120 Pt.7:1229-44, 1997.

[86] Sydykova D, Stahl R, Dietrich O, Ewers M, Reiser MF, Schoenberg SO, Möller HJ, Hampel H, Teipel SJ. Fiber connections between the cerebral cortex and the corpus callosum in Alzheimer's disease: a diffusion tensor imaging and voxel-based morphometry study. Cereb Cortex., 17(10):2276-82, 2007.

[87] Zahn R, Buechert M, Overmans J, Talazko J, Specht K, Ko CW, Thiel T, Kaufmann R, Dykierek P, Juengling F, Hüll M. Mapping of temporal and parietal cortex in progressive nonfluent aphasia and Alzheimer's disease using chemical shift imaging, voxel-based morphometry and positron emission tomography. Psychiatry Res., 140(2):115-31, 2005.

[88] Rabinovici GD, Seeley WW, Kim EJ, Gorno-Tempini ML, Rascovsky K, Pagliaro TA, Allison SC, Halabi C, Kramer JH, Johnson JK, Weiner MW, Forman MS, Trojanowski JQ, Dearmond SJ, Miller BL, Rosen HJ. Distinct MRI atrophy patterns in autopsy-proven Alzheimer's disease and frontotemporal lobar degeneration. Am J Alzheimers Dis Other Demen, 22(6):474-88, 2008.

[89] Chételat G, Landeau B, Eustache F, Mézenge F, Viader F, de la Sayette V, Desgranges B, Baron JC. Using voxel-based morphometry to map the structural 
changes associated with rapid conversion in $\mathrm{MCl}$ : a longitudinal MRI study. Neuroimage, 27(4):934-46, 2005.

[90] Migliaccio R, Agosta F, Rascovsky K, Karydas A, Bonasera S, Rabinovici GD, Miller BL, Gorno-Tempini ML. Clinical syndromes associated with posterior atrophy: early age at onset AD spectrum. Neurology., 73(19):1571-8, 2009.

[91] Teipel SJ, Flatz WH, Heinsen H, Bokde AL, Schoenberg SO, Stöckel S, Dietrich O, Reiser MF, Möller HJ, Hampel H. Measurement of basal forebrain atrophy in Alzheimer's disease using MRI. Brain, 128(Pt 11):2626-44, 2005.

[92] Bozzali M, Filippi M, Magnani G, Cercignani M, Franceschi M, Schiatti E, Castiglioni S, Mossini R, Falautano M, Scotti G, Comi G, Falini A. The contribution of voxel-based morphometry in staging patients with mild cognitive impairment. Neurology., 67(3):453-60., 2006.

[93] Nordberg A. Functional studies of cholinergic activity in normal and alzheimer disease states by imaging technique. Prog Brain Res., 145:303-10, 2004.

[94] Di Paola M, Macaluso E, Carlesimo GA, Tomaiuolo F, Worsley KJ, Fadda L, Caltagirone C. Episodic memory impairment in patients with Alzheimer's disease is correlated with entorhinal cortex atrophy. a voxel-based morphometry study. J Neurol., 254(6):774-81, 2007.

[95] Rosen HJ, Wilson MR, Schauer GF, Allison S, Gorno-Tempini ML, Pace-Savitsky C, Kramer JH, Levenson RW, Weiner M, Miller BL. Neuroanatomical correlates of impaired recognition of emotion in dementia. Neuropsychologia, 44(3):365-73, 2006. 
[96] Xie S, Xiao JX, Gong GL, Zang YF, Wang YH, Wu HK, Jiang XX. Voxel-based detection of white matter abnormalities in mild Alzheimer disease. Neurology, 66(12):1845-9, 2006.

[97] Hämäläinen A, Pihlajamäki M, Tanila H, Hänninen T, Niskanen E, Tervo S, Karjalainen PA, Vanninen RL, Soininen $H$. Increased $\mathrm{fMRI}$ responses during encoding in mild cognitive impairment. Neurobiol Aging., 28(12):1889-903, 2007.

[98] Waragai M, Okamura N, vFurukawa K, Tashiro M, Furumoto S, Funaki Y, Kato M, Iwata R, Yanai K, Kudo Y, Arai H. Comparison study of amyloid PET and voxel-based morphometry analysis in mild cognitive impairment and Alzheimer's disease. J Neurol Sci., 285(1-2):100-8, 2009.

[99] Josephs KA, Whitwell JL, Duffy JR, Vanvoorst WA, Strand EA, Hu WT, Boeve BF, Graff-Radford NR, Parisi JE, Knopman DS, Dickson DW, Jack CR Jr, Petersen RC. Progressive aphasia secondary to Alzheimer disease vs FTLD pathology. Neurology., 70(1):25-34, 2008.

[100] Thomaz CE, Aguiar NAO, Oliveira SHA, Duran FLS, Busatto GF, Gillies DF, Rueckert D. Extracting discriminative information from medical images: A multivariate linear approach. In proceedings of SIBGRAPI'06, IEEE CS Press, 2006.

[101] Villain N, Fouquet M, Baron JC, Mézenge F, Landeau B, de La Sayette V, Viader F, Eustache F, Desgranges B, Chételat G. Sequential relationships between grey matter and white matter atrophy and brain metabolic abnormalities in early Alzheimers disease. Brain, 133(11):3301-14, 2010. 
[102] Fischl B, Salat DH, Busa E, Albert M, Dieterich M, Haselgrove C, van der Kouwe A, Killiany R, Kennedy D, Klaveness S, Montillo A, Makris N, Rosen B, Dale AM. Whole brain segmentation: automated labeling of neuroanatomical structures in the human brain. Neuron, 31,33(3):341-55, 2002.

[103] Rao A, Lee Y, Gass A, Monsch A. Classification of Alzheimer's disease from structural MRI using sparse logistic regression with optional spatial regularization. IEEE Eng Med Biol Soc, pages 4499-502, 2011.

[104] Rosen HJ, Wilson MR, Schauer GF, Allison S, Gorno-Tempini ML, Pace-Savitsky C, Kramer JH, Levenson RW, Weiner M, Miller BL. Neuroanatomical correlates of impaired recognition of emotion in dementia. Brain, 128(Pt 11):2626-44, 2005.

[105] Guo X, Wang Z, Li K, Li Z, Qi Z, Jin Z, Yao L, Chen K. Voxel-based assessment of gray and white matter volumes in Alzheimer's disease. Neurosci Lett., 468(2):14650, 2010.

[106] Scahill RI, Schott JM, Stevens JM, Rossor MN, Fox NC. Mapping the evolution of regional atrophy in Alzheimer's disease: unbiased analysis of fluid-registered serial MRI. Proc Natl Acad Sci, 99(7):4703-7, 2002.

[107] Whitwell JL, Jack CR Jr, Kantarci K, Weigand SD, Boeve BF, Knopman DS, Drubach DA, Tang-Wai DF, Petersen RC, Josephs KA. Imaging correlates of posterior cortical atrophy. Neurobiol, 28(7):1051-61, 2007.

[108] Rémy F, Mirrashed F, Campbell B, Richter W. Verbal episodic memory impairment in Alzheimer's disease: a combined structural and functional MRI study. Neuroimage, 25(1):253-66, 2005. 
[109] Karas GB, Scheltens P, Rombouts S, van Schijndel R, Klein M, Jones B, van der Flier W, Vrenken H, Barkhof F. Precuneus atrophy in early-onset Alzheimer's disease: a morphometric structural MRI study. Neuroradiology, 49(12):967-76, 2007.

[110] Neumann J, Schroeter ML. Combined imaging markers dissociate Alzheimers disease and frontotemporal lobar degeneration - an ALE meta-analysis. Frontiers in Aging Neuroscience, 3:1-6, 2011.

[111] Perrini, RJ, Fagan AM, Holtzman DM. Multi-modal techniques for diagnosis and prognosis of Alzheimers disease. Nature, 461:916-922, 461.

[112] Davatzikos C, Bhatt P, Shaw LM, Batmanghelich KN, Trojanowski JQ. Prediction of mci to ad conversion, via mri, csf biomarkers, and pattern classification. Neurobiol Aging., 32(12):e19-27, 2011.

[113] Exalto LG, Biessels GJ, Karter AJ, Huang ES, Katon WJ, Minkoff JR, Whitmer RA. Risk score for prediction of 10 year dementia risk in individuals with type 2 diabetes: a cohort study. The Lancet Diabetes \& Endocrinology, 1:735-41, 2013.

[114] Kaffashian S, Dugravot A, Elbaz A, Shipley MJ, Sabia, S, Kivimäki M, SinghManoux A. Predicting cognitive decline - a dementia risk score vs the Framingham vascular risk scores. Neurology, 80:1300-1306, 2013.

[115] Kim JM, Stewart R, Shin IS, Yoon JS. Low cholesterol, cognitive function and alzheimer s disease in a community population with cognitive impairment. $J$ Nutr Health Aging, 6(5):320-3, 2002. 
[116] Crane PK, Walker R, Hubbard RA, Ge Li, Nathan DM, Zhen M, Haneuse S, Craft S, Montine TJ, Kahn SE, McCormick M, McCurry SM, Bowen JD, Larson EB. Glucose levels and risk of dementia. N Engl J Med, 369:540-548, 2013.

[117] Huang YP, Zaza S. Evaluating dementia risk from mri by fuzzy inference model. In ICNSC, pages 667-672, 2014.

[118] Guedes AC,Garcia SD,Nääs IA, Amaral FV,Nogueira M,Abe, JM. Diagnósticos de enfermagem em pacientes sob ventilação mecânica: Estratégia paraconsistente para tomada de decisão. Seleção Documental, 30:3-10, 2013. 


\section{Descrição das Bases de Dados}

Este Apêndice apresenta detalhes sobre as bases de dados utilizadas nos testes e análises dos modelos de Compromentimento Cognitivo e no modelo de Risco de demência.

\section{Base de Dados Hipotética de Compromentimento Cog-}

\section{nitivo}

A base de dados hipotética para o modelo de Compromentimento Cognitivo possui 40 casos, contendo escores de MEEM (média de $14 \pm 9$ ), Teste do Relógio (média de $3 \pm$ 1) e Fluência Verbal (média de $8 \pm 4$ ). As figuras 1 e 2 e 3 apresentam o espalhamento dos valores dos testes que compõe esta base de dados.

Figura 1: Espalhamento dos valores do teste de MEEM da base hipotética

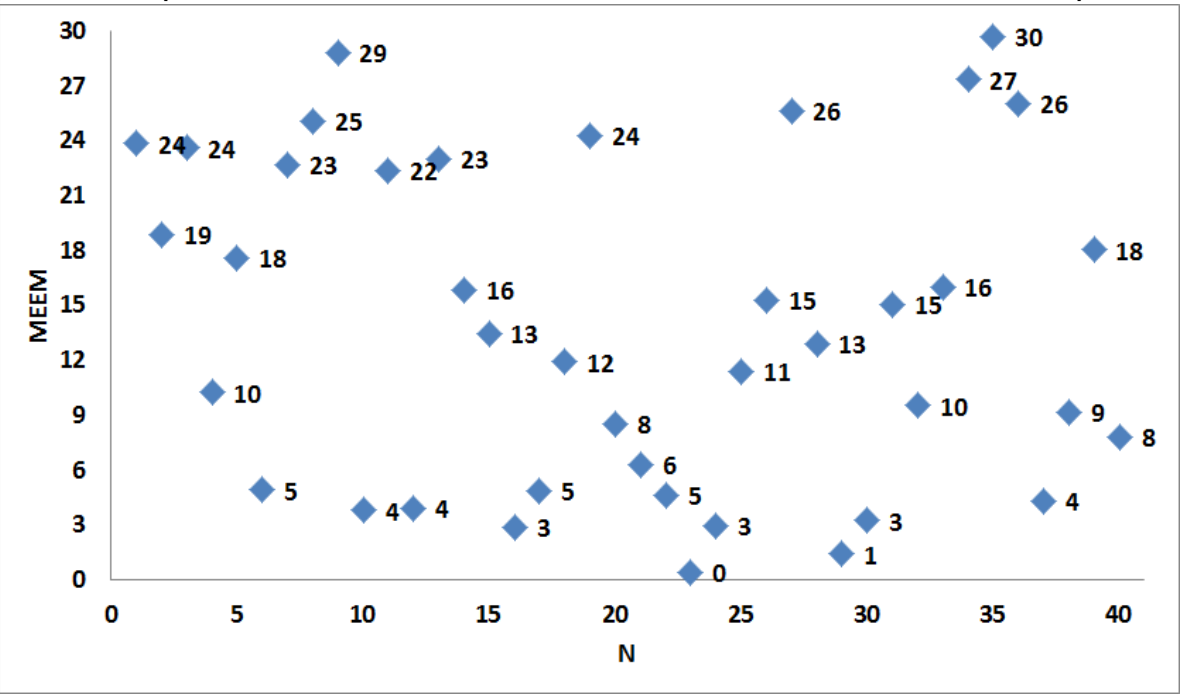


Figura 2: Espalhamento dos valores do teste do Teste do Relógio da base hipotética

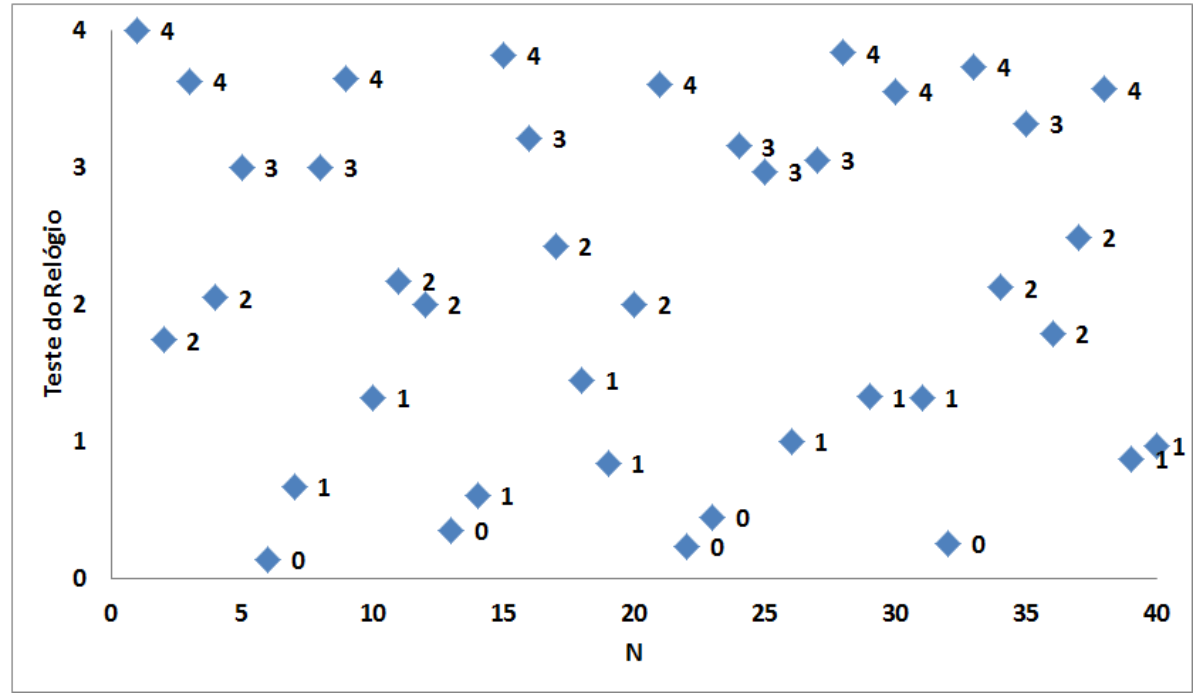

Figura 3: Espalhamento dos valores do teste de Fluência Verbal da base hipotética

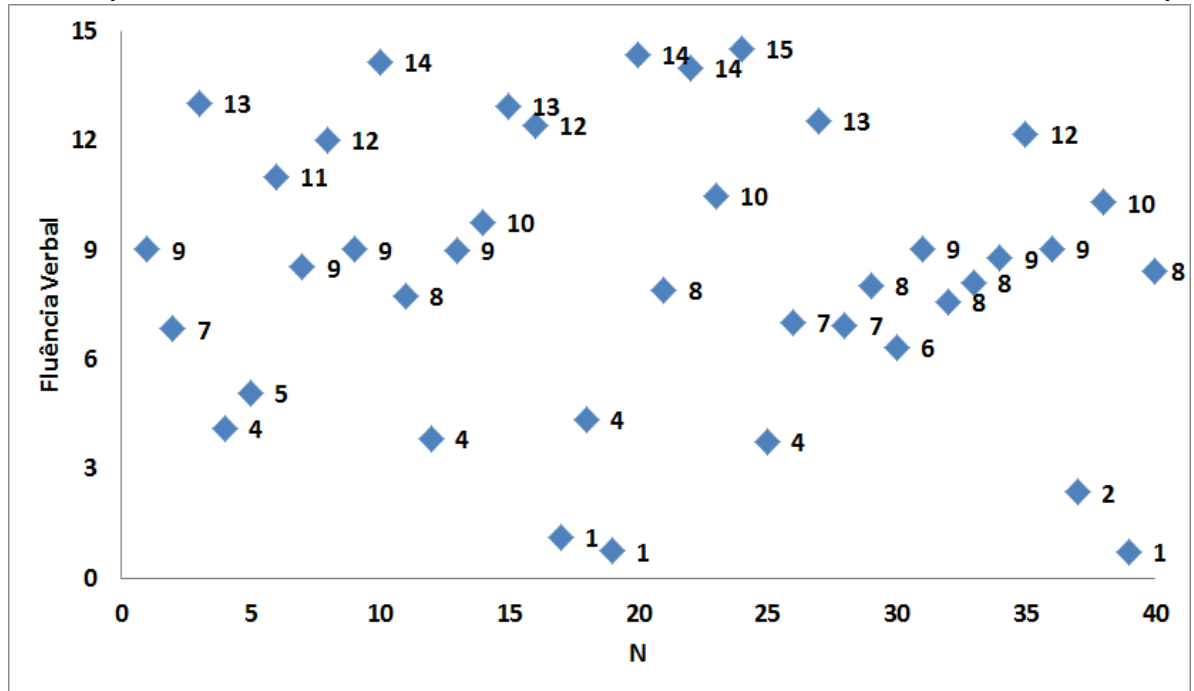

\section{Base de Dados do PROTER/IPq-USP para o Modelo}

\section{de Compromentimento Cognitivo}

A base de casos reais do PROTER/IPq-USP contém 60 casos completos ( $A$ base inicialmente conta com 104 casos, porém com alguns campos incompletos o que impossibilitou o uso dos dados) contendo escores de MEEM (média de $21 \pm 7$ ), Teste 
do Relógio (média de $2 \pm 1$ ) e Fluência Verbal (média de $3 \pm 2$ ) e a escolaridade (média de 7 anos $\pm 5,5$ anos). Esta base contém 20 casos classificados como CDR igual a 0 (equivalente a 33\%), 9 casos classificados como CDR igual a 0,5 (equivalente a 15\%), 12 casos com CDR igual a 2 (equivalente a 18\%) e 8 casos com CDR igual a 3 (equivalente a $13 \%)$.

\section{Base de Dados Hipotética para o Modelo de Risco de}

\section{Demência}

A base de dados hipotética para o Modelo de Risco de Demência tem 30 casos, contendo a nota dos fatores de risco, a nota dos fatores de proteção e o escore de compromentimento cognitivo. As figuras 4 e 5 e 6 apresentam o espalhamento das variavéis de Comprometimento Cognitivo, Fatores de Risco e Fatores de Proteção utilizados no modelo de risco de demência.

Figura 4: Espalhamento dos valores de compromentimento cognitivo da base hipotética para o modelo de Risco de Demência

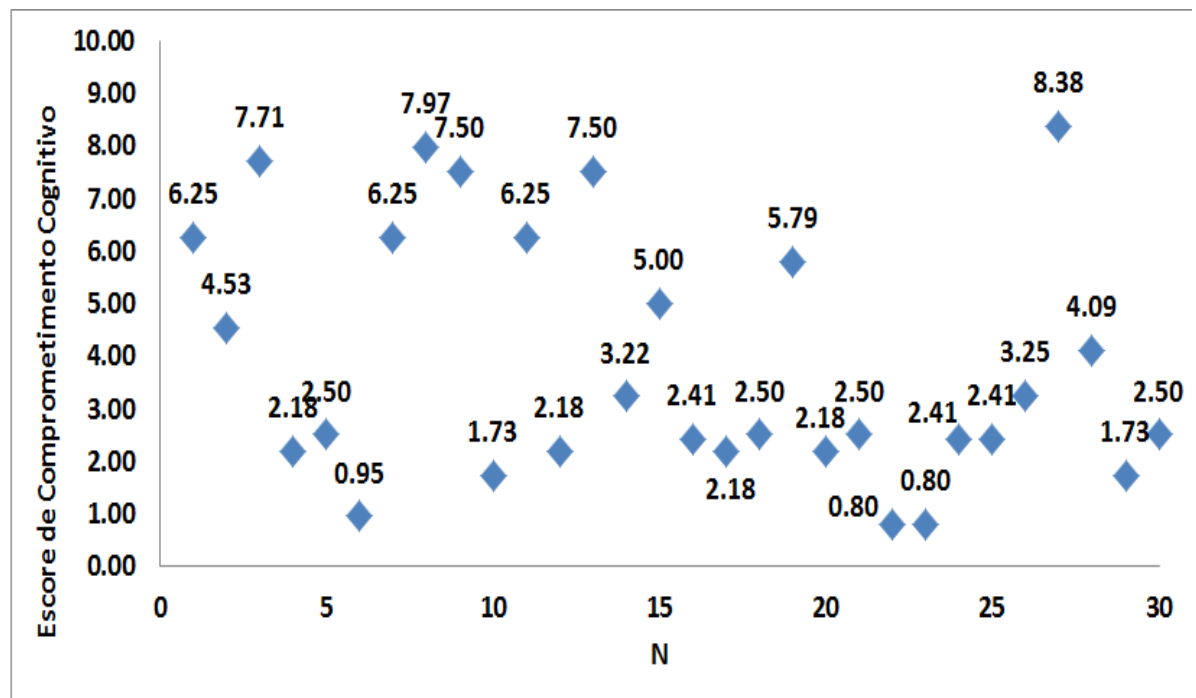


Figura 5: Espalhamento dos valores do questionário de fatores de risco para o Modelo de Risco de Demência

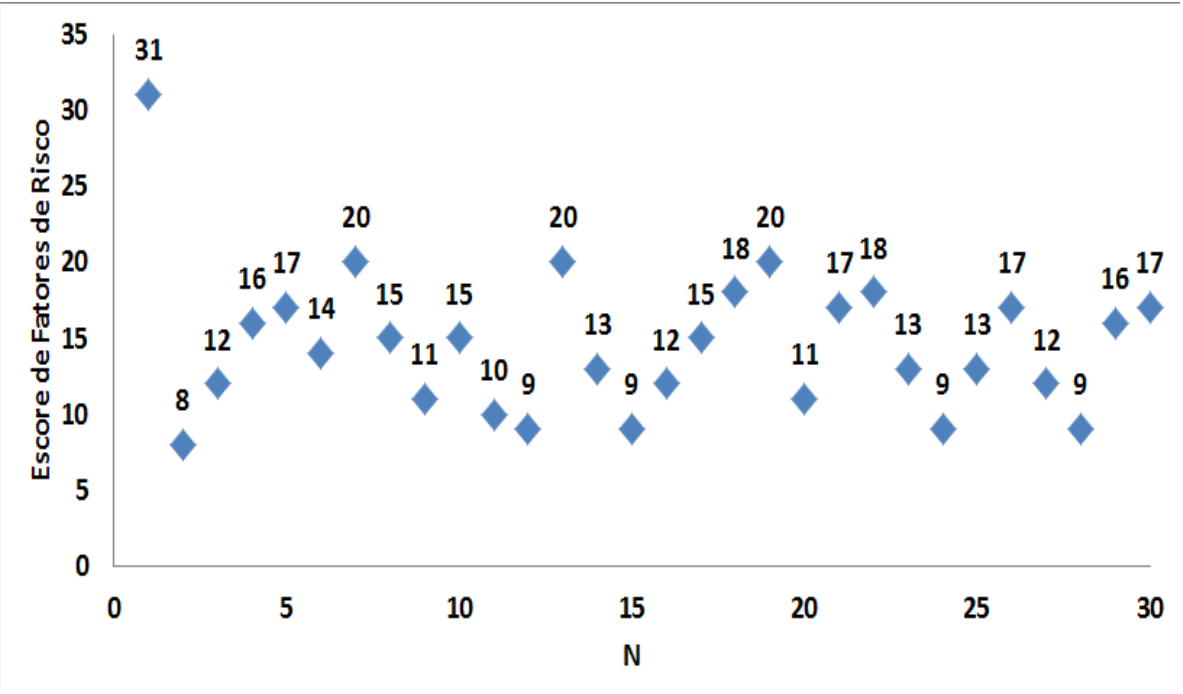

Figura 6: Espalhamento dos valores do questionário de fatores de proteção para o Modelo de Risco de Demência

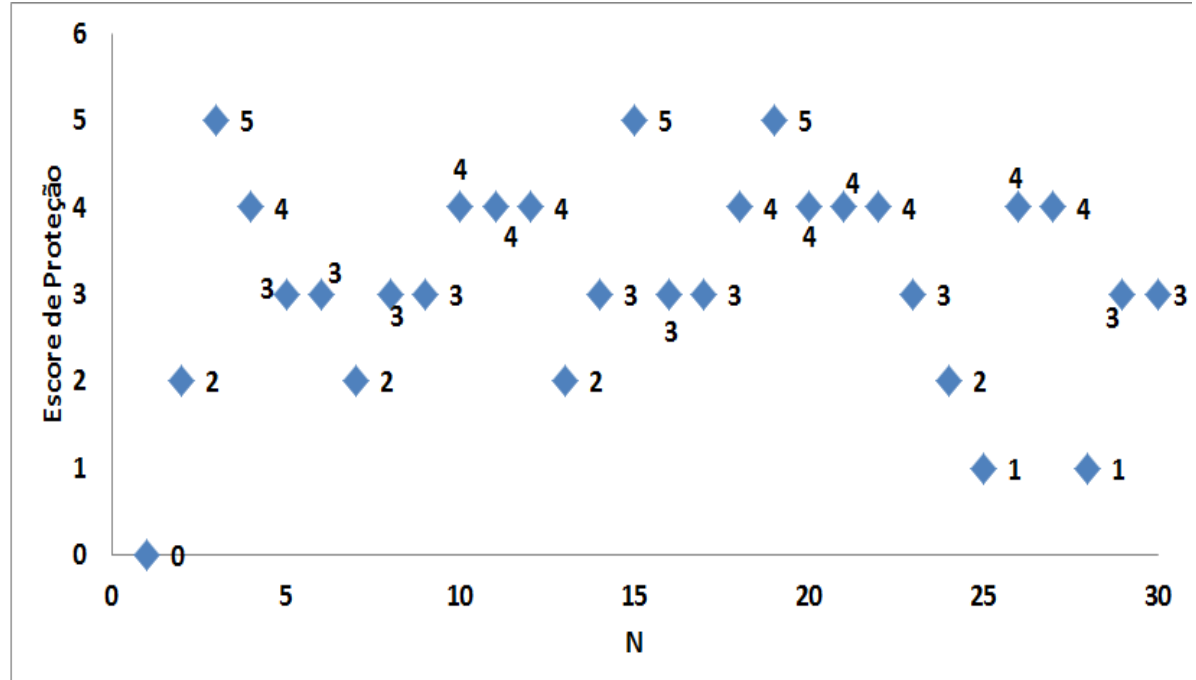

